To cite this article: Requejo-Castro, D., Giné-Garriga, R., Pérez-Foguet, A., 2020. Datadriven Bayesian Network modelling to explore the relationships between SDG 6 and the 2030 Agenda. Sci. Total Environ. 710, 136014.

To link to this article: $\underline{\text { https://doi.org/10.1016/i.scitotenv.2019.136014 }}$

\title{
DATA-DRIVEN BAYESIAN NETWORK MODELLING TO EXPLORE THE RELATIONSHIPS BETWEEN SDG 6 AND THE 2030 AGENDA
}

David Requejo-Castro, Ricard Giné-Garriga, Agustí Pérez-Foguet

\begin{abstract}
The Sustainable Development Goals (SDGs) are presented as integrated and indivisible. Therefore, for monitoring purposes, conventional indicator-based frameworks need to be combined with approaches that capture and describe the links and interdependencies between the Goals and their targets. In this study, we propose a data-driven Bayesian Network (BN) approach to identify and interpret SDGs interlinkages. We focus our analysis on the interlinkages of SDG 6, related to water and sanitation, across the whole 2030 Agenda. To do this, we use SDGs global available data corresponding to 179 countries, 16 goals, 28 targets and 44 indicators. BN results are analysed and validated by different means. First, we demonstrate the robustness of the BN approach in identifying indicator relationships (i.e. consistent results throughout different country sample sizes). Second, we show the coherency of the results obtained by comparing them with an exhaustive study developed by UN-Water. As an added value, our data-driven approach provides further interlinkages, which are contrasted against the existing literature. We conclude that the approach adopted is useful to accommodate a thorough analysis and interpretation of the complexities and interdependencies of the SDGs.
\end{abstract}

Keywords: Sustainable Development Goals, SDG 6, Bayesian Networks, interlinkages, data-driven 


\section{Introduction}

On $25^{\text {th }}$ September 2015, the 2030 Agenda resolution announced 17 Sustainable Development Goals (SDGs), remarking their integrated and indivisible nature (United Nations General Assembly, 2015). The SDGs seek to address in a holistic way the three dimensions of sustainable development (SD) environmental, social and economic - and their institutional/governance aspects (Costanza et al., 2016). Lack of integration across these dimensions in development strategies, policies and implementation has long been perceived as a major weakness in previous attempts towards SD, such as in the Millennium Development Goals (MDGs) (Le Blanc, 2015; Liu et al., 2018; Obersteiner et al., 2016). In the SDGs era, more holistic and integrated approaches are needed to elucidate the interdependencies among the different targets and goals, as well as to facilitate their effective implementation.

To date, indicator frameworks have been increasingly recognized as a useful tool for policy making, benchmarking and public communication (Nardo et al., 2005; Singh et al., 2009). They will represent the backbone of monitoring progress towards the SDGs at all levels (i.e. local, national, regional and global). Their assessment will require quality, accessible, timely and reliable disaggregated data from all countries (United Nations General Assmebly, 2015). This, in turn, will require much greater efforts and investments in building national statistical capacities and strengthening statistical quality and standards. However, this challenge comes together with a huge opportunity within the so-called "data revolution" (UN-IEAG, 2014). To date, data collection and harmonization has been assigned to at least one lead technical or specialist agency (SDSN, 2015). Some of these custodian agencies are already elaborating data baselines and reports, and therefore, presenting a starting point for SDGs achievement. This step forward has promoted an emerging catalogue of publications already reviewed elsewhere (Allen et al., 2018), which include indicator-based assessments. An illustrative example is the development of an unofficial SDG Index (Sachs et al., 2018), as a tool to provide indicative country-level estimates and trends, covering 111 and 88 indicators for the OEDC and the 193 UN member countries, respectively. Countries are ranked according to the index values, and those 
indicators which require priority attention are identified for each country. Nevertheless, and despite of the likely utility of this approach, indicator-based assessments may fall short on explaining how multiple and interacting forces have led to specific outcomes (Schmalzbauer and Visbeck, 2016). Such assessments, therefore, need to be complemented with analyses that enable interlinkages among targets and indicators to be assessed (Le Blanc, 2015; Allen et al., 2018).

In this sense, the literature shows several contributions that address, to a certain extent, SDGs interlinkages. From a more conceptual and qualitative perspective, SDGs have been read as a network of targets connecting the different goal areas (Le Blanc, 2015), or analysed and presented as a list of relationships (ICSU-ISSC, 2015). They have been also organized through a grading system of interactions (Nilsson et al., 2016), with specific focus on one SDG (Bangert et al., 2017; Coopman et al., 2016; Hall et al., 2018; Herrera, 2019; Singh et al., 2018; UN-ESCAP, 2016), or on a "nexus approach" (e.g. water-energy-food nexus) (Fader et al., 2018; Rasul, 2016; Pahl-Wostl, 2017) with the aim to understand connections, synergies and trade-offs (Liu et al., 2018). On the other hand, from a quantitative point of view, SDGs relationships have been assessed to assist planning and decisionmaking for their implementation by applying sophisticated modelling approaches to evaluate reduced and different sets of Goals (Mainali et al., 2018; Collste et al., 2017; Gao and Bryan, 2017), to assess the (in)consistency of the SDG framework (Spaiser et al., 2017), to simulate and evaluate the interactions among multiple SDG policy options over one specific Goal (Obersteiner et al., 2016), and to introduce stakeholder's knowledge (Khalili et al., 2017; Kanter et al. 2016).

In parallel, Bayesian Networks (BNs) have gained popularity among practitioners (Aguilera et al., 2011; Marcot, 2017; Marcot and Penman, 2019) to explore the interdependencies and cause-effect relationships, simulating complex problems that involve a large number of variables that are highly interlinked. Briefly, BNs are probabilistic graphical models compounded with nodes (variables), links (representing informational or cause-effect relationships) and conditional probability tables (quantification of the dependencies among nodes). BNs flexibility is commonly exploited in scenario simulation and analysis (e.g. Bromley et al., 2005; Dang et al., 2019; Eldridge et al., 2019; GonzalezRedin et al., 2019; Molina et al., 2009), but has also been used to identify the key factors that 
influence aspects of interest ( $\mathrm{Li}$ et al., 2019; Song et al., 2018), to replicate hierarchical composite indicators (Requejo-Castro et al., 2019), or to elucidate the network structure underlying the data-athand, through associated structure learning algorithms (SLA) (Alameddine et al., 2011; Garcia-Prats et al, 2018).

In this study, we propose a data-driven Bayesian Network (BN) approach to identify and interpret SDGs interlinkages. Specifically, we apply SLA to automatically capture those interlinkages spurred on by data. We select SDG 6 on water and sanitation as a case study. We develop a BN model, and we then carry out a comprehensive analysis of achieved results, checking their robustness and validating them through an extensive literature review.

\section{Case study}

The dedicated goal on water and sanitation has been selected in this study to explore its interlinkages across the 2030 Agenda. SDG 6 reads "to guarantee the availability of water and its sustainable management and sanitation for all" (United Nations General Assembly, 2015), and includes eight targets: six of them are based on outcomes, and two are based on the means of implementation. In more detail, targets 6.1 and 6.2 relate to drinking-water, sanitation and hygiene. Target 6.3 expands the framework beyond the use of sanitation facilities to focus on wastewater and water quality. Targets 6.4 and 6.5 refer to water-use efficiency and water scarcity, and the implementation of Integrated Water Resources Management (IWRM), respectively. Target 6.6 focuses on healthy waterrelated ecosystems. Finally, targets 6.a and 6.b suggest the importance of international cooperation and local stakeholder participation to achieve previous targets.

Main reason for this selection is that an extensive literature puts water and sanitation at the very core of sustainable development (Mugagga and Nabaasa, 2016; Nhamo et al., 2018; United Nations, 2018a; UN-Water, 2016; WWAP, 2019). Available water and adequate sanitation for all and for different purposes are pillars of human health and well-being, thus contributing to the achievement of other development goals such as health, adequate nutrition, gender equality, education and the eradication of poverty (Bartram et al., 2005; Cairncross et al., 2010; Cohen and Sullivan, 2010; Joint Monitoring Programme, 2015; UN-Women, 2018). We seek to capture the bi-directionality of the 
interlinkages: incorporating water and sanitation in other Goals is necessary for the achievement of Goal 6, and implementing targets under Goal 6 enables the achievement of a number of other targets across the 2030 Agenda. In doing so, we contribute to the existing applications of BN modelling to the SDG 6. To date, BNs flexibility has been exploited to address the inherent complexity of individual SDG 6 targets, and the literature shows several studies on target 6.1 (Fisher et al., 2015; Cronk and Bartram, 2017; 2018), 6.1 and 6.2 (Dondeynaz et al., 2013; Giné-Garriga et al., 2018; Requejo-Castro et al., 2019) or 6.4 and 6.5 (Mohajerani et al., 2017; Molina et al., 2009; 2013). To the best of our knowledge, however, BNs have not been applied to explore the relationships between targets of different goals.

We take as a reference point the UN-Water Analytical Brief entitled "Water and sanitation interlinkages across the 2030 Agenda for Sustainable Development" (UN-Water, 2016). This report captures the complex nature of the SDGs and gives a qualitative snapshot as far as the relationships between the SDG 6 and the 2030 Agenda, providing an overview of the target-level linkages and their interdependencies (UN-Water, 2016). This report allows comparing the results obtained in our study and validating the proposed data-driven approach.

\section{Methods}

In this section, we first introduce in detail the criteria and steps followed for data selection and preprocess. Specifically, we focus on the process to select the final set of indicators for the BN analysis — as well as a complete definition of these indicators -, the assumptions made to deal with missing data, and the normalization process for the correct data management. Second, we briefly describe the background underlying this data-driven approach, including the initial settings considered. Third, we describe the steps followed to carry out the BNs analysis. 


\subsection{Data selection and data pre-process}

\section{Indicator selection}

SDGs global available data are provided by the different specialist agencies and published online by the United Nations Statistic Division (UNSD) ${ }^{1}$. In their website, latest official available data for all indicators is published and regularly updated at both the regional and country level. In this study, a first screening of eligible indicators was conducted based on the study developed by UN-Water (2016). This report analyses the relationships between targets of Goal 6 and rest of Goals' targets included in the 2030 Agenda. It comprises 107 outcome-based targets (excluding those related to the means of implementation) and 169 indicators. It provides a summary table of all these linkages, identifying as well whether the link represents a synergy (positive impact) or a conflict (negative impact). The report shows, for instance, the water and sanitation links with those targets related to the reduction of poverty (i.e. SDG targets 1.1, 1.2 and 1.4). In contrast, none of the SDG 6 targets are linked to SDG target 11.5 , which deals with the reduction of deaths and people affected by natural disasters. In order to work with a manageable number of variables, we select those SDG targets showing a high number of synergies and/or conflicts (i.e. 3 or more linkages with SDG 6 targets). However, we have also considered Target 4.2 - related to the access to quality early childhood development, with only two identified linkages with SDG6 -, to represent Goal 4. In doing so, all SDGs reflected in the report are represented in this study with, at least, one target.

In total, $52 \mathrm{SDG}$ targets and 80 associated indicators were analysed. However, global data were only available for 28 out of these 51 (55\%) targets and 44 (55\%) different indicators (UNSD, 2018). Although no indicators related to the means of implementation were considered, SDG Target 6.a was exceptionally included due to its relevance for the study. Table 1 presents the final list of indicators, their definition, the custodian agency in charge of data reporting, and the number of countries with available information. For each indicator, we also specify how we have dealt with missing data and data normalization (see next section).

\footnotetext{
${ }^{1}$ Data available at https://unstats.un.org/sdgs/indicators/database.
} 
Table 1. SDG indicators employed in the data-driven Bayesian Network analysis. Source: UNSD, 2018.

\begin{tabular}{|c|c|c|c|c|}
\hline SDG & Indicator (units) & Year(s)* & Source(s) & $\begin{array}{l}\text { Countries } \\
\text { with } \\
\text { information }\end{array}$ \\
\hline & 1.1.1. Poverty line of US $\$ 1.90$ per day (\% population) & $2003-2016$ & WB \& ILO & $155^{\mathrm{a}, 1}$ \\
\hline 1 & $\begin{array}{l}\text { 1.2.1. Poverty line below the national threshold ( } \% \\
\text { population) }\end{array}$ & $2000-2017$ & WB & $133^{\mathrm{b}, 1}$ \\
\hline 2 & 2.1.1. Prevalence of undernourishment (\% population) & 2015 & $\mathrm{FAO}$ & $167^{\mathrm{a}, \mathrm{c}, 1}$ \\
\hline \multirow{6}{*}{3} & $\begin{array}{l}\text { 3.1.1. Maternal mortality ratio (number per } 100,000 \text { live } \\
\text { births) }\end{array}$ & 2015 & WHO & $180^{\mathrm{a}, 1}$ \\
\hline & $\begin{array}{l}\text { 3.2.1. Under-five mortality rate (number per 1,000 live } \\
\text { births) }\end{array}$ & 2016 & UNICEF & $187^{1}$ \\
\hline & $\begin{array}{l}\text { 3.3.5. People requiring interventions against neglected } \\
\text { tropical diseases, NTD (number) }\end{array}$ & 2016 & WHO & $185^{\mathrm{b}, 1}$ \\
\hline & $\begin{array}{l}\text { 3.8.1. Universal health coverage (UHC) service coverage } \\
\text { index }(0-100)\end{array}$ & 2015 & WHO & 181 \\
\hline & $\begin{array}{l}\text { 3.9.1. Age-standardized mortality rate attributed to } \\
\text { household air pollution (deaths per } 100,000 \text { people) }\end{array}$ & 2016 & WHO & $145^{\mathrm{a}, \mathrm{b}, 1}$ \\
\hline & $\begin{array}{l}\text { 3.9.2. Mortality rate attributed to unsafe water, unsafe } \\
\text { sanitation and lack of hygiene (deaths per } 100,000 \text { people) }\end{array}$ & 2016 & WHO & $181^{1}$ \\
\hline 4 & 4.2.2. Participation rate in organized learning ( $\%$ children) & $2000-2017$ & UNESCO-UIS & $152^{\mathrm{a}}$ \\
\hline \multirow{2}{*}{5} & $\begin{array}{l}\text { 5.5.1. Proportion of seats held by women in national } \\
\text { parliaments ( } \% \text { women) }\end{array}$ & 2018 & $\begin{array}{l}\text { UN-Women \& } \\
\text { IPU }\end{array}$ & $186^{\mathrm{a}}$ \\
\hline & $\begin{array}{l}\text { 5.5.2. Proportion of women in managerial positions }(\% \\
\text { women) }\end{array}$ & $2000-2016$ & ILO & $149^{\mathrm{b}}$ \\
\hline \multirow{7}{*}{6} & $\begin{array}{l}\text { 6.1.1. Proportion of population using AT LEAST BASIC } \\
\text { drinking water services ( } \% \text { population) }\end{array}$ & 2015 & JMP & 187 \\
\hline & $\begin{array}{l}\text { 6.2.1. Proportion of population using AT LEAST BASIC } \\
\text { sanitation services ( } \% \text { population) }\end{array}$ & 2015 & JMP & 187 \\
\hline & 6.4.1. Water-Use Efficiency (USD/m3) & 2014 & FAO & $165^{\mathrm{b}}$ \\
\hline & $\begin{array}{l}\text { 6.4.2. Freshwater withdrawal as a proportion of available } \\
\text { freshwater resources }(\%)\end{array}$ & 2014-2015 & FAO & $179^{\mathrm{a}, 1}$ \\
\hline & $\begin{array}{l}\text { 6.5.1. Integrated Water Resource Management } \\
\text { implementation }(\%)\end{array}$ & 2017 & UNEP & $153^{\mathrm{a}}$ \\
\hline & 6.6.1. Water body extent (permanent) ( $\%$ of total land area) & 2016 & UNEP & 188 \\
\hline & $\begin{array}{l}\text { 6.a.1. Total official flows for water supply and sanitation, } \\
\text { by recipient (billions USD) }\end{array}$ & 2016 & WHO \& OECD & $130^{\mathrm{a}, \mathrm{b}}$ \\
\hline \multirow{4}{*}{7} & $\begin{array}{l}\text { 7.1.1. Proportion of population with access to electricity } \\
(\%)\end{array}$ & 2016 & WB & 189 \\
\hline & $\begin{array}{l}\text { 7.1.2. Proportion of population with primary reliance on } \\
\text { clean fuels and technology }(\%)\end{array}$ & 2016 & WHO & $183^{a}$ \\
\hline & $\begin{array}{l}\text { 7.2.1. Renewable energy share in the total final energy } \\
\text { consumption }(\%)\end{array}$ & 2016 & $\begin{array}{l}\text { IEA \& UN- } \\
\text { DESA }\end{array}$ & 189 \\
\hline & $\begin{array}{l}\text { 7.3.1. Energy intensity level of primary energy } \\
\text { (Megajoules per constant } 2011 \text { purchasing power parity } \\
\text { GDP) }\end{array}$ & 2015 & $\begin{array}{l}\text { IEA \& UN- } \\
\text { DESA }\end{array}$ & $183^{\mathrm{a}, 1}$ \\
\hline
\end{tabular}




\begin{tabular}{|c|c|c|c|c|}
\hline \multirow{3}{*}{8} & 8.1.1. Growth rate of real GDP per capita (\%) & 2016 & UN-DESA & 189 \\
\hline & 8.2.1. Annual growth rate of real GDP per employee (\%) & 2017 & ILO & $178^{\mathrm{a}}$ \\
\hline & $\begin{array}{l}\text { 8.5.2. Unemployment rate, } 15 \text { years old and over, both } \\
\text { sexes (\% population) }\end{array}$ & $2000-2017$ & ILO & $174^{\text {a, } 1}$ \\
\hline \multirow[t]{2}{*}{9} & $\begin{array}{l}\text { 9.1.2. Passenger volume, by air transport (tonne } \\
\text { kilometres) }\end{array}$ & 2016 & ICAO & $178^{\mathrm{b}}$ \\
\hline & 9.4.1. Emissions of carbon dioxide (millions metric tons) & 2015 & IEA \& UNIDO & $137^{\mathrm{b}, 1}$ \\
\hline 10 & $\begin{array}{l}\text { 10.1.1. Growth rates of household expenditure or income } \\
\text { per capita among the bottom } 40 \text { per cent of the population } \\
(\%)\end{array}$ & $2009-2016$ & WB & $94^{\mathrm{b}}$ \\
\hline \multirow{3}{*}{11} & 11.1.1. Urban population living in slums (\%) & $2000-2014$ & UN-Habitat & $92^{\mathrm{a}, \mathrm{b}, \mathrm{c}, 1}$ \\
\hline & $\begin{array}{l}\text { 11.6.1. Municipal Solid Waste collection coverage, by } \\
\text { cities (\%) }\end{array}$ & $2001-2017$ & $\begin{array}{l}\text { UN-Habitat \& } \\
\text { UN-DESA }\end{array}$ & $98^{\mathrm{b}}$ \\
\hline & $\begin{array}{l}\text { 11.6.2. Annual mean levels of fine particulate matter } \\
\left(\mathrm{PM}_{2.5}\right) \text { in cities }\left(\mu \mathrm{g} / \mathrm{m}^{3}\right)\end{array}$ & 2016 & WHO & $186^{1}$ \\
\hline \multirow{3}{*}{12} & $\begin{array}{l}\text { 12.2.1. Material footprint per capita - raw material - } \\
\text { (tonnes) }\end{array}$ & 2017 & UNEP & $166^{\mathrm{a}, 1}$ \\
\hline & $\begin{array}{l}\text { 12.2.2. Domestic material consumption per capita - raw } \\
\text { material - (tonnes) }\end{array}$ & 2017 & UNEP & $140^{\mathrm{a}, 1}$ \\
\hline & $\begin{array}{l}\text { 12.4.1. Compliance with the Stockholm Convention on } \\
\text { hazardous waste and other chemicals (\%) }\end{array}$ & 2015 & UNEP & $171^{\mathrm{a}, \mathrm{b}}$ \\
\hline 13 & 13.1.1. People affected by disaster (number) & $1990-2017$ & UNISDR & $112^{\mathrm{b}, 1}$ \\
\hline 14 & $\begin{array}{l}\text { 14.5.1. Average proportion of Marine Key Biodiversity } \\
\text { Areas (KBAs) covered by protected areas (\%) }\end{array}$ & 2018 & UNEP-WCMC & $137^{\mathrm{a}, \mathrm{b}, \mathrm{c}}$ \\
\hline \multirow{6}{*}{15} & 15.1.1. Forest area as a proportion of total land area (\%) & 2015 & FAO & 188 \\
\hline & $\begin{array}{l}\text { 15.1.2.1. Average proportion of Freshwater Key } \\
\text { Biodiversity Areas (KBAs) covered by protected areas (\%) }\end{array}$ & 2018 & UNEP-WCMC & $133^{\mathrm{a}, \mathrm{b}}$ \\
\hline & $\begin{array}{l}\text { 15.1.2.2. Average proportion of Terrestrial KBAs covered } \\
\text { by protected areas (\%) }\end{array}$ & 2018 & UNEP-WCMC & $185^{\mathrm{a}}$ \\
\hline & 15.2.1. Forest area net change rate $(\%)$ & 2015 & FAO & $187^{\mathrm{a}}$ \\
\hline & $\begin{array}{l}\text { 15.4.1. Average proportion of Mountain KBAs covered by } \\
\text { protected areas (\%) }\end{array}$ & 2018 & UNEP-WCMC & $146^{\mathrm{a}}$ \\
\hline & 15.4.2. Mountain Green Cover Index (\%) & 2017 & FAO & $161^{\mathrm{a}}$ \\
\hline 16 & $\begin{array}{l}\text { 16.5.2. Bribery incidence }(\% \text { of firms experiencing at least } \\
\text { one bribe payment request })\end{array}$ & $2006-20$ & WB \& UNODC & $138^{\mathrm{a}, 1}$ \\
\hline \multicolumn{5}{|c|}{$\begin{array}{l}\text { * By the time of this study, and for each indicator-country pair, the more recent data were used. When data } \\
\text { were obtained from different years, the time period is specified. }\end{array}$} \\
\hline \multicolumn{5}{|c|}{$\begin{array}{l}\text { Missing data and data gaps have been addressed by applying: a) Regional data, b) HDI groups related } \\
\text { information, c) literature review. In some cases, missing data treatment was required for those indicators with } \\
\text { more than } 179 \text { countries as to reach the final list of countries with information associated with all indicators } \\
\text { considered. }\end{array}$} \\
\hline \multicolumn{5}{|c|}{ ': Indicators transformed from the scale "less is better" to "more is better". } \\
\hline
\end{tabular}


The final set of 44 indicators was assessed, to a different extent, in 189 countries. The full dataset of 189 countries and available data for all 44 indicators was extracted from the UNSD database. These countries were classified according to their Human Development Index (HDI) (UNDP, 2018). The purpose of this classification was two-fold. First, it shows the unbiased nature of the sample in terms of countries development context. Second, it assists us in how to deal with missing data. From Table 2, it is observed that a representative number of countries from each HDI group was included. However, only 7 countries have available data for the 44 indicators considered, and more than $50 \%$ of selected countries do not have data for five or more indicators. To increase the final sample of countries, a set of assumptions were made for missing data treatment in the first three groups (referred to the number of indicators with no data available). A total number of 179 countries were finally included in the analysis.

Table 2. Number of countries considered in the study according to their HDI. Sources: UNDP, 2018; UNSD, 2018.

\begin{tabular}{cccccc}
\hline & \multicolumn{5}{c}{ Number of countries } \\
\cline { 2 - 6 } $\begin{array}{c}\text { Human Development } \\
\text { Index (HDI) group }\end{array}$ & \multicolumn{5}{c}{$\begin{array}{c}\text { Indicators with no data available } \\
\text { (out of 44) }\end{array}$} \\
\cline { 3 - 6 } & & \multicolumn{5}{c}{$\leq \mathbf{1 0}$} & $\leq \mathbf{1 5}$ & $\geq \mathbf{1 5}$ \\
\hline Very High & 59 & 19 & 27 & 10 & 3 \\
High & 53 & 30 & 11 & 8 & 4 \\
Medium & 39 & 25 & 10 & 1 & 3 \\
Low & 38 & 18 & 15 & 5 & 0 \\
\hline Total & $\mathbf{1 8 9}$ & $\mathbf{9 2}$ & $\mathbf{6 3}$ & $\mathbf{2 4}$ & $\mathbf{1 0}$ \\
\hline
\end{tabular}

Imputation of missing data

BNs are only fully functional in absence of missing data. The following assumptions have been considered when dealing with missing data:

- When SDG regional data were available, they were used to fill information gaps at the country level. This assumption applied to $55 \%$ (24 out of 44 ) of the indicators considered (the number of countries using regional data for each indicator varied between indicators). 
- When regional data were not available, information gaps were replaced considering country HDI groups (UNDP, 2018) in two different manners. For some indicators, VH HDI countries obtained the highest score (e.g., $0 \%$ of population below the international poverty line of US\$1.90 per day (SDG 1.1.1); or 0 billion of USD were received as official flows for water supply and sanitation (SDG 6.a.1)). In other indicators, average values were assigned to replace missing data according to HDI group (i.e. very high, high, medium or low). In total, this was applied to $35 \%$ of the indicators within this study (the information gaps varied from one indicator to another).

- Values from the literature were also considered, when available. For example, a value of $1.2 \%$ prevalence of undernourishment rate (SDG indicator 2.1.1) was assumed for $\mathrm{VH}$ and $\mathrm{H}$ HDI countries with missing data (SDSN, 2016); or 6\% of European urban dwellers living in extremely precarious conditions (UN-Habitat, 2015), which we computed it as proportion of urban population living in slums (SDG indicator 11.1.1). Considerations from existing literature were applied to $10 \%$ of the indicators considered.

\section{Normalization}

Prior to the BN analysis, indicators were normalized between 0 and 100 , with 0 denoting the worst performance and 100 describing the optimum. To do this, those indicators expressed in percentage were kept invariable. On the other hand, the rest of indicators were normalized using "min-max" technique. This method normalizes indicators to have an identical range by subtracting the minimum value and dividing by the range of the indicator values (Nardo et al., 2005). No max-min thresholds were fixed and maximum and minimum values were defined according to the best and worst performance of the indicators, applying logarithms when values were either considerably lower or greater than the rest. Finally, a last transformation was required for several indicators according to "more is better" scale (see Table 1). For instance, SDG indicator 9.4.1 ( $\mathrm{CO}_{2}$ emissions), which represents a "less is better" goal, was assessed by calculating the complementary value. In contrast, similar examples to SDG indicator 7.1.1 (proportion of population with access to electricity), 
representing a "more is better" indicator and presented in percentage, were kept constant according to the scale fixed.

\subsection{Data-driven Bayesian network background and initial settings}

In terms of network construction, BNs can be developed manually or automatically (Aguilera et al., 2013) and, within the latter, a range of SLA (Liu et al., 2017; Madsen et al., 2016) provide the optimum structure of the network (i.e. identification of interlinkages spurred on by data). There are three types of SLA: constraint-based, score-based or a hybrid approach. Briefly, the constraint-based method learns the network structure by analysing the probabilistic relations with conditional independence (C-Ind) tests; while the score-based method assigns a score to each candidate $\mathrm{BN}$ and then tries to maximize it with a heuristic search algorithm (Scutari, 2010). In this study, we have opted for the constraint-based SLA since it reduces the subjectivity of the links among the nodes of the network (Requejo-Castro et al., 2019). In addition, despite the large amount of data needed to guarantee the reliability of the C-Ind tests, a recent study points out that constraint-based algorithms are more accurate than score-based algorithms for small sample sizes (Scutari et al., 2018).

In this study, we use the free R software and its package bnlearn (version 4.4), developed by Scutari (2010). This package implements the following constraint-based learning algorithms (Scutari, 2010): grow-shrink (gs), incremental association (iamb), fast incremental association (fast.iamb), interleaved incremental association (inter.iamb) and max-min parent and children (mmpc). We consider that all indicators follow a normal distribution (see Supplementary Material Fig. S1). The C-Ind tests are chosen with respect to this data typology. Avoiding intensive computing time, C-Ind test selection is reduced to linear correlation (cor), Fisher's Z (zf) and mutual information (mi-g) tests (Scutari, 2010). By applying the combination of both SLA and C-Ind tests to the database, 16 candidate networks are obtained.

Scutari et al. (2017) suggest the selection of a single BN model from the data and draw the conclusions from this model, treating it as a "fixed" quantity. However, this model is not "fixed" and it carries its own uncertainty from the selection procedure used to learn it from the data. To reduce this source of uncertainty, we apply the bootstrap technique (re-sampling), which has been largely 
used in the determination of confidence intervals (Henderson, 2005). Moreover, this technique has been used to test the stabilities and strength of the links among variables and to obtain the direction of these links (Chao et al., 2018; Scutari et al., 2017).

\subsection{Data-driven Bayesian Network model generation and analysis settings}

In order to facilitate the implementation of other similar studies (i.e., with a focus on a different SDG), a step-by-step methodology is provided to carry out this data-driven BN analysis. For validation purposes, it is recommended to identify in the literature relevant reference studies. We take as a reference the UN-Water Analytical Brief (UN-Water, 2016), which allows us to compare achieved results and to validate the proposed approach.

The process to develop the analysis is divided in two complementary stages (see Fig.1). The first stage aims to develop a BN model that allows the identification and assessment of the interlinkages between selected targets and indicators. The second stage aims to assess the robustness of the achieved results (i.e. consistency of the interlinkages obtained through the data-driven approach). The step-by-step procedure to construct the $\mathrm{BN}$ model (i.e. first stage) from the dataset is as follows: 


\section{Stage 1: BN modelling}

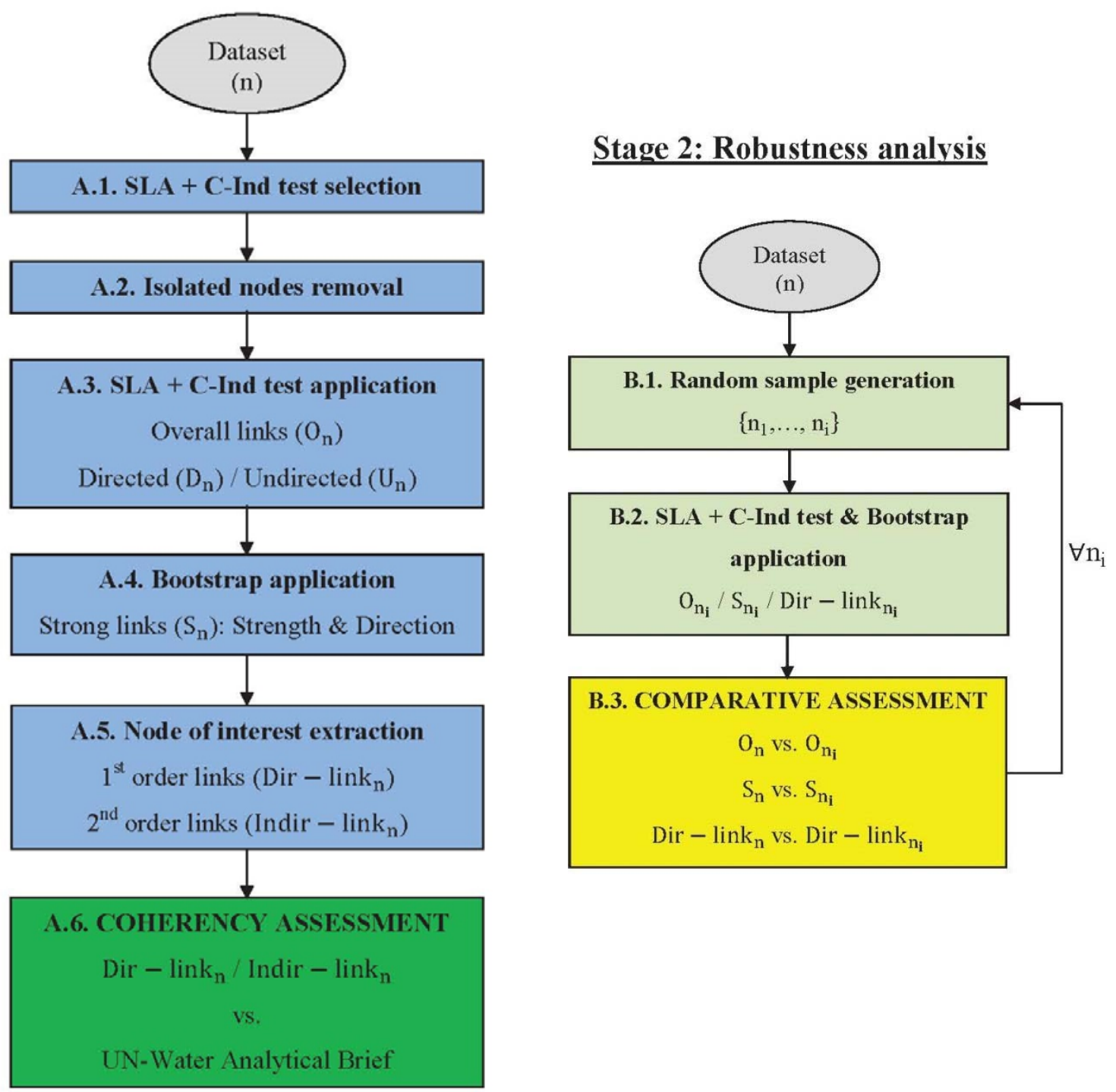

Fig. 1. Process followed to carry out the $\mathrm{BN}$ analysis.

A1. SLA + C-Ind test tandem selection. In this initial stage, we apply three selection criteria to identify the most suitable BN network. It should: i) identify a higher number of links associated with the objective nodes (i.e. SDG-6 associated indicators) ii) present a higher number of directed links; and iii) leave a lower number of nodes isolated.

A2. Isolated nodes removal. As these nodes do not contribute to the analysis, they are removed. 
A.3. SLA + C-Ind test tandem application. The overall interlinkages $\left(\mathrm{O}_{\mathrm{n}}\right)$ identified by the model are obtained. They are differentiated between directed links $\left(D_{n}\right)$, which imply one-way directions, and undirected links $\left(\mathrm{U}_{\mathrm{n}}\right)$, which imply two-ways directions.

A.4. Bootstrap technique application. When applying bootstrap, the so-called strong links $\left(\mathrm{S}_{\mathrm{n}}\right)$ are identified. To do this, data are re-sampled 500 times and the selected tandem SLA + C-Ind test is performed separately on each of the resulting samples, thus collecting 500 networks. Then, the frequency of the links with which each appears in those networks is computed (known as arc strength) and those resulted links that have a frequency above a certain threshold are selected (in this case, a value of 0.80 over 1). Specifically, three are the steps followed: i) computing 100 bootstrapped networks to get a reference list of relationships, ii) selecting those links which are repeated more than $60 \%$ from 100 new bootstrapped networks in comparison to the previous list, and iii) obtaining the directions of the strong links (i.e. cause-effect direction).

A.5. Node of interest extraction. As our focus is on those indicators related to SDG 6, we extract from $\mathrm{O}_{\mathrm{n}}$ those "first order" or "direct" links (Dir-link $\mathrm{n}_{\mathrm{n}}$ ) which associate these indicators with the neighbouring ones. Moreover, we analyze the "second order" links (Indir-link $\mathrm{n}_{\mathrm{n}}$ ), which represent indirect relationships through the above mentioned neighbour indicators.

A.6. Coherency assessment. The interlinkages obtained in the previous step are then contrasted against those ones selected from the literature or based on expert opinion. In our case, we focus our comparative analysis on the UN-Water Analytical Brief (2016), complemented by an extensive literature review.

Regarding the second stage of this analysis, we carry out the following steps:

B.1. Random samples generation $\left(n_{i}\right)$ from the initial number of 179 countries. We opt for the following sample sizes: 175, 160, 145, 130, 115, 100 and 85 countries. For each sample size, we generate 100 different networks.

B.2. SLA + C-Ind test and Bootstrap application. For each network associated to each sample size, we apply the selected SLA + C-Ind test tandem (Step A.1) and the bootstrap technique. We then distil the overall relationships $\left(\mathrm{O}_{\mathrm{n}_{\mathrm{i}}}\right)$, the strong links $\left(\mathrm{S}_{\mathrm{n}_{\mathrm{i}}}\right)$ and the "first order" (Dir-link $\left.\mathrm{n}_{\mathrm{i}}\right)$ linkages. 
B.3. Comparative assessment. Obtained relationships are then compared to the ones identified from the overall sample size. This comparison is complemented with further quality analysis in terms of results coherence.

\section{Results and Discussion}

In this section, we present and discuss achieved results, relating them to the step-by-step methodology presented above. The objective is three-fold: i) identify the different interlinkages of interest from the overall dataset; ii) test the robustness of the above results by comparing these results against the ones obtained from the different sample sizes; and iii) carry out an in-depth assessment of results regarding the interlinkages between the SDG 6 and the 2030 Agenda.

\subsection{Identifying interlinkages of interest}

The tandem SLA + C-Ind test produced 16 candidate networks. The tandem incremental association (iamb) algorithm and mutual information (mi-g) test showed the best performance - according to the 3 criteria described - and was thus selected for the analysis (Step A.1). Specifically, it identified 23 links associated to SDG 6 indicators and 61 directed links (out of 65). Two nodes with no relationship within the network (6.6.1 and 15.2.1 indicators) were removed (Step A.2). Figure 2 depicts the key elements of this analysis: the overall interlinkages $\left(\mathrm{O}_{\mathrm{n}}\right)$ among SDG indicators are represented by grey dot arrows; and the strong links $\left(\mathrm{S}_{\mathrm{n}}\right)$ and their direction are represented by black solid arrows, as an outcome of bootstrap application (Steps A.3 and A.4). 


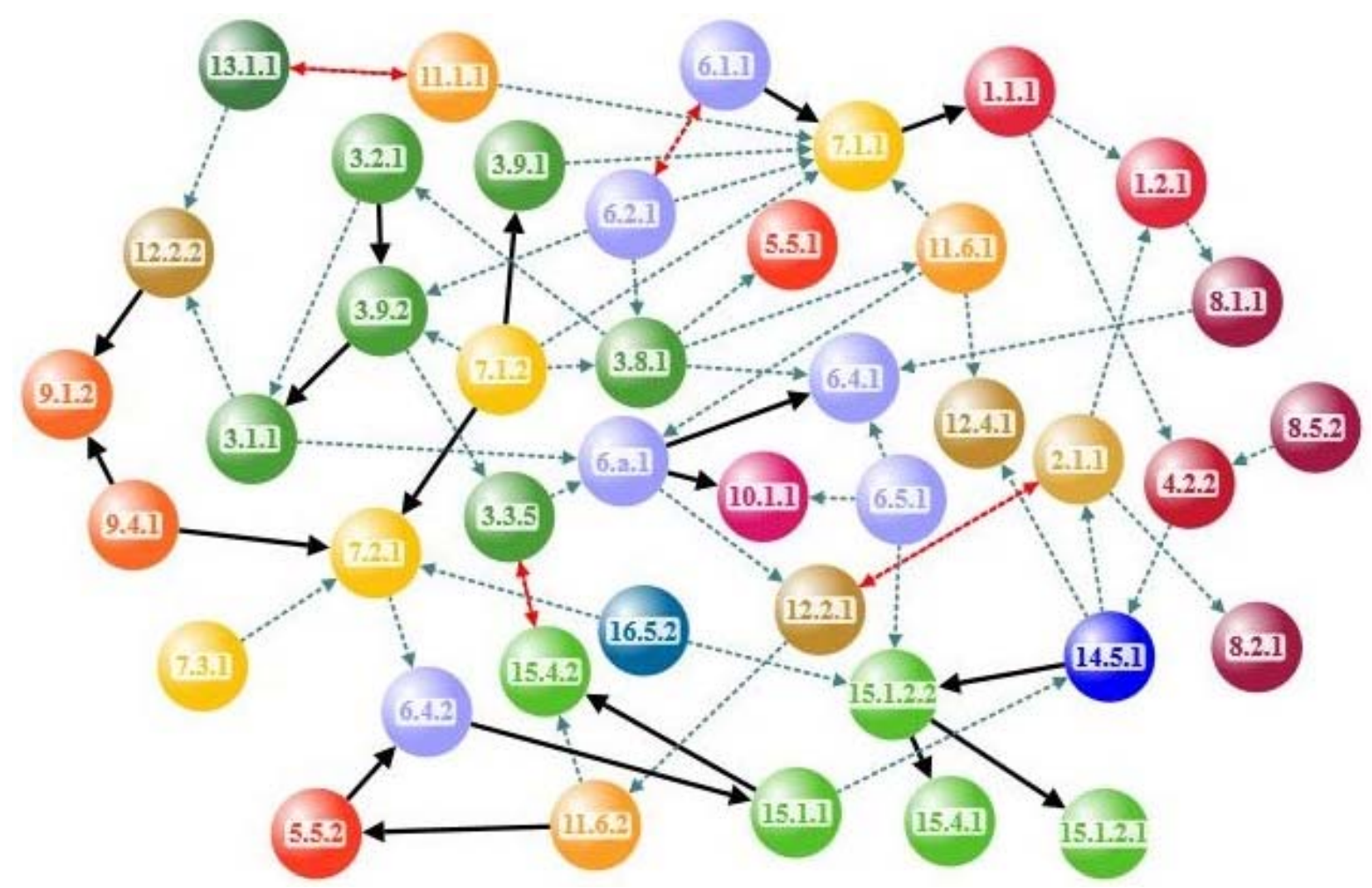

Fig. 2. Reference network showing the interlinkages between the SDG indicators considered. Corresponding definitions to these indicators can be found in Table 1. This network was obtained through the tandem SLA (iamb) and C-Ind test (mi-g). Three different elements are shown; strong links, $\mathrm{S}_{\mathrm{n}}$ (black solid arrows), directed links, $\mathrm{D}_{\mathrm{n}}$ (grey dot arrows) and undirected links, $\mathrm{U}_{\mathrm{n}}$ (bi-directional red dot arrows).

\subsection{Testing the data-driven approach robustness}

To demonstrate the robustness of results shown in Fig 2, different random samples were generated (Step B.1). For each sample size and for each of the 100 networks generated, SDG indicators links $\left(\mathrm{O}_{\mathrm{n}}\right)$ were identified together with the strong links $\left(\mathrm{S}_{\mathrm{n}}\right)$ and their direction (Step B.2). Fig. 3 shows how the overall link repetitiveness decreases while reducing the sample size of countries (Step B.3). This decrease appears slightly more pronounced for the samples of $n=175$ and $n=160$ countries. When reducing the sample size to 115 countries (65\% of the total), the repetitiveness mean value still reaches $71.8 \%$. Maximum and minimum values present unequal fluctuations, but those related to $90^{\text {th }}$ and $10^{\text {th }}$ percentiles show a trend similar to the repetitiveness mean value. 


\section{Link repetitiveness compared to the reference network}

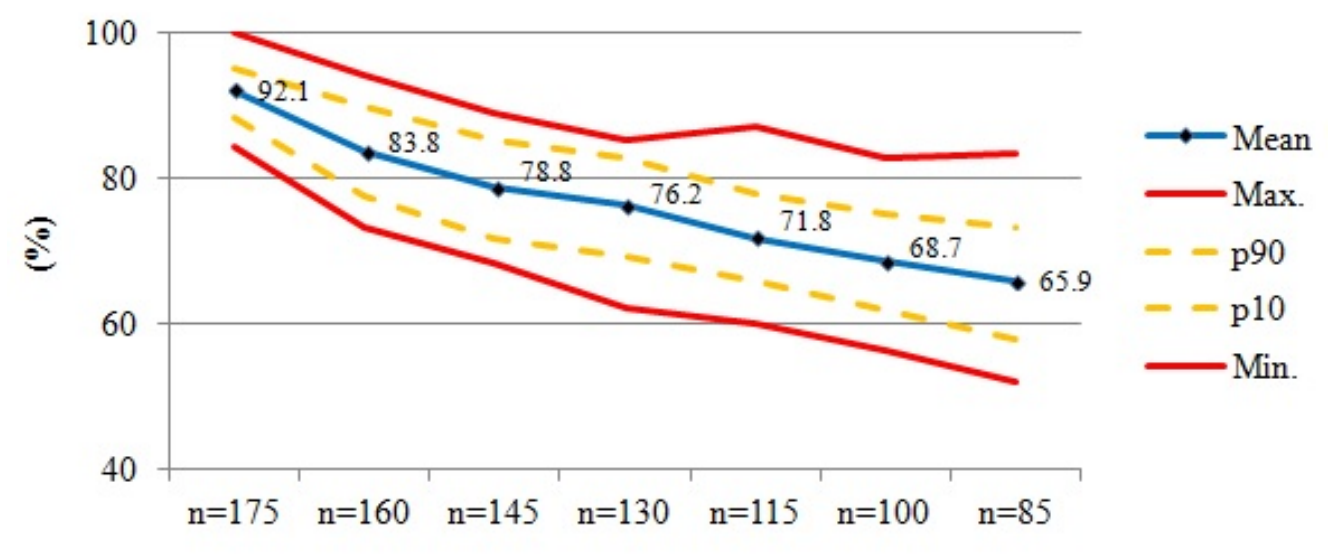

Random sample size

Fig. 3. Overall link repetitiveness for the different random samples of countries in comparison to the reference network (179 countries and 42 SDG indicators).

As regard those interlinkages identified as strong ones, the same decreasing tendency is observed (Step B.3). For instance, when country sample is reduced at $72 \%(n=130)$, approximately half of the strong links $(55 \%, 10$ out of 18$)$ are identified in at least $70 \%$ of the bootstrapped networks. This ratio increases to 62,74 and $100 \%$ for the samples of $n=145,160$ and 175, respectively (see Supplementary Material Table S1). Two trends are observed. On the one hand, there are strong links presenting a high repetitiveness even if the sample size of countries is reduced drastically. On the other, there are strong links with low repetitiveness when reducing the sample size (see Supplementary Material Table S1). The performance of the model is positively evaluated up to the sample size of 130 countries.

Complementary to this, an in-depth analysis of the direction (i.e. cause-effect direction) of these strong links is carried out. To do this, the strong links are firstly disaggregated considering all of them as undirected, although they are not (see Fig. 2). For instance, the obtained link from 3.9.2 to 3.1.1 is considered from 3.1.1 to 3.9.2 as well. The direction of a link is obtained through the bootstrap technique which assigns a value between 0.5 and 1 , where 0.5 is related to an undirected link and 1.0 assures the direction of the link. Positively, $72 \%$ (13 out of 18) of the strong links are identified in one specific direction throughout the different sample sizes (see Supplementary Material Table S2). 
However, most of the links present values close to 0.5 , which should be taken carefully before stating a clear cause-effect of the links (see Supplementary Material Table S3).

A further complementary assessment is carried out considering the "first-order" or direct (Dir-link $\left.\mathrm{n}_{\mathrm{n}}\right)$ relationships associated with SDG 6 indicators (Step B.3) (see Table 3). In this case, only their frequency is taking into account and not their strength and direction. From the results shown in Table 3 , it is observed that, for $n=130,12$ out of 27 (44\%) links are identified in more than $70 \%$ of the bootstrap networks. This value increases up to 60 and $67 \%$ for sample sizes $n=145$ and 160 , respectively (see full details in Supplementary Material Table S4). Again, two trends are observed. First, there are links which present a high repetitiveness while reducing the sample size (most of them coincide with the links identified as strong). Second, there are relationships whose repetitiveness is reduced rapidly when decreasing the number of countries within the sample. These linkages require special attention for final consideration.

Extending this assessment in terms of quality measures, we analyse the impact of the approach for missing data treatment in model results (Step B.3). We carry out the process described in Section 3 but considering only those countries with 10 or less SDG indicators presenting missing data (see Table 2). Thus, 155 countries are employed for a second $\mathrm{BN}$ model construction. Table 6 shows that $78 \%$ (21 out of 27) of the links related to SDG-6 indicators are identified in the new model. In addition, $86 \%$ (6 out of 7 ) of the strong links are shown. This confirms that the approach employed for fulfilling information gaps has a slight impact on the results achieved.

Table 3. Links identified in relation to SDG-6 indicators, for different country samples.

\begin{tabular}{|c|c|c|c|c|c|c|}
\hline & \multirow{2}{*}{\multicolumn{2}{|c|}{ SDG6-related links identified }} & \multicolumn{4}{|c|}{ Repetitiveness (\%) } \\
\hline & & & \multirow{2}{*}{$\begin{array}{c}\mathbf{n}=\mathbf{1 7 5} \\
100\end{array}$} & \multirow{2}{*}{$\begin{array}{c}\mathbf{n}=\mathbf{1 6 0} \\
100 \\
\end{array}$} & \multirow{2}{*}{$\begin{array}{c}\mathbf{n}=\mathbf{1 4 5} \\
100\end{array}$} & \multirow{2}{*}{$\begin{array}{c}\mathbf{n}=\mathbf{1 3 0} \\
86\end{array}$} \\
\hline \multirow{5}{*}{$\begin{array}{c}3.9 .2 \\
\text { (mortality } \\
\text { rate due to } \\
\text { unsafe } \\
\text { WaSH) }\end{array}$} & 3.1.1 & Maternal mortality ratio* & & & & \\
\hline & 3.2.1 & Infant mortality rate* & 100 & 100 & 100 & 100 \\
\hline & 3.3 .5 & $\begin{array}{l}\text { People requiring interventions } \\
\text { against NTD* }\end{array}$ & 100 & 99 & 94 & 89 \\
\hline & 6.2 .1 & $\begin{array}{l}\text { Population using AT LEAST } \\
\text { BASIC sanitation services* }\end{array}$ & 100 & 98 & 84 & 86 \\
\hline & 7.2 .1 & $\begin{array}{l}\text { Renewable energy share in total } \\
\text { final energy consumption }\end{array}$ & 85 & 51 & 42 & 28 \\
\hline \multirow{2}{*}{$\begin{array}{c}\text { 6.1.1 } \\
\text { (basic } \\
\text { drinking } \\
\text { water) } \\
\end{array}$} & 6.2 .1 & $\begin{array}{l}\text { Population using AT LEAST } \\
\text { BASIC sanitation services* }\end{array}$ & 99 & 87 & 70 & 68 \\
\hline & 7.1.1 & $\begin{array}{l}\text { Population with access to } \\
\text { electricity* }\end{array}$ & 100 & 100 & 100 & 96 \\
\hline 6.2 .1 & 3.8 .1 & Universal health coverage (UHC)* & 84 & 80 & 74 & 63 \\
\hline
\end{tabular}




\begin{tabular}{|c|c|c|c|c|c|c|}
\hline \multirow[t]{3}{*}{$\begin{array}{c}\text { (basic } \\
\text { sanitation) }\end{array}$} & 3.9 .2 & $\begin{array}{l}\text { Mortality rate attributed to unsafe } \\
\text { WaSH* }\end{array}$ & 100 & 98 & 84 & 86 \\
\hline & 6.1 .1 & $\begin{array}{l}\text { Population using AT LEAST } \\
\text { BASIC drinking water services* }\end{array}$ & 99 & 87 & 70 & 68 \\
\hline & 7.1 .2 & $\begin{array}{l}\text { Population with primary reliance on } \\
\text { clean fuels and tech* }\end{array}$ & 94 & 64 & 60 & 59 \\
\hline \multirow{4}{*}{$\begin{array}{l}\quad 6.4 .1 \\
\text { (water-use } \\
\text { efficiency) }\end{array}$} & 3.8 .1 & Universal health coverage (UHC) & 63 & 49 & 27 & 30 \\
\hline & 6.5 .1 & Degree of IWRM implementation* & 89 & 62 & 52 & 38 \\
\hline & 6.a.1 & $\begin{array}{l}\text { Total official development } \\
\text { assistance (ODA)* }\end{array}$ & 100 & 100 & 100 & 99 \\
\hline & 8.1 .1 & $\begin{array}{l}\text { Annual growth rate of real GDP per } \\
\text { capita }\end{array}$ & 97 & 78 & 62 & 59 \\
\hline \multirow{3}{*}{$\begin{array}{c}6.4 .2 \\
\text { (freshwater } \\
\text { withdrawal) }\end{array}$} & 5.5 .2 & $\begin{array}{l}\text { Proportion of women in } \\
\text { managerial positions* }\end{array}$ & 100 & 100 & 99 & 97 \\
\hline & 7.2 .1 & $\begin{array}{l}\text { Renewable energy share in the total } \\
\text { final energy consumption }\end{array}$ & 62 & 49 & 56 & 51 \\
\hline & 15.1.1 & $\begin{array}{l}\text { Forest area as a proportion of } \\
\text { total land area }\end{array}$ & 100 & 100 & 97 & 94 \\
\hline \multirow{3}{*}{$\begin{array}{c}6.5 .1 \\
(\mathrm{IWRM})\end{array}$} & 6.4 .1 & Water-Use Efficiency* & 62 & 52 & 38 & 38 \\
\hline & 10.1.1 & $\begin{array}{l}\text { Growth rates of household } \\
\text { expenditure (bottom } 40 \% \text { pop.)* }\end{array}$ & 63 & 46 & 30 & 27 \\
\hline & 15.1.2.2 & $\begin{array}{l}\text { Average proportion of KBAs } \\
\text { covered by protected areas* }\end{array}$ & 83 & 69 & 62 & 53 \\
\hline \multirow{6}{*}{$\begin{array}{l}\text { 6.a.1 } \\
\text { (ODA for } \\
\text { water and } \\
\text { sanitation) }\end{array}$} & 3.1 .1 & Maternal mortality ratio* & 83 & 67 & 63 & 52 \\
\hline & 3.3 .5 & $\begin{array}{l}\text { People requiring interventions } \\
\text { against NTD* }\end{array}$ & 66 & 71 & 60 & 58 \\
\hline & 6.4 .1 & Water-Use Efficiency** & 100 & 100 & 99 & 95 \\
\hline & 10.1.1 & $\begin{array}{l}\text { Growth rates of household } \\
\text { expenditure (bottom } 40 \% \text { pop.) } * *\end{array}$ & 98 & 93 & 88 & 78 \\
\hline & 11.6 .1 & $\begin{array}{l}\text { Municipal Solid Waste collection } \\
\text { coverage }\end{array}$ & 47 & 35 & 36 & 32 \\
\hline & 12.2 .1 & $\begin{array}{l}\text { Material footprint per capita (raw } \\
\text { material )* }\end{array}$ & 98 & 94 & 82 & 82 \\
\hline $\begin{array}{l}\text { In bold, strong } \\
* \text { Links identif } \\
* * \text { Links identi }\end{array}$ & $\begin{array}{l}\text { s. } \\
\text { n the s } \\
\text { in the }\end{array}$ & $\begin{array}{l}\text { an model (155 countries). } \\
\text { ond BN model but not as strong links. }\end{array}$ & & & & \\
\hline
\end{tabular}

We analyze in more depth the coherency of the results obtained by constructing the contingency tables associated with the links presented in Table 3 (see also Supplementary Material Table S5). To do this, we discretize the continuous values of the indicators in 5 different intervals. As an example, the relationship between the proportion of population using at least basic drinking water services (6.1.1) and the proportion of population with access to electricity (7.1.1) is considered. This link, identified as strong one, shows a positive correlation according to the values of the diagonal of the table. In other words, an improvement in one of these indicators might generate a similar impact in the other one. This is consistent with the fact that access to drinking water services requires energy for the extraction, treatment and distribution of water. Reciprocally, water is required 
to produce all forms of energy to some degree (United Nations 2018a; UN-Water 2016; WWAP 2014).

Summarizing the results presented in this sub-section, it has been demonstrated that the applied datadriven approach provides robust results up to certain sample size (i.e. $n=130$, which represents approximately $70 \%$ of the overall countries considered). Moreover, the strategy employed for missing data treatment does not impact significantly on the final results and it might be considered as an appropriate approach for other studies. The applied data-driven techniques (SLA + C-Ind test and bootstrapping) allow identifying different kind of links (i.e. strong or not). However, these fall short on identifying specifically the direction (i.e. cause-effect) of the links.

\subsection{Assessing the SDG-6 interlinkages across the 2030 Agenda}

This sub-section assesses the results achieved with the aim to validate the proposed data-driven approach. To do this, we first compare the results obtained from the data with those presented in the UN-Water Analytical Brief (2016). We do not consider the direction of the links identified within this assessment and we focus on dependencies between the indicators employed. In addition to this, and for each SDG 6 target, we explore both "first order" (Dir-link $\left.{ }_{\mathrm{n}}\right)$ and "second order" (Indir-link $\left.\mathrm{n}_{\mathrm{n}}\right)$ interlinkages identified (Step A.5) to evaluate their coherency with the main findings from an extensive literature review. This sub-section ends with a short recapitulation of results and we give an insight of further applications derived from this data-driven BN approach.

The UN-Water Analytical Brief argues how Goal 6 impregnates the social, environmental and economic dimensions of sustainable development, identifying relationships with all SDGs. From the results depicted in Fig. 4, it is observed that "first order" (direct) interlinkages are identified in relation to Goals on health (SDG 3), gender (5), energy (7), economic growth (8), inequality (10), sustainable cities and communities (11), sustainable consumption and production (12) and terrestrial ecosystems (15). When considering "second order" (indirect) links, identified interdependencies also includes the goals on poverty (1), food (2), infrastructure and industry (9), oceans (14) and peace and security (16). Specifically, 37 out of 42 indicators (88\%) are connected as a result of the BN model generated. Indicators related to the participation rate in organized learning (4.2.2), economic growth 
per employee (8.2.1), unemployment rate (8.5.2), passenger volume by air transport (9.1.2) and people affected by a disaster (13.1.1) fall out of the direct and indirect relationships considered (not shown in Fig. 4). These results are summarized in Table 4, including those targets i) identified in both the UN-Water Analytical Brief (2016) and the BN model (considering direct and indirect links), ii) identified within the Analytical Brief but not by the BN model, iii) identified by BN the model but not within the Analytical Brief, and iv) with no information available.

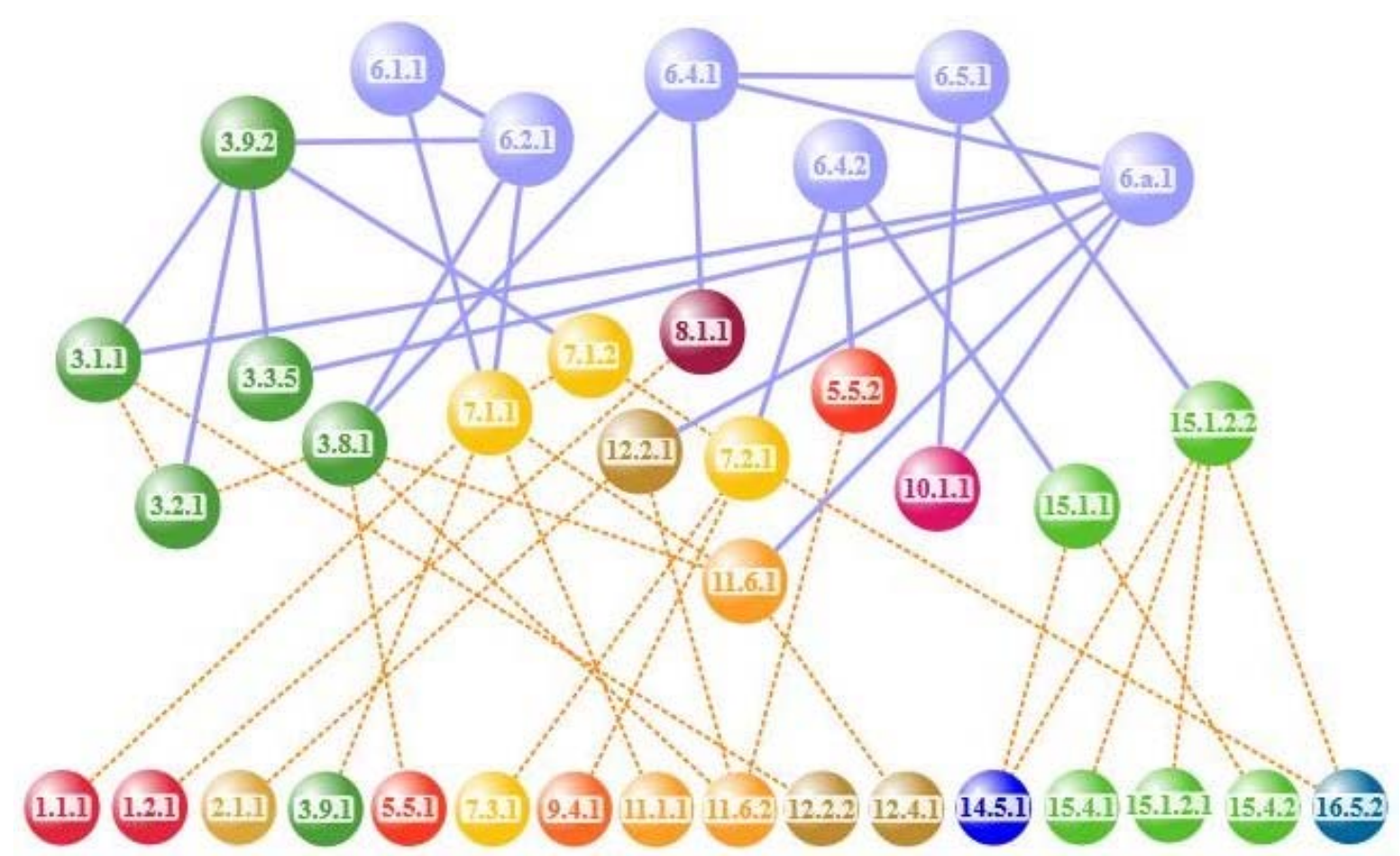

Fig. 4. SDG-6 related interlinkages identified. "First order" (Dir-link $\left.k_{n}\right)$ linkages are represented by solid blue arrows. "Second order" (Indir-link $k_{n}$ ) relationships by dot orange arrows. 
Table 4. Summary of interlinkages (direct and indirect) associated with SDG-6 in comparison to those ones identified in the UN-Water Analytical Brief (2016).

\begin{tabular}{|c|c|c|c|c|}
\hline \multirow[b]{2}{*}{ Indicators } & \multicolumn{2}{|c|}{ Links identified (data-driven approach) } & \multicolumn{2}{|c|}{ UN-Water Analytical Brief (2016) (Synergies \& Conflicts) } \\
\hline & "First order" (direct) & “Second order" (indirect) & Data available & $\begin{array}{l}\text { Insufficient or no data } \\
\text { available }\end{array}$ \\
\hline $\begin{array}{l}\text { Access to at least basic } \\
\text { drinking water services } \\
\text { (SDG 6.1.1) }\end{array}$ & $\begin{array}{l}2 \text { direct links: Access to at } \\
\text { least basic sanitation services } \\
(1.4 .1 \& 6.1 .2) ; \text { Access to } \\
\text { electricity }(7.1 .1)\end{array}$ & $\begin{array}{l}7 \text { indirect links: International poverty line (1.1.1); } \\
\text { Essential health (3.8.1); Mortality due to air pollution } \\
\text { (3.9.1); Mortality due to unsafe WaSH (3.9.2); Clean } \\
\text { fuels and technology (7.1.2); Population in slums } \\
\text { (11.1.1); Solid waste collection (11.6.1) }\end{array}$ & \multirow{2}{*}{$\begin{array}{l}\text { Links in Analytical Brief but not in } \\
\text { network: Hunger (T2.1); Childhood } \\
\text { development (T4.2); Economic growth } \\
\text { (T8.1); Economic productivity (T8.2); } \\
\text { Full employment (T8.5); Resilient } \\
\text { infrastructure (T9.1); Sustain income } \\
\text { growth (T10.1); Resilience to climate- } \\
\text { related hazards and natural disasters } \\
\text { (T13.1); Terrestrial and inland } \\
\text { freshwater, forest and mountain } \\
\text { ecosystems (T15.1, T15.2 \& T15.4); } \\
\text { Corruption and bribery (T16.5) }\end{array}$} & \multirow{3}{*}{$\begin{array}{l}\text { Malnutrition (T2.2); Small- } \\
\text { scale agricultural productivity } \\
\text { (T2.3); Sustainable food } \\
\text { production (T2.4); Education } \\
\text { for sustainable development } \\
\text { (4.7); Gender equality (T5.1, } \\
\text { T5.2); Labour rights (T8.8); } \\
\text { Sustainable tourism (T8.9); } \\
\text { Inequalities (T10.2 \& 10.3); } \\
\text { Sustainable urbanization } \\
\text { (T11.3); Marine pollution } \\
\text { (T14.1); Desertification and } \\
\text { loss of biodiversity (T15.3 \& } \\
\text { T15.5); Accountability (T16.6) }\end{array}$} \\
\hline \multirow[t]{2}{*}{$\begin{array}{l}\text { Access to at least basic } \\
\text { sanitation services } \\
\text { (SDG 6.2.1) }\end{array}$} & \multirow{2}{*}{$\begin{array}{l}\mathbf{4} \text { direct links: } \\
\text { Essential health } \\
\text { services (3.8.1); } \\
\text { Mortality due to unsafe } \\
\text { WaSH (3.9.2); Access } \\
\text { to drinking water (1.4.1 } \\
\text { \& 6.1.1); Access to } \\
\text { electricity (7.1.1) }\end{array}$} & \multirow{2}{*}{$\begin{array}{l}10 \text { indirect links: International poverty line } \\
\text { (1.1.1); Maternal mortality ratio (3.1.1); } \\
\text { Under-5 mortality rate (3.2.1); Interventions } \\
\text { against NTD (3.3.5); Mortality due to air } \\
\text { pollution (3.9.1); Women in governmental seats } \\
\text { (5.5.1); Clean fuels and technology (7.1.2); } \\
\text { Population in slums (11.1.1); Solid waste } \\
\text { collection (11.6.1); Levels of PM (11.6.2) }\end{array}$} & & \\
\hline & & & $\begin{array}{l}\text { Links in network but not in } \\
\text { Analytical Brief: Universal electricity } \\
\text { (T7.1) }\end{array}$ & \\
\hline $\begin{array}{l}\text { Water-Use Efficiency } \\
\text { (SDG 6.4.1) }\end{array}$ & $\begin{array}{l}4 \text { direct links: Essential } \\
\text { health services (3.8.1); } \\
\text { IWRM (6.5.1); ODA for } \\
\text { water and sanitation (6.a.1); } \\
\text { Growth rate (8.1.1) }\end{array}$ & $\begin{array}{l}11 \text { indirect links: National poverty line }(1.2 .1) \text {; } \\
\text { Maternal mortality ratio (3.1.1); Under-5 mortality } \\
\text { rate (3.2.1); Interventions against NTD (3.3.5); } \\
\text { Women in governmental seats }(5.5 .1) \text {; Access to } \\
\text { sanitation (1.4.1 \& 6.1.2); Household growth rates } \\
\text { (10.1.1); Solid waste collection (11.6.1); Levels of } \\
\text { PM (11.6.2); Material footprint (12.2.1); Terrestrial } \\
\text { KBAs (15.1.2.2) }\end{array}$ & $\begin{array}{l}\text { Links in Analytical Brief but not in } \\
\text { network: Hunger (T2.1); Economic } \\
\text { productivity (T8.2); Environmental } \\
\text { degradation (T8.4); Resilient } \\
\text { infrastructure (T9.1); Safe and } \\
\text { affordable housing (T11.1); Waste } \\
\text { management (T12.4); Climate-related } \\
\text { hazards and natural disasters (T13.1); } \\
\text { Forest area change (T15.2) }\end{array}$ & \multirow{2}{*}{$\begin{array}{l}\text { Malnutrition (T2.2); Small scale } \\
\text { agricultural productivity (T2.3); } \\
\text { Sustainable food production } \\
\text { (T2.4); Education for } \\
\text { sustainable development (4.7); } \\
\text { Sustainable tourism (T8.9); } \\
\text { Sustainable industrialization } \\
\text { (T9.2); Sustainable urbanization } \\
\text { (T11.3); Green and public } \\
\text { spaces (T11.7); Waste } \\
\text { generation (T12.5); } \\
\text { Desertification and loss of } \\
\text { biodiversity (T15.3 \& T15.5); } \\
\text { Accountability (T16.6) }\end{array}$} \\
\hline $\begin{array}{l}\text { Freshwater withdrawal } \\
\text { (SDG 6.4.2) }\end{array}$ & $\begin{array}{l}3 \text { direct links: Women in } \\
\text { managerial positions }(5.5 .2) \\
\text { Renewable energy }(7.2 .1) \\
\text { Forest area }(15.1 .1)\end{array}$ & $\begin{array}{l}7 \text { indirect links: Clean fuels and technology (7.1.2); } \\
\text { Energy efficiency (7.3.1); } \mathrm{CO}_{2} \text { emissions (9.4.1); } \\
\text { Levels of PM (11.6.2); Marine KBAs (14.5.1); } \\
\text { Mountain Green Cover Index (15.4.2); Firms } \\
\text { involved in bribery (16.5.2) }\end{array}$ & $\begin{array}{l}\text { Links in network but not in } \\
\text { Analytical Brief: Maternal mortality } \\
\text { (T3.1); Child mortality (T3.2); Water- } \\
\text { borne diseases (T3.3); Universal health } \\
\text { (T3.8); Women's participation (T5.5); } \\
\text { Marine ecosystems (T14.5) }\end{array}$ & \\
\hline
\end{tabular}


Integrated Water

Resource Management

(SDG 6.5.1)
3 direct links: Water-use

efficiency (6.4.1); Household

growth rates (10.1.1);

Terrestrial KBAs (15.1.2.2)
7 indirect links: Essential health services (3.8.1); ODA for water and sanitation (6.a.1); Growth rate (8.1.1); Marine KBAs (14.5.1); Freshwater KBAs (15.1.2.1); Mountain KBAs (15.4.1); Firms involved in bribery (16.5.2)
Links in Analytical Brief but not in network: Poverty (T1.1 \& 1.2); Basic services (T1.4); Hunger (T2.1) Women's full and effective participation (T5.5); Universal electricity (T7.1); Renewable energy (T7.2); Energy efficiency (T7.3); Economic productivity (T8.2); Full employment (8.5); Resilient infrastructure (T9.1); Environmentally sound technology (T9.4); Safe and affordable housing (T11.1)

Environmental impact of cities (T11.6) Sustainable management of natural resources (T12.2); Waste management (T12.4); Climate-related hazards and natural disasters (T13.1)

Links in network but not in Analytical Brief: Household growth rates (10.1.1); Universal health (T3.8); Economic growth (T8.1); Marine ecosystems (T14.5)
Malnutrition (T2.2); Smallscale agricultural productivity (T2.3); Sustainable food

production (T2.4); Education for sustainable development (4.7); Gender equality (T5.1, T5.2); Labour rights (T8.8); Sustainable tourism (T8.9);

Inequalities (T10.2 \& 10.3); Sustainable urbanization

(T11.3); Green and public spaces (T11.7); Sustainable consumption and production (T12.1 \&T12.3); Waste generation (T12.5); Marine pollution and ecosystems (T14.1 \& T14.2);

Desertification and loss of biodiversity (T15.3 \& $\mathrm{T} 15.5)$ Accountability (T16.6)

Synergies (plain text): Links which are likely to be mainly positive in that they may be mutually reinforcing or have positive interdependencies (UN-Water 2016).

Potential conflict (underlined text): Links which usually still have positive aspects, but there exists a potential conflict in one or both directions (UN-Water 2016). 


\subsubsection{SDG targets 6.1 and 6.2 on access to drinking water and sanitation}

These indicators refer specifically to the access to "at least basic" drinking water and sanitation services. The former relates to improved drinking water sources where collection time is not more than 30 minutes for a round trip (including queuing). The latter refers to improved facilities which are not shared with other households (Joint Monitoring Programme, 2017a).

Considering both "first order" (direct) and "second order" (indirect) interlinkages, the BN model identified, for the case of water, $30 \%$ (7 out of 23 ) of the target-level relationships pointed out within the UN-Water Analytical Brief. In contrast, this result rises up to 48\% (11 out of 23) for the sanitation-related indicator (see Table 4).

In Table 5, the coherency of the results is expanded and contrasted against the existing literature. Specifically, this comparison is carried out on 3 levels: whether the link identified by the BN model is related to i) a direct relationship, ii) an indirect relationship, and iii) a missed relationship.

As regard direct relationships, it is observed the link between both SDG 6 indicators and the links with Goal 3 (health) and Goal 7 (energy). The latter is of particular relevance, as the UN-Water Analytical Brief does not refer to it specifically. However, water is required to produce energy, and vice versa (United Nations, 2018a; UN-Water, 2016; WWAP, 2014). In addition to this, energy is required to treat faecal sludge and wastewater. In turn, it is possible to produce energy from wastewater in the form of heat, biogas and biofuels (United Nations, 2018a; UN-Water, 2016).

When considering indirect links, the spectrum of health and energy is expanded to the relationships between access to water and sanitation and Goal 1 (poverty), Goal 5 (gender) and Goal 11 (sustainable cities and communities). For instance, the results show a relationship with the population living below the international poverty line (1.1.1). As pointed by Cohen and Sullivan (2010), there exists a mass of literature which examines the interlinkages between water and poverty from different points of view (e.g. economic assessment, physical accessibility or basic needs perspective). As an illustrative example, access to water (and sanitation) is a component of the Multidimensional Poverty Index formulated by the United Nations Development Programme (Alkire and Jahan, 2018). Additionally, and per definition, SDG 1 includes a target for universal access to basic services (Target 
1.4). Another result points at the link with the proportion of seats held by women in national parliaments (5.5.1). The lack of adequate sanitation facilities might expose women and young girls to illness and safety risks, compromising their learning experience (UN-Women, 2018). Thus, it hinders the opportunities to reach professional positions of national responsibility.

From those relationships not identified by the BN model (see Table 4), we acknowledge the absence of the links related to the participation rate in pre-primary school (4.2.2) and the proportion of women in managerial positions (5.5.2), which might be treated together. Women and girls are responsible for water collection in 8 out of 10 households with water off-premises (UN-Women, 2018). In different world regions, if women and young girls reduced the time to collect water, then they would have more time and opportunity to improve their lives through education, paid work and better health (ILO, 2019; Fisher, 2008; UNDP, 2006a; Willetts et al., 2010). Moreover, it would give the opportunity to combat further problems that threaten poor women's well-being (Kevany and Huisingh, 2013). However, it cannot be assumed that increased water access reduces women's workload or strengthens women's empowerment (Ivens, 2008). This implies an unequal sharing of family and household responsibilities, which means that when public services such as education, childcare, water and sanitation are cut back or become less affordable, it is usually women and young girls who fill gap and the overall families who do not enjoy these services (Desai and Alva, 1998; UN-Women, 2018). In addition to this, the BN model does not identify any relationship with Goal 8 (economic growth). Economic growth (8.1.1) and jobs rely on limited environmental resources such as water (ILO, 2018). Specifically, 78\% of the jobs constituting the global workforce are water dependent (WWAP, 2016). Furthermore, the provision of WaSH services at home and in the workplace enables a robust economy by contributing to a healthy and productive population workforce (8.2.1) (WWAP, 2016). Investments in WaSH have paved a path to economic growth and unemployment rates (8.5.2) reduction and new business opportunities appear as a result of policies which address, for example, water (and sanitation) infrastructures (UN-EMG, 2011; WWAP, 2016). 
Table 5. Literature review in relation to the relationships identified (i.e. direct and indirect) and missed for the case of SDG Targets 6.1 and 6.2.

\begin{tabular}{|c|c|c|c|}
\hline & $\begin{array}{c}\text { SDG 6 } \\
\text { indicator }\end{array}$ & Interlinkages identified & Relationship assessment \\
\hline \multirow{6}{*}{ 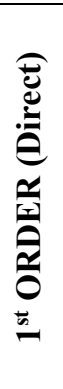 } & 6.1 .1 & \multirow{2}{*}{$\begin{array}{l}\text { 6.1.1 - 6.2.1: Access to "at least basic" } \\
\text { water and sanitation services }\end{array}$} & \multirow{2}{*}{$\begin{array}{l}\text { Water and sanitation have been jointly monitored together since 1930. A WaSH implementation approach has } \\
\text { been in place since } 1970 \text { (Bartram et al., 2014; Herrera, 2019) }\end{array}$} \\
\hline & 6.2 .1 & & \\
\hline & 6.2 .1 & $\begin{array}{l}\text { 3.8.1: Coverage of essential health } \\
\text { services }\end{array}$ & $\begin{array}{l}\text { The human right to essential health includes, among others, access to an adequate supply of basic sanitation } \\
\text { (Backman et al., 2008) }\end{array}$ \\
\hline & 6.2 .1 & $\begin{array}{l}\text { 3.9.2: Mortality rate attributed to unsafe } \\
\text { WaSH services }\end{array}$ & Intrinsically related per definition \\
\hline & 6.1 .1 & \multirow{2}{*}{ 7.1.1: Access to electricity } & \multirow{2}{*}{$\begin{array}{l}\text { Water as a source to produce energy, and vice versa (United Nations, 2018a; UN-Water, 2016; WWAP, 2014). } \\
\text { Energy is required to treat faecal sludge and wastewater. Energy can be produced in the form of heat, biogas and } \\
\text { bio-fuels (United Nations, 2018a; UN-Water, 2016) }\end{array}$} \\
\hline & 6.2 .1 & & \\
\hline \multirow{14}{*}{ 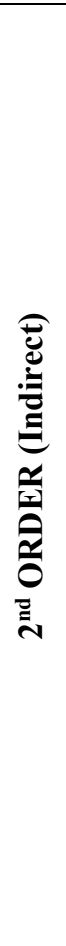 } & 6.1 .1 & \multirow{2}{*}{$\begin{array}{l}\text { 1.1.1: Population living below the } \\
\text { international poverty line }\end{array}$} & \multirow{2}{*}{$\begin{array}{l}\text { Direct linkages between water and poverty from different points of view (e.g. economic assessment, physical } \\
\text { accessibility or basic needs perspective) (Cohen and Sullivan, 2010; Sullivan, 2002) } \\
\text { Water and sanitation are components of the UNDP Multidimensional Poverty Index (Alkire and Foster, 2007; } \\
\text { Alkire and Jahan, 2018; Alkire and Santos, 2014; Giné-Garriga and Pérez-Foguet, 2019) } \\
\text { SDG } 1 \text { includes a target for universal access to basic services, such as water and sanitation (Target 1.4) }\end{array}$} \\
\hline & 6.2 .1 & & \\
\hline & 6.2 .1 & 3.1.1: Maternal mortality rate & \multirow{2}{*}{$\begin{array}{l}\text { Extensive literature dealing with the effects of WaSH on health (e.g. Bartram et al., 2005; Cairncross et al., } \\
\text { 2010; Esrey et al., 1991; Feachem, 1984; Cheng et al., 2012) }\end{array}$} \\
\hline & 6.2 .1 & 3.2.1: Under-five mortality rate & \\
\hline & 6.2 .1 & $\begin{array}{l}\text { 3.3.5: People requiring interventions } \\
\text { against NTD }\end{array}$ & $\begin{array}{l}\text { WaSH interventions can reduce the number of people requiring interventions against NTD (e.g. Fitzpatrick and } \\
\text { Engels, 2015; Hotez et al., 2015; United Nations, 2018a; WHO, 2015a) }\end{array}$ \\
\hline & 6.1 .1 & $\begin{array}{l}\text { 3.8.1: Coverage of essential health } \\
\text { services }\end{array}$ & The human right to health includes, as well, an adequate supply of safe water (Backman et al., 2008) \\
\hline & 6.1 .1 & \multirow{2}{*}{$\begin{array}{l}\text { 3.9.1: Mortality rate attributed to } \\
\text { household and ambient air pollution }\end{array}$} & \multirow{2}{*}{$\begin{array}{l}\text { Consequence of using solid fuels for domestic purposes, such as cooking, heating or treating water } \\
\text { Countries presenting higher 3.9.1 rates coincide with countries presenting higher 3.9.2 rates (mortality due to } \\
\text { unsafe WaSH) (WHO, 2018) }\end{array}$} \\
\hline & 6.2 .1 & & \\
\hline & 6.2 .1 & $\begin{array}{l}\text { 5.5.1: Proportion of women in national } \\
\text { parliaments }\end{array}$ & $\begin{array}{l}\text { Lack of adequate sanitation facilities might expose women and young girls to illness and safety risks, } \\
\text { compromising their learning experience and hindering the opportunities to develop a professional career (UN- } \\
\text { Women, 2018) }\end{array}$ \\
\hline & 6.1 .1 & \multirow{2}{*}{$\begin{array}{l}\text { 7.1.2: Primary reliance on clean fuels } \\
\text { and technology }\end{array}$} & \multirow{2}{*}{$\begin{array}{l}\text { Lack of 7.1.2 access leads to high levels of household air pollution (United Nations, 2018b; World Bank, 2018). } \\
\text { Potential link if it is considered the existing relationship between air pollution and unsafe WaSH }\end{array}$} \\
\hline & 6.2 .1 & & \\
\hline & $\frac{6.1 .1}{621}$ & 11.1.1: Urban population living in slums & Access to water and sanitation helps in promoting better housing and slum upgrading (UN-Habitat, 2018) \\
\hline & $\frac{0.2 .1}{6.1 .1}$ & \multirow{2}{*}{ 11.6.1: Urban solid waste collection } & \multirow{2}{*}{$\begin{array}{l}\text { Existing connection with SDG } 11 \text { is established through Target } 11.6 \text { (reduction environmental impact of cities) } \\
\text { (UN-Habitat, 2018) }\end{array}$} \\
\hline & 6.2 .1 & & \\
\hline
\end{tabular}


6.1 .1

2.1.1: Prevalence of undernourishment

6.2 .1

6.1.1 3.1.1: Maternal mortality rate 3.2.1: Under-five mortality rate

6.1.1 4.2.2: Participation rate in organized learning

5.5.1: Proportion of women in national

parliaments (only for 6.1.1)

5.5.2: Proportion of women in

6.2.1 managerial positions

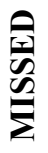

6.1 .1

8.1.1: Economic growth

8.2.1: Growth rate per employee

6.2 .1

8.5.2: Unemployment rate

6.1 .1

9.1.2: Air traffic

6.2 .1

$\frac{6.1 .1}{6.2 .1}$ 9.4.1: $\mathrm{CO}_{2}$ emissions

\begin{tabular}{ll}
6.1 .1 & 10.1.1: Growth rates inequalities \\
\hline 6.2 .1 & \\
\hline 6.1 .1 & 13.1.1: People affected by disasters \\
\hline 6.2 .1 & 15.1.1: Forest areas
\end{tabular}

Caused by inadequate dietary intake and infectious diseases such as diarrhoea. WaSH interventions are

frequently implemented to reduce the latter (Dangour et al., 2013)

"Zero hunger" is highly dependent on progress in ensuring availability and sustainable management of water and sanitation (ICSU-ISSC, 2017)

Increasing literature applying nexus approaches, such as water-energy-food nexus (Rasul, 2016; Pahl-Wostl, 2017)

Extensive literature dealing with the effects of WaSH on health (e.g. Bartram et al., 2005; Cairncross et al., 2010; Esrey et al., 1991; Feachem, 1984; Cheng et al., 2012)

Women are responsible for water collection in 8 out of 10 households with water off-premises (UN-Women, 2018)

Reducing the time to collect water would provide more time and opportunities through education, paid work and better health (ILO, 2019; Fisher, 2008; UNDP, 2006a; Willetts et al., 2010)

Opportunity to combat further problems that threaten poor women's well-being (Kevany and Huisingh, 2013)

Increased water access might not reduce women's workload or strengthen women's empowerment (Ivens, 2008)

Due to unequal sharing of household responsibilities, and availability and affordability of public services (e.g.

education, water and sanitation), women and young girls usually fill the gap and the overall families do not enjoy these services (Desai and Alva, 1998; UN-Women, 2018)

Based on limited environmental resources such as water (ILO, 2018)

$78 \%$ of the jobs constituting the global workforce are water dependent (WWAP, 2016)

WaSH services enable a robust economy by contributing to a healthy and productive population workforce (WWAP, 2016)

Investments in WaSH have paved a path to economic growth, unemployment rates reduction and new business opportunities (UN-EMG, 2011; WWAP, 2016)

Growth in traffic at airports also brings growth in the direct jobs generated (ATAG, 2018)

Peripheral regions air activity appears to boost regional development, while in core regions regional growth causes airport activity (Mukkala and Tervo, 2013)

Relationship between air traffic and economic growth and employment links with the access to water

Global economic and population growth as the most important drivers. Contribution of economic growth has risen sharply comparing to population growth (IPCC, 2014)

Inequalities in access to water and sanitation services between SDG regions, between countries within each region, within individual countries, between urban and rural areas, sub-national regions and wealth quintiles (Joint Monitoring Programme, 2017b)

WaSH interventions can prevent outbreaks of waterborne diseases in both emergency settings and displaced population (Brown et al., 2012; Watson et al., 2007)

Forest play a large role in regulating fluxes of atmospheric moisture and rainfall patterns over land through evapotranspiration and transpiration (Ellison et al., 2012; 2017) 
Natural forests transport water locally and globally (Ellison et al., 2017). These are suggested to be capable of "pumping" atmospheric moisture from the ocean to land in order to compensate the river runoff and ensuring maximum ecosystem productivity (Makarieva and Gorshkov, 2007)

Land conversions from forests to agriculture or forest protection might imply trade-offs in both downstream and upstream communities (Ellison et al., 2017; Pramova et al., 2012; Sheil et al., 2016)

6.1.1 15.1.2.1: Freshwater KBAs

15.1.2.2: Terrestrial KBAs

6.2.1 15.4.1: Mountain KBAs

6.1 .1

6.2.1
16.5.2: Bribery practices
These provide a range of important ecosystem services, being drinking water a significant one (UNEP-WCMC and IUCN, 2016; UNEP-WCMC et al., 2018; United Nations, 2018b)

Clear link between the treatment of faecal sludge and wastewater and the environment health (UN-Water, 2016)

Water sector is not exempt of suffering from bribery practices, such as expediting new service connections after payment or favouritism in public procurement (Stålgren, 2006)

These practices contribute to millions of people dying from illnesses caused by lack of access to sanitation (and clean water) (Stålgren, 2006) 


\subsubsection{SDG target 6.4 on water-use efficiency and water stress}

This target includes two indicators which are strongly linked and offer complementary information. On the one hand, indicator 6.4.1 assesses to what extent a country's economic growth is dependent on the use of water resources, representing an economic indicator. On the other hand, indicator 6.4.2 is an environmental indicator, tracking the physical availability of freshwater resources (FAO, 2018).

In this case, the $\mathrm{BN}$ model identified 15 out of $20(75 \%)$ of the target-level relationships extracted from the UN-Water Analytical Brief, taking into account both direct and indirect links. Similarly to the case of access to water and sanitation, the links identified refer as well to Goals on poverty (1), health (3), gender (5), energy (7) and cities (11). However, in this case, the spectrum of the relationships obtained expands to Goal 12 (sustainable consumption and production), Goal 14 (oceans), Goal 15(terrestrial ecosystems) and Goal 16 (peace and security) (see Table 4).

As in the case of Targets 6.1 and 6.2, Table 6 provides a summary of the academic contributions behind the direct, indirect and missed interlinkages associated with the BN analysis. In this sense, and focusing on the direct links identified, it is observed, for instance, a relationship of water-use efficiency (6.4.1) with the degree of IWRM implementation (6.5.1) and the ODA for water supply and sanitation (6.a.1). Regarding the former, IWRM has been presented during the last decades as the framework to support, among others, the achievement of an efficient use of water (GWP, 2000; UNEP, 2018). According to the latter, Target 6.a advocates expanding international cooperation and capacity-building in water-related activities and programmes, such as water efficiency. In fact, a recent survey to 24 external support agencies show that more than $40 \%$ promote water use efficiency and sustainable withdrawals and 50\% support the implementation of IWRM as "very high" priority areas (GLAAS, 2017). On the other hand, the results show a relationship between water-stress (6.4.2) and the renewable energy share in the total final energy consumption (7.2.1). Water is used for nonrenewable energy generation (e.g. in the extractive industries for producing fuels or for cooling purposes in power plants), but for renewable energy generation as well (e.g. as an input for energy crops or as driving force for hydroelectric turbines) (WWAP, 2014). However, the latter is also identified as a potential conflict, as hydropower and bio-energy might have significant impacts on 
land and water resources and ecosystems (UN-Water, 2016). In this study, the tendency of the data employed shows that when the share of renewable energy increases, less countries show water stress (see Supplementary Material Table S5). Another direct link identified is that one associated with the forest area as a proportion of total land area (15.1.1). Natural resources, such as land, have been acquired to satisfied immediate human needs, often at the expense of degrading the environment. Forests have been cleared for intensive agriculture and livestock, and for expanding urban settlements. Water demands associated with these practices, especially irrigation for agriculture, directly affect freshwater supplies and increase water scarcity levels (Foley et al., 2005; Mekonnen and Hoekstra, 2016; United Nations, 2018a). Similar to the previous relationship identified, the tendency of the data used in this study suggests that there is a positive correlation between high rates of forest coverage and low levels of water stress (see Supplementary Material Table S5). In addition to these direct links associated to water-use efficiency (6.4.1) and water stress (6.4.2), we highlight those relationships identified by the BN model and not reflected within the Analytical Brief. For instance, it is observed a link between water-use efficiency (6.4.1) and the essential health service coverage (3.8.1) and, indirectly, to other health-related targets (see Table 6). It is acknowledged that an increase in water-use efficiency makes more water available for drinking and other uses (UNEP, 2018). Access to improved water (and sanitation) represents a tracer indicator for universal health coverage achievement (WHO, 2015b) and is especially useful for monitoring the progressive realization of the right to health (Backman et al., 2008). In the case of water stress (6.4.2), it is observed a direct link with the proportion of women in managerial positions (5.5.2). Although this link has not been addressed within this specific focus, its interdependency has been largely analyzed. Several publications affirm that women's involvement in water management is a key aspect to improving programme and project effectiveness due to women's roles, concerns and priorities in water-related issues (Ivens, 2008) and, thus, balancing the access to the control over resources such as water (Panda, 2007; UNDP, 2006b) and hastening the achievement of sustainability in the management of scarce water resources (GWA, 2003). The data employed in this study suggest that the higher the participation of women is, the lower the water stress is (see Supplementary Material Table S5). 
When paying attention to the indirect links, several relationships are provided by the $\mathrm{BN}$ model which are not reflected in the Analytical Brief. In particular, it is observed an indirect relationship between water-use efficiency (6.4.1) and maternal mortality (3.1.1), child mortality (3.2.1) and the number of people requiring interventions against neglected tropical diseases (3.3.5). As mentioned previously, an increase in water-use efficiency makes more water available which, in turn, impacts positively in health issues. In the case of water stress (6.4.2), it is observed a relationship with the marine Key Biodiversity Areas (14.5.1). In this sense, it is acknowledged that much of the pollution affecting oceans and coastal zones comes from human activities, such agriculture or industry (United Nations, 2018a). In addition to this, population and economic growth are some of the major drivers that affect and will affect water resources (Ercin and Hoekstra, 2014; Vörösmarty et al., 2000). It is suggested, as well, that in this stress context the protection of marine areas would raise. 
Table 6. Literature review in relation to the relationships identified (i.e. direct and indirect) and missed for the case of SGD Target 6.4.

\begin{tabular}{|c|c|c|c|}
\hline & $\begin{array}{c}\text { SDG 6 } \\
\text { indicator }\end{array}$ & Interlinkages identified & Relationship assessment \\
\hline \multirow{7}{*}{ 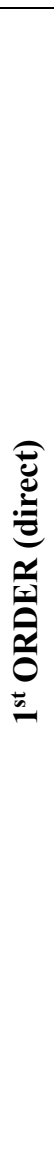 } & 6.4 .1 & $\begin{array}{l}\text { 3.8.1: Coverage of essential health } \\
\text { services }\end{array}$ & $\begin{array}{l}\text { An increase in 6.4.1 makes more water available for drinking and other uses (UNEP, 2018) } \\
\text { Access to improved water (and sanitation) represents a tracer indicator for universal health coverage } \\
\text { achievement (WHO, 2015b) } \\
\text { Useful for monitoring the progressive realization of the human right to health (Backman et al., 2008). }\end{array}$ \\
\hline & 6.4 .2 & $\begin{array}{l}\text { 5.5.2: Proportion of women in managerial } \\
\text { positions }\end{array}$ & $\begin{array}{l}\text { Women's involvement improves programme and project effectiveness due to their roles, concerns and priorities } \\
\text { in water-related issues (Ivens, 2008) } \\
\text { It balances the access to the control over resources such as water (Panda, 2007; UNDP, 2006b) and accelerates } \\
\text { the achievement of sustainability in scarce water resources management (GWA, 2003) } \\
\text { Higher participation of women is correlated to lower levels of water stress (see Supplementary Material Table } \\
\text { S5) }\end{array}$ \\
\hline & 6.4 .1 & 6.5.1: Degree of IWRM implementation & IWRM promotes the achievement of an efficient use of water (GWP, 2000; UNEP, 2018) \\
\hline & 6.4 .1 & $\begin{array}{l}\text { 6.a.1: ODA for water supply and } \\
\text { sanitation }\end{array}$ & $\begin{array}{l}\text { Support to water efficiency programmes included in Target } 6 . \text { a definition } \\
\text { More than } 40 \% \text { and } 50 \% \text { of surveyed agencies consider, respectively, water use efficiency and sustainable } \\
\text { withdrawals and IWRM implementation as "very high" priority areas (GLAAS, 2017) }\end{array}$ \\
\hline & 6.4 .2 & 7.2.1: Renewable energy share & $\begin{array}{l}\text { Water is used for non-renewable energy generation (e.g. extractive industries or for power plants), but for } \\
\text { renewable energy generation as well (e.g. input for energy crops or driving force for hydroelectric turbines) } \\
\text { (WWAP, 2014) } \\
\text { Potential conflict, as hydropower and bio-energy might have significant impacts on land and water resources } \\
\text { and ecosystems (UN-Water, 2016) } \\
\text { Tendency of lower levels of water stress when increasing 7.2.1 (see Supplementary Material Table S5) }\end{array}$ \\
\hline & 6.4 .1 & 8.1.1: Economic growth & $\begin{array}{l}\text { An increase in } 8.1 .1 \text { might enhance technological advancements that can improve efficiency in using water and, } \\
\text { thus, reduce the exploitation of water resources (El Khanji, 2016; FAO, 2018) }\end{array}$ \\
\hline & 6.4 .2 & 15.1.1: Forest area & $\begin{array}{l}\text { Forests have been cleared for intensive agriculture and livestock, and for expanding urban settlements. Water } \\
\text { demands associated with these practices, especially irrigation for agriculture, directly affect freshwater supplies } \\
\text { and increase water scarcity levels (Foley et al., 2005; Mekonnen and Hoekstra, 2016; United Nations, 2018a) } \\
\text { Positive correlation between high rates of forest coverage and low levels of water stress (see Supplementary } \\
\text { Material Table S5) }\end{array}$ \\
\hline
\end{tabular}




\begin{tabular}{|c|c|c|c|}
\hline & 6.4 .1 & $\begin{array}{l}\text { 1.2.1: Population living below the national } \\
\text { poverty line }\end{array}$ & $\begin{array}{l}\text { Increasing water availability by using water more efficiently impacts positively on poverty alleviation. Potential } \\
\text { conflict if development for poverty reduction and economic growth are not taken carefully to use water } \\
\text { sustainably (UN-Water, 2016) }\end{array}$ \\
\hline \multirow{11}{*}{ 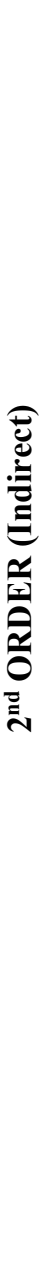 } & \multirow{6}{*}{6.4 .1} & $\begin{array}{l}\text { 6.2.1: Access to at least basic sanitation } \\
\text { services }\end{array}$ & \multirow{6}{*}{$\begin{array}{l}\text { Higher levels of } 6.4 .1 \text { increases water availability for different purposes (UNEP, 2018). This improves mother's } \\
\text { and children's health, reduces the number of people requiring interventions against NTD, provides more } \\
\text { learning opportunities for women and reduces environmental impacts of cities }\end{array}$} \\
\hline & & 3.1.1: Maternal mortality rate & \\
\hline & & 3.2.1: Under-five mortality rate & \\
\hline & & $\begin{array}{l}\text { 3.3.5: People requiring interventions } \\
\text { against NTD }\end{array}$ & \\
\hline & & $\begin{array}{l}\text { 4.2.2: Participation rate in organized } \\
\text { learning }\end{array}$ & \\
\hline & & $\begin{array}{l}\text { 5.5.1: Proportion of women in national } \\
\text { parliaments }\end{array}$ & \\
\hline & 6.4 .2 & $\begin{array}{l}\text { 7.1.2: Primary reliance on clean fuels and } \\
\text { technology }\end{array}$ & $\begin{array}{l}\text { Same people who lack access to improved water (and sanitation) are also likely to lack access to electricity and } \\
\text { rely on solid fuel for cooking (WHO, 2018; WWAP, 2014) } \\
\text { Considering some exceptions, water stress is consider the symptom of water scarcity, which hinders the access } \\
\text { of this resource (United Nations, 2018a) }\end{array}$ \\
\hline & 6.4 .2 & 7.1.3: Energy efficiency & $\begin{array}{l}\text { Water is required for energy production and more efficient processes in this concern reduces water consumption } \\
\text { and, thus, water stress (ICSU-ISSC, 2017; Ringler et al., 2013; United Nations, 2018a; UN-Water, 2016) } \\
\text { Resource savings might be invested to increase production and thus hindering to achieve an overall decrease in } \\
\text { demand (Unver et al., 2017; WWAP, 2014) }\end{array}$ \\
\hline & 6.4 .2 & 9.4.1: $\mathrm{CO}_{2}$ emissions & $\begin{array}{l}\text { Energy generation contributes with the highest levels of } \mathrm{CO}_{2} \text { emissions (IPCC, 2014) and consumes large } \\
\text { amounts of water ( } \mathrm{Li} \text { et al., 2012) } \\
\text { Water sector as a greenhouse-gases emitter (Rothausen and Conway, 2011) } \\
\text { Higher levels of water withdrawals are related to "medium" levels of emissions in relative terms (see Table S6) } \\
\text { Different picture if the so-called "virtual water" is considered within the analysis (Hoekstra and Hung, 2002; } \\
\text { Longo and York, 2009). }\end{array}$ \\
\hline & 6.4 .1 & 10.1.1: Growth rates inequalities & $\begin{array}{l}\text { Increasing } 6.4 .1 \text { implies an increase in drinking water availability. This impacts positively in people's health and } \\
\text { in economy and, thus, contributes in reducing inequalities }\end{array}$ \\
\hline & 6.4 .1 & $\begin{array}{l}\text { 11.6.1: Solid waste management } \\
\text { 11.6.2: Levels of fine particulate matter } \\
(\mathrm{PM})\end{array}$ & $\begin{array}{l}\text { 6.4.1 and } 6.4 .2 \text { supportive to waste reduction and improve its management, as well as to progress on air quality } \\
\text { levels (UN-Water, 2016) } \\
\text { Effective waste management systems are crucial to access to safe WaSH services and to improve water } \\
\text { resources quality and sustainability (UN-Habitat, 2018) }\end{array}$ \\
\hline
\end{tabular}




\begin{tabular}{|c|c|c|c|}
\hline & \multicolumn{2}{|l|}{6.4 .2} & $\begin{array}{l}\text { Waste disposal cost rises in tandem with the investments and operating costs for reducing emissions to water } \\
\text { (UN-Habitat, 2010) } \\
\text { Anthropogenic sources of PM include, among others, solid-fuel combustion, and industrial and agricultural } \\
\text { activities (Kim et al., 2015) } \\
\text { These water consumer activities contribute to air pollution and hinder the sustainability of natural resources, as } \\
\text { well as economic and social development (UN-Water, 2016; WWAP, 2016) }\end{array}$ \\
\hline & 6.4 .1 & 12.1.1: Material footprint & $\begin{array}{l}\text { Humans rely on raw materials to meet basic needs such as access to water } \\
\text { Water is used to material extraction processes, linking material and water footprints (United Nations, 2018a; } \\
\text { Wiedmann et al., 2015) } \\
\text { Resource efficiency means a small footprint per unit of product (Hoekstra and Wiedmann, 2014) }\end{array}$ \\
\hline & 6.4 .2 & 14.5.1: Marine KBAs & $\begin{array}{l}\text { Protected areas can work against improving rights and access to resources (Target 1.4) if they are established } \\
\text { and enforced without engaging local stakeholders (Singh et al., 2018). This study does not point at the specific } \\
\text { link with basic services } \\
\text { Much of the pollution affecting oceans and coastal zones comes from human activities, such agriculture or } \\
\text { industry (United Nations, 2018a) } \\
\text { Population and economic growth are some of the major drivers that affect and will affect water resources (Ercin } \\
\text { and Hoekstra, 2014; Vörösmarty et al., 2000). It might be suggested that in this stress context the protection of } \\
\text { marine areas would raise } \\
10 \% \text { of the countries suffer water stress while protecting a low percentage of marine areas (see Table S6) }\end{array}$ \\
\hline & 6.4 .1 & 15.1.2.2: Terrestrial KBAs & $\begin{array}{l}\text { Effort towards achieving water-use efficiency must incorporate, among others, the principle of conserving, } \\
\text { protecting and enhancing natural ecosystems (Unver et al., 2017) }\end{array}$ \\
\hline & 6.4 .2 & 15.4.2: Mountain Green Cover Index & $\begin{array}{l}\text { Mountains provide between } 60 \% \text { and } 80 \% \text { of the Earth's freshwater (FAO, 2015) } \\
\text { Green coverage of mountain areas (i.e. forests, shrubs and trees) increases water availability and, thus, reduces } \\
\text { potential water stress } \\
53 \% \text { of the countries ( } 95 \text { out of } 179 \text { ) show a positive correlation (see Supplementary Material Table S6) }\end{array}$ \\
\hline & 6.4 .2 & 16.5.2: Bribery practices & $\begin{array}{l}\text { When water becomes scare, so does the competition for this resource. This creates more incentives to resort to } \\
\text { corruption to grab more than one's fair share (Transparency International, 2008) } \\
\text { Data used do not suggest a clear relationship (see Table S6) }\end{array}$ \\
\hline$\underset{\Omega}{\mathscr{2}}$ & 6.4 .2 & 2.1.1: Prevalence of undernourishment & $\begin{array}{l}\text { Hunger and food security (secure access to sufficient amounts of safe and nutritious food for normal growth and } \\
\text { development and an active and healthy life) are intrinsically related, and water plays an important role in this } \\
\text { process (United Nations, 2018a) } \\
\text { Regions with high levels of water stress show high prevalence of severe food insecurity, but the latter is present } \\
\text { in regions with low water stress as well (United Nations, 2018a) } \\
\text { Agriculture plays a key role towards "zero hunger" and it accounts for approximately } 70 \% \text { of water withdrawals } \\
\text { Agricultural productivity, if not properly managed, jeopardizes the availability, sustainability and quality of } \\
\text { water for multiple purposes and users (ICSU-ISSC, 2017) } \\
\text { Water-energy-food nexus has been extensively reviewed elsewhere (Albrecht et al., 2018) }\end{array}$ \\
\hline
\end{tabular}




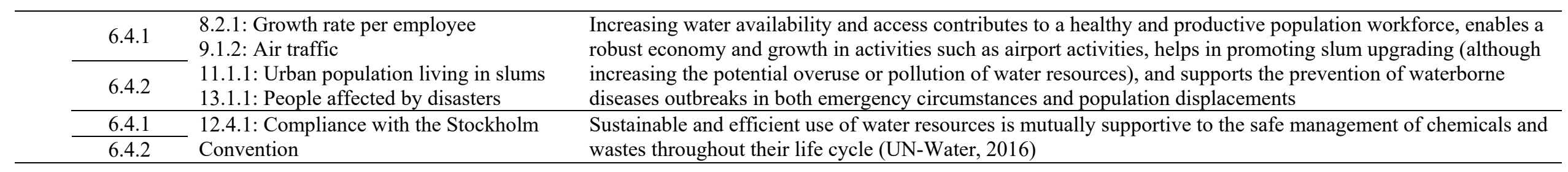




\subsubsection{SDG target 6.5 on integrated water resources management}

IWRM represents a process-oriented and aspirational target instead of an outcome as the previous ones. Its implementation supports balancing the environmental, social and economic dimensions of sustainable development and achieving all Goals across the 2030 Agenda (UNEP, 2018). Specifically, indicator 6.5.1 refers to the degree of IWRM implementation, which it is assessed through a selfassessed country questionnaire, organized into four main dimensions; enabling environment, institutions and participation, management instruments and financing (UNEP, 2018).

Overall relationships related to the degree of IWRM implementation encompass 33\% (7 out of 21) of the target-level links pointed within the UN-Water Analytical Brief (see Table 4). Even though, IWRM is per definition wide in scope, it should be taken into consideration that, due to the aggregated nature of this indicator, it might mask further potential links. In this case, from Table 7 it is observed that those linkages identified are related to Goal 3 (health), Goal 8 (economic growth), Goal 10 (inequality), Goal 14 (oceans) Goal 15 (terrestrial ecosystems) and Goal 16 (peace and security) (see Table 7).

Unlike the UN-Water Analytical Brief, the BN model show a direct relationship between IWRM (6.5.1) and growth rates inequalities (10.1.1). It is acknowledged that water (and sanitation) is essential to reduce inequalities. IWRM concept calls to "leave no one behind". This highlights overlapping aspects between IWRM and the human rights based-approach to water and sanitation (i.e. equality, equity, participation and governance) (WWAP, 2019).

Indirectly, it is observed a link between IWRM and the coverage of essential health services (3.8.1) and economic growth (8.1.1). These links are not reflected in the Analytical Brief. However, a recent report states the existence of a positive correlation with the Human Development Index (UNEP, 2018), where life expectancy (health) is one of its parameters (UNDP, 2018). Furthermore, it states that wealthier countries present higher degrees of IWRM implementation (UNEP, 2018). The BN analysis shows, as well, a relationship between IWRM and marine KBAs (14.5.1). In general, Key Biodiversity Areas provide a range of ecosystem services (e.g. drinking water) both upstream and 
downstream. A key principle of IWRM is that water resources also need to be managed according to hydrological boundaries (UNEP, 2018).

\subsubsection{SDG target 6.a on international cooperation and capacity-building support}

Unlike previous targets, this one focuses on the means of implementation to achieve SDG 6 . Specifically, it assesses the amount of water- and sanitation-related official development assistance (ODA) that is part of a government-coordinated spending plan (6.a.1). Due to fact that there is no room for comparison to the UN-Water Analytical Brief, only the direct links obtained from the BN model are considered to evaluate their coherency.

Interestingly, this indicator shows the highest number of direct links identified (see Table 8). Specifically, these refer to Goal 3 (health), Goal 10 (inequality), Goal 11(sustainable cities and communities) and Goal 12 (sustainable consumption and production). For instance, the BN model shows a link between the ODA (6.a.1) and the maternal mortality (3.1.1) and the number of people requiring interventions against neglected tropical diseases (3.3.5). Relatively, ODA for health has been much greater in countries with highest levels of maternal (and child) mortality (GLAAS, 2017; Pitt et al., 2010). In addition to this, from the data used in this study, the ODA for water and sanitation is greater in countries with higher rates of maternal mortality and more interventions against neglected tropical diseases (see Supplementary Material Table S5). However, some authors considered necessary to increase the share of ODA for NTD control (Liese and Schubert, 2009). Another example points at the relationship with the growth rates inequalities (10.1.1). A recent study states that ODA plays an important role in reducing gender inequalities and rural-urban disparities in social and human development (Ndikumana and Pickbourn, 2017). 
Table 7. Literature review in relation to the relationships identified (i.e. direct and indirect) and missed for the case of SGD Target 6.5.

\begin{tabular}{|c|c|c|}
\hline & Interlinkages identified & Relationship assessment \\
\hline \multirow{3}{*}{ 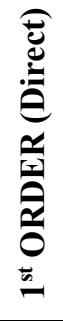 } & 6.4.1: Water-use efficiency & IWRM promotes the achievement of an efficient use of water (GWP, 2000; UNEP, 2018) \\
\hline & 10.1.1: Growth rates inequalities & $\begin{array}{l}\text { Water (and sanitation) is essential to reduce inequalities } \\
\text { IWRM concept calls to "leave no one behind". This highlights overlapping aspects between IWRM and the human rights } \\
\text { based-approach to water and sanitation (i.e. equality, equity, participation and governance) (WWAP, 2019). }\end{array}$ \\
\hline & 15.1.2.2: Terrestrial KBAs & $\begin{array}{l}\text { Terrestrial ecosystems are important for rainwater infiltration, groundwater recharge and river flow regimes. These } \\
\text { influence water availability and quality and must be considered in the overall planning and management of the water } \\
\text { resources (GWP, 2000). }\end{array}$ \\
\hline \multirow{5}{*}{ 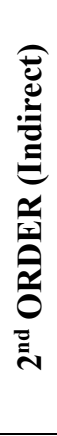 } & $\begin{array}{l}\text { 3.8.1: Coverage of essential health } \\
\text { services }\end{array}$ & $\begin{array}{l}\text { Positive correlation with the Human Development Index (UNEP, 2018), where life expectancy (health) is one of its } \\
\text { parameters (UNDP, 2018) }\end{array}$ \\
\hline & $\begin{array}{l}\text { 6.a.1: ODA for water supply and } \\
\text { sanitation }\end{array}$ & $\begin{array}{l}\text { ODA is mentioned within the financing dimension of IWRM as a potential and complementary source for its } \\
\text { implementation (UNEP, 2018) }\end{array}$ \\
\hline & 8.1.1: Economic growth & Positive correlation with the HDI. Wealthier countries present higher degrees of IWRM implementation (UNEP, 2018) \\
\hline & $\begin{array}{l}\text { 14.5.1: Marine KBAs } \\
\text { 15.1.2.1: Freshwater KBAs } \\
\text { 15.4.1: Mountain KBAs }\end{array}$ & $\begin{array}{l}\text { These areas provide a range of ecosystem services (e.g. drinking water) both upstream and downstream. A key principle of } \\
\text { IWRM is that water resources also need to be managed according to hydrological boundaries (UNEP, 2018) }\end{array}$ \\
\hline & 16.5.2: Bribery practices & $\begin{array}{l}\text { Countries with low perception of corruption count with a higher HDI and, in consequence, with higher levels of IWRM } \\
\text { implementation (UNEP, 2018) }\end{array}$ \\
\hline \multirow[t]{2}{*}{ 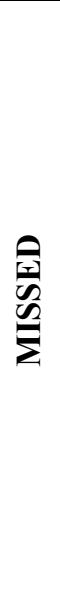 } & $\begin{array}{l}\text { 3.1.1: Maternal mortality rate } \\
\text { 3.2.1: Under-five mortality rate } \\
\text { 3.3.5: People requiring interventions } \\
\text { against NTD } \\
\text { 3.9.1: Mortality rate attributed to } \\
\text { household and ambient air pollution } \\
\text { 3.9.2: Mortality rate attributed to unsafe } \\
\text { WaSH services } \\
\text { 4.2.2: Participation rate in organized } \\
\text { learning }\end{array}$ & $\begin{array}{l}\text { Countries likely to achieve the global target } 6.5 \text { are predominantly "high" and "very high" HDI countries (UNEP, 2018). } \\
\text { Positive correlation with those indicators related to life expectancy, education and standard of living }\end{array}$ \\
\hline & $\begin{array}{l}\text { 5.5.1: Proportion of women in national } \\
\text { parliaments } \\
\text { 5.5.2: Proportion of women in } \\
\text { managerial positions } \\
\text { 13.1.1: People affected by disasters }\end{array}$ & $\begin{array}{l}\text { The self-assessed country survey for } 6.5 .1 \text { indicator quantification (UNEP, 2018) integrates specific questions on women's } \\
\text { participation at different levels and on the management instruments to reduce impacts of water-related disasters (partially } \\
\text { related to 13.1.1) }\end{array}$ \\
\hline
\end{tabular}


1.1.1: Population living below the international poverty line

1.2.1: Population living below the national poverty line

8.2.1: Growth rate per employee

8.5.2: Unemployment rate

2.1.1: Prevalence of undernourishment

7.1.1: Access to electricity

7.2.1: Renewable energy share

7.3.1: Energy efficiency
Water supply for different uses is a critical element of reducing poverty, creating good working conditions and making industrialization and consumption patterns sustainable with increased resource-use efficiency and environmentally sound processes

Implementing the different SDG 6 targets provides operating mechanisms for IWRM implementation, as it promotes the coordination of different potential stakeholders and captures the impacts under those targets

Coordinated efforts, such as the water-energy-food (WEF) nexus, have been documented as a complementary and catalys approach to IWRM (United Nations, 2018a; UN-Water, 2016; WWAP, 2019)

Defence of nexus approach over IWRM due to its multi-centric nature instead of water-centric one (Nhamo et al., 2018)

IWRM challenged by suggestions supporting nexus approaches of interrelated development priorities (Woodhouse and

Muller, 2017)

WEF nexus analyses the links between achieving food, water and energy security and the impacts of these activities, aiming towards an efficient and fair balance of sector needs

Table 8. Literature review in relation to the direct relationships identified in relation to SGD Target 6.a.

\section{Interlinkages identified}

3.1.1: Maternal mortality rate

3.3.5: People requiring interventions against NTD

\subsection{1: Water-use efficiency}

10.1.1: Growth rates inequalities

11.6.1: Urban solid waste collection

\section{Relationship assessment}

Relatively, ODA for health much greater in countries with highest levels of maternal (and child) mortality (GLAAS, 2017; Pitt et al., 2010)

ODA for water and sanitation greater in countries with higher rates of maternal mortality and more interventions against NTD

(see Supplementary Material Table S5)

Some authors considered necessary to increase the share of ODA for NTD control (Liese and Schubert, 2009)

Support to water efficiency programmes included in Target 6.a definition

More than $40 \%$ of surveyed agencies consider it as a "very high" priority area (GLAAS, 2017)

ODA effectiveness might turn negative as countries scale up the income ladder (Gopalan and Rajan, 2016)

Service delivery to the most vulnerable as a "very high" priority for $67 \%$ of the surveyed agencies (GLAAS, 2017)

ODA important role in reducing gender inequalities and rural-urban disparities in social and human development (Ndikumana and Pickbourn, 2017) Existing connection with SDG 11 is established through Target 11.6 (reduction environmental impact of cities) (UN-Habitat, 2018)

Countries with higher levels of material footprint receive more ODA for water and sanitation (see Supplementary Material Table S5)

Connection between material and water footprint suggests that increasing water-use efficiency supports their reduction 


\subsection{Potential applications in decision-making processes}

Up to this point, we have demonstrated the potentiality of this BN data-driven approach to identify the relationships among global development indicators. In particular, we have presented the coherency of the results obtained comparing them with an exhaustive study developed by UN-Water. As an added value, our data-driven approach provided further linkages, which have been contrasted against the existing literature. As stated previously, understanding these linkages enables the full exploitation of synergies, conflict resolution and trade-offs balances. On the basis of these linkages, integrated planning and management can support decision-making, reduce investment costs and facilitate implementation of a number of strategies that are geared towards sustainable development.

Having said this, current data gaps for a number of indicators and countries clearly limit the scope of the study and the lessons learnt. We have tested the robustness of our approach, showing that its performance is positive until a specific side of the sample. Credible data are the lifeblood of decisionmaking (IEAG, 2014), as are needed to underpin sector advocacy, stimulate political commitment and trigger well-placed investment towards optimum health, environment and economic gains (UN-Water, 2016). Moreover, data are the raw material for BN models, since the validity of their outcomes are directly dependant on both data quality and quantity. At present, there are several global initiatives that are monitoring different aspects of the development Agenda, but a coherent framework is missing. To the extent that existing efforts expands to ensure harmonised and integrated monitoring of SDGs, increasing high-quality data availability, it is expected that a wide range of potential uses may emerge in relation to BNs applications.

For instance, the study might focus on the sub-national level where decisions are taken by decentralized administrations. In this sense, the presented approach appears as a flexible tool to be adapted to a specific context. In fact, the 2030 Agenda resolution encourages each Government to set "its own national targets guided by the global level of ambition but taking into account national circumstances" (United Nations General Assembly, 2015). Specifically, it exits the possibility to simulate different scenarios and to infer the impact of potential interventions. To illustrate this idea, and taking as an example Figure 2, different levels of improvement (investments) regarding node 
6.2.1 (access to "at least basic" sanitation services) might be simulated (through CPTs modification). Thus, the impacts on immediate nodes 6.1.1 (access to drinking water services), 3.9.2 (mortality rate due to unsafe WaSH), 3.8.1 (coverage of essential health services) and 7.1.1 (access to electricity) could be evaluated. Similarly, further connected nodes to the latest could be analyzed as well. This requires a shift on the way that potential interventions are assessed, encouraging decision-makers to integrate interdisciplinary perspectives which, in turn, it is essential for sustainable development. In this scenario-based analysis, and considering the difficulty of countries to collect all the information related to the 17 SDGs, BNs might be also especially helpful when there is scarcity or some degree of uncertainty in the data. For example, and following with the same example, if there is no information related to the access to sanitation services, it is possible to set up different hypothesis and assess the potential impacts on associated nodes.

A last potential application of BNs falls on its inverse use (Li et al., 2019; Song et al., 2018; RequejoCastro et al., 2019). Contrary to the methodology in scenario simulation, where one or more nodes can be modified to assess the impact in subsequent nodes, this use allows establishing a desirable value in an objective node and obtaining the new values of connected nodes in order to reach that value. Thus, specific interventions can be design, assess and implement. This possibility might be useful for planning purposes, allowing decision-makers to optimize these interventions in order to achieve the expected results.

\section{Conclusions}

As per definition, the SDGs are presented as integrated and indivisible. Therefore, conventional indicator-based frameworks need to be combined with innovative approaches for an accurate assessment of interlinkages and interdependencies between targets and indicators. With this in mind, we have tested the validity of a data-driven BN approach to elucidate SDGs interlinkages. In particular, we have applied our approach to explore the relationships of SDG 6 across the 2030 Agenda. 
The relevance of the proposed approach and achieved results has been discussed and validated in different means. First, we have demonstrated the robustness of the approach in identifying indicator interlinkages. Specifically, results were consistently obtained up to a sample size of 130 countries. This aspect is particularly important when considering that the results are spurred on by the data used. Furthermore, this sample size represents the potentiality this approach to deal with a relative low amount of data. However, this approach fell short on identifying the cause-effect relationships, which might be of interest and represents a limitation of this approach. In any case, these results might be considered as a potential starting point for further discussion. Second, we have demonstrated the coherency of the results obtained. Taking as a starting point the UN-Water Analytical Brief, we have compared the results provided by the $\mathrm{BN}$ model with the main water and sanitation interlinkages on the SDGs identified by this study. On the one hand, our results have reached different levels of coincidence when considering both "first order" (direct) and "second order" (indirect) relationships. Positively, relationships regarding SDG target 6.4 have reached $75 \%$ of coincidence. In contrast, lower levels of concurrence have been obtained for targets $6.1(30 \%), 6.2(48 \%)$ and $6.5(33 \%)$. On the other hand, our analysis has identified other linkages which were not reflected in the UN Water Analytical Brief, which have been positively contrasted against the existing literature. Thus, this result represents an added value of our approach.

We conclude that a data-driven BN approach complements existing approximations, which is neededto increase the understanding and the interpretation of the complexities and interdependencies of the SDGs. 


\section{References}

Aguilera, P.A., Fernández, A., Fernández, R., Rumí, R., Salmerón, A., 2011. Bayesian Networks in environmental modelling. Environ. Model. Softw. 26 (12), 1376-1388.

https://doi.org/10.1016/j.envsoft.2011.06.004.

Aguilera, P.A., Fernández, A., Ropero, R.F., Molina, L., 2013. Groundwater quality assessment using data clustering based on hybrid Bayesian Networks. Stoch. Environ. Res. Risk Assess. 27 (2), 435-447. https://doi.org/10.1007/s00477-012-0676-8.

Alameddine, I., Cha, Y.K., Reckhow, K.H., 2011. An evaluation of automated structure learning with Bayesian networks: an application to estuarine chlorophyll dynamics. Environ. Model. Softw. 26 (2), 163-172. https://doi.org/10.1016/j.envsoft.2010.08.007.

Albrecht, T.R., Crootof, A., Scott, C.A., 2018. The water-energy-food nexus: A systematic review of methods for nexus assessment. Environ. Res. Lett. 13 (4): 043002. https://doi.org/10.1088/1748-9326/aaa9c6.

Alkire, S., Foster, J., 2008. Counting and multidimensional poverty measurement. OPHI Working Paper 7 , University of Oxford. https://www.ophi.org.uk/wp-content/uploads/ophi-wp7_vs2.pdf (accessed 2019.03.06).

Alkire, S. Jahan, S., 2018. The new global MPI 2018: Aligning with the Sustainable Development Goals. HDRO Occasional Paper, United Nations Development Programme (UNDP).

http://hdr.undp.org/sites/default/files/2018_mpi_jahan_alkire.pdf (accessed 2019.04.05).

Alkire, S., Santos, M.E., 2014. Measuring acute poverty in the developing world: Robustness and scope of the Multidimensional Poverty Index. World Dev. 59, 251-274. https://doi.org/10.1016/j.worlddev.2014.01.026.

Allen, C., Graciela, M., Wiedmann, T., 2018. Initial progress in implementing the Sustainable Development Goals (SDGs): a review of evidence from countries. Sustain. Sci. 13 (5), 1453-1467.

https://doi.org/10.1007/s11625-018-0572-3.7.

ATAG (Air Transport Action Group), 2018. Aviation: Benefits without borders. Geneva. https://aviationbenefits.org/media/166344/abbb18 full-report_web.pdf (accessed 2019.03.21).

Backman, G., Hunt, P., Khosla, R., Jaramillo-Strouss, C., Fikre, B.M., Rumble, C., Pevalin, D., Acurio Páez, D., Armijos Pineda, M., Frisancho, A., Tarco, D., Motlagh, M., Farcasanu, D., Vladescu, C., 2008. Health systems and the right to health: An assessment of 194 countries. The Lancet 372 (9655), 2047-2085.

https://doi.org/10.1016/S0140-6736(08)61781-X.

Bangert, M., Molyneux, D.H., Lindsay, S.W., Fitzpatrick, Ch., Engels, D., 2017. The cross-cutting contribution of the end of neglected tropical diseases to the Sustainable Development Goals. Infect. Dis. Poverty 6: 73. https://doi.org/10.1186/s40249-017-0288-0.

Bartram, J., Brocklehurst, Cl., Fisher, M.B., Luyendijk, R., Hossain, R., Wardlaw, T., Gordon, B., 2014. Global monitoring of water supply and sanitation: History, methods and future challenges. Int. J. Environ. Res. Public Health 11 (8), 8137-8165; https://doi.org/10.3390/ijerph110808137.

Bartram, J., Lewis, K., Lenton, R., and Wright, A., 2005. Focusing on improved water and sanitation for health. The Lancet 365 (9461), 810-812. https://doi.org/10.1016/S0140-6736(05)17991-4.

Bromley, J., Jackson, N.A., Clymer, O.J., Giacomello, A.M., Jensen, F.V., 2005. The use of Hugin ${ }^{\circledR}$ to develop Bayesian Networks as an aid to integrated water resource planning. Environ. Model. Softw. 20 (2), 231-242. https://doi.org/10.1016/j.envsoft.2003.12.021. 
Brown, J., Cavill, S., Cumming, O., Jeandron, A., 2012. Water, sanitation, and hygiene in emergencies: Summary review and recommendations for further research. Waterlines 31 (1-2), 11-29. https://doi.org/10.3362/1756-3488.2012.004.

Cairncross, S., Hunt, C., Boisson, S., Bostoen, K., Curtis, V., Fung, I.C., Schmidt, W.P., 2010. Water, sanitation and hygiene for the prevention of diarrhoea. Int. J. Epidemiol. 39, i193-i205. https://doi.org/10.1093/ije/dyq035.

Chao, Y-S., Scutari, M., Chen, T-S., Wu, C-J., Durand, M., Boivin, A., Wu, H-C., Chen, W-C., 2018. A network perspective of engaging patients in specialist and chronic illness care: The 2014 International Health Policy Survey. PLoS ONE 13 (8): e0201355. https://doi.org/10.1371/journal.pone.0201355.

Cheng, J.J., Schuster-Wallace, C.J., Watt, S., Newbold, B.K., Mente, A., 2012. An ecological quantification of the relationships between water, sanitation and infant, child, and maternal mortality. Environ. Health 11:3, 1-8. https://doi.org/10.1186/1476-069X-11-4.

Cohen, A., Sullivan, C.A., 2010. Water and poverty in rural China: Developing an instrument to assess the multiple dimensions of water and poverty. Ecol. Econ. 69, 999-1009.

https://doi.org/10.1016/j.ecolecon.2010.01.004.

Collste, D., Pedercini, M., Cornell, S.E., 2018. Policy coherence to achieve the SDGs: Using integrated simulation models to assess effective policies. Sustain. Sci. 12 (6), 921-931. https://doi.org/10.1007/s11625017-0457-x.

Coopman, A., Osborn, D., Ullah, F., Auckland, E., Long, G., 2016. Seeing the whole: Implementing the SDGs in an integrated and coherent way. Stakeholder forum, Bioregional and Newcastle University. https://sf.stakeholderforum.org/fileadmin/files/SeeingTheWhole.ResearchPilotReportOnSDGsImplementation.p df (accessed 2019.04.05).

Cronk, R., Bartram, J., 2017. Factors influencing water system functionality in Nigeria and Tanzania: A Regression and Bayesian Network analysis. Environ. Sci. Technol. 51 (19), 11336-11345. https://doi.org/10.1021/acs.est.7b03287.

Cronk, R., Bartram, J., 2018. Identifying opportunities to improve piped water continuity and water system monitoring in Honduras, Nicaragua, and Panama: Evidence from Bayesian Networks and Regression analysis. J. Clean. Prod. 196, 1-10. https://doi.org/10.1016/j.jclepro.2018.06.017.

Costanza, R., Daly, L., Fioramonti, L., Giovannini, E., Kubiszewski, I., Mortensen, L.F., Pickett, K.E., Ragnarsdottir, K.V., De Vogli, R., Wilkinson, R., 2016. Modelling and measuring sustainable wellbeing in connection with the UN Sustainable Development Goals. Ecol. Econ., 130, 350-355.

https://doi.org/10.1016/j.ecolecon.2016.07.009.

Dang, K.B., Windhorst, W., Burkhard, B., Müller, F., 2019. A Bayesian Belief Network - Based approach to link ecosystem functions with rice provisioning ecosystem services. Ecol. Indic. 100, 30-44.

https://doi.org/10.1016/j.ecolind.2018.04.055.

Dangour, A.D., Watson, L., Cumming, O., Boisson, S., Che, Y., Velleman, Y., Cavill, S., Allen, E., Uauy, R., 2013. Interventions to improve water quality and supply, sanitation and hygiene practices, and their effects on the nutrition status of children. Cochrane DB. Syst. Rev. Issue 8. Art. No.: CD009382.

https://doi.org/10.1002/14651858.CD009382.PUB2.

Desai, S., Alva, S., 1998. Maternal education and child health: Is there a strong causal relationship? Demography 35 (1), 71-81. 
Dondeynaz, C., López Puga, J., Carmona Moreno, C., 2013. Bayesian Networks modelling in support to crosscutting analysis of water supply and sanitation in developing countries. Hydrol. Earth Syst. Sci. 17 (9), $3397-$ 3419. https://doi.org/10.5194/hess-17-3397-2013.

El Khanji, S., 2016. An exploration of the interaction between socio-economic productivity and water withdrawal. Environ. Dev. Sustain. 19 (2), 653-677. https://doi.org/10.1007/s10668-016-9757-z.

Eldridge, D.J., Paul, K.I., Roxburgh, S., Butler, D.W., Ramp, D., 2019. Risks to carbon dynamics in semi-arid woodlands of eastern Australia under current and future climates. J. Environ. Manag. 235, 500-510. https://doi.org/10.1016/j.jenvman.2019.01.076.

Ellison, D., Futter, M.N., Bishop, K., 2012. On the forest cover-water yield debate: From demand- to supplyside thinking. Glob. Chang. Biol. 18 (3), 806-820. https://doi.org/10.1111/j.1365-2486.2011.02589.x.

Ellison, D., Morris, C.E., Locatelli, B., Sheil, D., Cohen, J., Murdiyarso, D., Gutierrez, V., van Noordwijk, M., Creed, I.F., Pokorny, J., Gaveau, D., Spracklen, D.V., Bargués Tobella, A., Ilstedt, U., Teuling, A.J., Gebreyohannis Gebrehiwot, S., Sands, D.C., Muys, B., Verbist, B., Springgay, E., Sugandi, Y., Sullivan, C.A., 2017. Trees, forests and water: Cool insights for a hot world. Glob. Environ. Chang. 43, 51-61.

https://doi.org/10.1016/j.gloenvcha.2017.01.002.

Ercin, A.E., Hoekstra, A.Y., 2014. Water footprint scenarios for 2050: A global analysis. Environ. Int. 64, 7182. https://doi.org/10.1016/j.envint.2013.11.019.

Esrey, S.A., Potash, J.B., Roberts, L., Shiff, C. 1991. Effects of improved water supply and sanitation on ascariasis, diarrhoea, dracunculiasis, hookworm infection, schistosomiasis, and trachoma. Bulletin of the World Health Organization 69, 609-621.

Fader, M., Cranmer, C., Lawford, R., Engel-Cox, J., 2018. Toward an understanding of synergies and trade-offs between water, energy, and food SDG targets. Front. Environ. Sci. 6:112. 1-11.

https://doi.org/10.3389/fenvs.2018.00112.

FAO (Food and Agriculture Organization), 2015. Mapping the vulnerability of mountain peoples to food insecurity. Rome. http://www.fao.org/3/a-i5175e.pdf (accessed 2019.04.10).

FAO (Food and Agriculture Organization), 2018. Progress on water use efficiency - Global baseline for SDG 6 indicator 6.4.1 2018. Rome. http://www.unwater.org/publications/progress-on-water-use-efficiency-641 (accessed 2019.04.08).

Feachem, R.G. 1984. Interventions for the control of diarrhoeal diseases among young children: promotion of personal and domestic hygiene. Bulletin of the World Health Organization 62, 467-476.

Fisher, J., 2008. Women in water supply, sanitation and hygiene programmes. In Proceedings of the ICE:

Municipal Engineer, 161 (4), 223-229. https://dspace.lboro.ac.uk/dspace-

jspui/bitstream/2134/9920/13/muen161-223.pdf (accessed 2019.04.11).

Fisher, M.B., Shields, K.F., Chan, T.U., Christenson, E., Cronk, R.D., Leker, H., Samani, D., Apoya, P., Lutz, A., Bartram, J., 2015. Understanding handpump sustainability: Determinants of rural water source functionality in the Greater Afram Plains Region of Ghana. Water Resour. Res. 51 (10), 8431-8449.

https://doi.org/10.1002/2014WR016770.

Fitzpatrick, C., Engels, D., 2016. Leaving no one behind: A neglected tropical disease indicator and tracers for the Sustainable Development Goals. Int. Health 8 (Suppl 1), i15-i18. https://doi.org/10.1093/inthealth/ihw002.

Foley, J.A., DeFries, R., Asner, G.P., Barford, C., Bonan, G., Carpenter, S.R., Chapin, F.S., Coe, M.T., Daily, G.C., Gibbs, H.K., Helkowski, J.H., Holloway, T., Howard, E.A., Kucharik, C.J., Monfreda, C., Patz, J.A., 
Prentice, I.C., Ramankutty, N., Snyder, P.K., 2005. Global consequences of land use. Science 309, 570-574. https://doi.org/10.1126/science.1111772.

Gao, L., Bryan, Br.A., 2017. Finding pathways to national-scale land-sector sustainability. Nature 544, 217 235. https://doi.org/10.1038/nature21694.

Garcia-Prats, A., González-Sanchis, M., Del Campo, A.D., Lull, C., 2018. Hydrology-oriented forest management trade-offs. A modeling framework coupling field data, simulation results and Bayesian networks. Sci. Total Environ. 639, 725-741. https://doi.org/10.1016/j.scitotenv.2018.05.134.

Giné-Garriga, R., Pérez-Foguet, A., 2019. Monitoring and targeting the sanitation poor: A multidimensional approach. Nat. Resour. Forum 43 (2), 82-94. https://doi.org/10.1111/1477-8947.12171.

Giné-Garriga, R., Requejo-Castro, D., Molina, J.L., Pérez-Foguet, A., 2018. A novel planning approach for the water, sanitation and hygiene (WaSH) sector: The use of object-oriented Bayesian Networks. Environ. Model. Softw. 103, 1-15. https://doi.org/10.1016/j.envsoft.2018.01.021.

GLAAS (Global Analysis and Assessment of Sanitation and Drinking-water), 2017. Financing universal water, sanitation and hygiene under the Sustainable Development Goals. Geneva.

http://www.unwater.org/publications/un-water-glaas-2017-financing-universal-water-sanitation-hygienesustainable-development-goals (accessed 2019.04.08).

Gonzalez-Redin, J., Gordon, I.J., Hill, R., Polhill, J.G., Dawson, T.P., 2019. Exploring sustainable land use in forested tropical social-ecological systems: A case-study in the Wet Tropics. J. Environ. Manag. 231, 940-952. https://doi.org/10.1016/j.jenvman.2018.10.079.

Gopalan, S., Rajan, R.S., 2016. Has foreign aid been effective in the water supply and sanitation sector? Evidence from panel data. World Dev. 85, 84-104. http://dx.doi.org/10.1016/j.worlddev.2016.04.010.

GWA (Gender and Water Alliance), 2003. The gender and water development report 2003: Gender perspectives on policies in the water sector. Delft. http://genderandwater.org/en/gwa-products/policy-influencing/genderperspectives-on-policies-in-the-water-sector/view (accessed 2019.04.03).

GWP (Global Water Partnership), 2000. Integrated Water Resource Management. TAC Background Papers No. 4. Stockholm. https://www.gwp.org/globalassets/global/toolbox/publications/background-papers/04-integratedwater-resources-management-2000-english.pdf (accessed 2019.04.03).

Hall, N. L., Ross, H., Richards, R., Barrington, D. J., Dean, A. J., Head, B. W., Jagals, P., Reid, S., Hill, P. S. 2018. Implementing the United Nations' Sustainable Development Goals for water and beyond in Australia: A proposed systems approach. Australasian J. Water Resour. 22 (1), 29-38.

https://doi.org/10.1080/13241583.2018.1481563.

Henderson, A.R., 2005. The bootstrap: A technique for data-driven statistics. Using computer-intensive analyses to explore experimental data. Clin. Chim. Acta 359 (1-2), 1-26. https://doi.org/10.1016/j.cccn.2005.04.002.

Herrera, V., 2019. Reconciling global aspirations and local realities: Challenges facing the Sustainable Development Goals for water and sanitation. World Dev. 118, 106-117.

https://doi.org/10.1016/j.worlddev.2019.02.009.

Hoekstra, A.Y., Hung, P.Q., 2002. Virtual water trade: A quantification of virtual water flows between nations in relation to international crop trade. Value of Water Research Report Series No. 11. Delft.

http://www.ayhoekstra.nl/pubs/Report11.pdf (accessed 2019.04.13).

Hoekstra, Y. A., Wiedmann, T.O., 2014. Humanity's unsustainable environmental footprint. Science 344 (6188), 1114-1117. https://doi.org/10.1126/science.1248365. 
Hotez, P.J., Bottazzi, M.E., Strych, U., Chang, L.Y., Lim, Y.A.L., Goodenow, M.M., AbuBakar, S., 2015. Neglected tropical diseases among the Association of Southeast Asian Nations (ASEAN): Overview and Update. PLoS Negl Trop Dis 9 (4), e0003575. https://doi.org/10.1371/journal.pntd.0003575.

ICSU - ISSC, 2015. Review of the Sustainable Development Goals: The science perspective. International Council for Science / International Social Science Council. Paris. https://council.science/cms/2017/05/SDGReport.pdf (accessed 2019.01.11).

ICSU - ISSC, 2017. A guide to SDG interactions: From science to implementation. International Council for Science / International Social Science Council. Paris. https://council.science/publications/a-guide-to-sdginteractions-from-science-to-implementation (accessed 2019.01.11).

ILO (International Labour Organization), 2018. World Employment Social Outlook 2018: Greening with jobs. Geneva. https://www.ilo.org/weso-greening/documents/WESO_Greening_EN_web2.pdf (accessed 2019.03.18).

ILO (International Labour Organization), 2019. A quantum leap for gender equality: For a better future of work for all. Geneva. https://www.ilo.org/wcmsp5/groups/public/---dgreports/---dcomm/--publ/documents/publication/wcms 674831.pdf (accessed 2019.03.18).

IPCC (Intergovernmental Panel on Climate Change), 2014. Climate Change 2014: Synthesis Report. Geneva. https://www.ipcc.ch/site/assets/uploads/2018/05/SYR_AR5_FINAL_full_wcover.pdf (accessed 2019.03.22).

Ivens, S, 2008. Does increased water access empower women? Development 51 (1), $63-67$. https://doi.org/10.1057/palgrave.development.1100458.

Joint Monitoring Programme, 2015. Progress on sanitation and drinking water: 2015 update and MDG assessment. New York / Geneva. https://washdata.org/sites/default/files/documents/reports/2017-06/JMP-2015Report.pdf (accessed 2019.01.08).

Joint Monitoring Programme, 2017a. WaSH in the Agenda 2030: New global indicators for drinking water, sanitation and hygiene. New York / Geneva. https://washdata.org/sites/default/files/documents/reports/201707/JMP-2017-WASH-in-the-2030-agenda.pdf (accessed 2019.01.21).

Joint Monitoring Programme, 2017b. Progress on drinking water, sanitation and hygiene: 2017 update and SDG baselines. Geneva. New York / Geneva. https://washdata.org/reports?text=\&page=1 (accessed 2019.01.21).

Kanter, D.R., Schwoob, M.H., Baethgen, W.E., Bervejillo, J.E., Carriquiry, M., Dobermann, A., Ferraro, Br., Lanfranco, Br., Mondelli, M., Penengo, C., Saldias, R., Silva, M.E., de Lima, J.M.S., 2016. Translating the Sustainable Development Goals into action: A participatory backcasting approach for developing national agricultural transformation pathways. Glob. Food Secur-Agr. 10, 71-79.

https://doi.org/10.1016/j.gfs.2016.08.002.

Kevani, K., Huisingh, D., 2013. A review of progress in empowerment of women in rural water management decision-making processes. J. Clean. Prod. 60, 53-64. https://doi.org/10.1016/j.jclepro.2013.03.041.

Khalili, N.R., Cheng, W., McWilliams, A., 2017. A Methodological approach for the design of sustainability initiatives: In pursuit of sustainable transition in China. Sustain. Sci. 12 (6), 933-956.

https://doi.org/10.1007/s11625-017-0463-z.

Kim, K.H, Kabir, E., Kabir, S., 2015. A review on the human health impact of airborne particulate matter. Environ. Int. 74, 136-143. https://doi.org/10.1016/j.envint.2014.10.005.

Le Blanc, D., 2015. Towards integration at last? The Sustainable Development Goals as a network of targets.

Sustain. Dev. 23 (3), 176-187. https://doi.org/10.1002/sd.1582. 
Li, X., Feng, K., Siu, Y.L., Hubacek, K., 2012. Energy-water nexus of wind power in China: The balancing act between $\mathrm{CO}_{2}$ emissions and water consumption. Energ. Policy 45, 440-448.

https://doi.org/10.1016/j.enpol.2012.02.054.

Li, J., Song, G., Semakula, H.M., Zhang, Sh., 2019. Climatic burden of eating at home against away-fromhome: A novel Bayesian Belief Network model for the mechanism of eating-out in urban China. Sci. Total Environ. 650, 224-232. https://doi.org/10.1016/j.scitotenv.2018.09.015.

Liese, B.H., Schubert, L., 2009. Official development assistance for health-how neglected are neglected tropical diseases? An analysis of health financing. Int. Health 1 (2), 141-147.

https://doi.org/10.1016/j.inhe.2009.08.004.

Liu, J., Hull, V., Godfray, H. Ch.J., Tilman, D., Gleick, P., Hoff, H., Pahl-Wostl, C., Xu, Z., Chung, M. G., Sun, J., Li, Sh., 2018. Nexus approaches to global sustainable development. Nat. Sustain. 1, 466-476.

https://doi.org/10.1038/s41893-018-0135-8.

Liu, H., Zhou, S., Lam,W., Guan, J., 2017. A new hybrid method for learning Bayesian Networks: Separation and reunion. Knowl.-Based Syst. 121, 185-197. https://doi.org/10.1016/j.knosys.2017.01.029.

Longo, S.B., York, R., 2009. Structural influences on water withdrawals: An exploratory macro-comparative analysis. Hum. Ecol. Rev. 16 (1), 75-83. https://www.jstor.org/stable/24707738.

Madsen, A.L., Jensen, F., Salmerón, A., Langseth, H., Nielsen, T.D., 2016. A parallel algorithm for Bayesian Network structure learning from large data sets. Knowl.-Based Syst. 117, 46-55.

https://doi.org/10.1016/j.knosys.2016.07.031.

Mainali, Br., Luukkanen, J., Silveira, S., Kaivo-Oja, J., 2018. Evaluating synergies and trade-offs among Sustainable Development Goals (SDGs): Explorative analyses of development paths in South Asia and SubSaharan Africa. Sustainability 10 (3), 815. https://doi.org/10.3390/su10030815.

Makarieva, A.M., Gorshkov, V.G., 2007. Biotic pump of atmospheric moisture as driver of the hydrologicalcycle on land. Hydrol. Earth Syst. Sci. 11, 1013-1033, https://doi.org/10.5194/hess-11-1013-2007.

Marcot, B.G. 2017. Common quandaries and their practical solutions in Bayesian Network modeling. Ecol. Model. 358, 1-9. https://doi.org/10.1016/j.ecolmodel.2017.05.011.

Marcot, B.G., Penman, T.D., 2019. Advances in Bayesian Network modelling: Integration of modeling technologies. Environ. Model. Softw. 111, 386-393. https://doi.org/10.1016/j.envsoft.2018.09.016.

Mekonnen, M.M., Hoekstra, Y. A., 2016. Four billion people facing severe water scarcity. Sci. Adv. 2, e1500323. doi: 10.1126/sciadv.1500323. https://advances.sciencemag.org/content/2/2/e1500323.

Mohajerani, H., Kholghi, M., Mosaedi, A., Farmani, R., Sadoddin, S., Casper, M., 2017. Application of Bayesian Decision Networks for groundwater resources management under the conditions of high uncertainty and data scarcity. Water Resour. Manage. 31 (6), 1859-1879. https://doi.org/10.1007/s11269-017-1616-7.

Molina, J.L., Bromley, J., García-Arostegui, J.L., Sullivan, C.A., Benavente, J., 2010. Integrated water resources management of overexploited hydrogeological systems using Object-Oriented Bayesian Networks. Environ. Model. Softw. 25 (4), 383-397. https://doi.org/10.1016/j.envsoft.2009.10.007.

Molina, J.L., García Aróstegui, J.L., Benavente, J., Varela, C., de la Hera, A., López Geta, J.A., 2009. Aquifers overexploitation in SE Spain: A proposal for the integrated analysis of water management. Water Resour. Manage. 23 (13), 2737-2760. https://doi.org/10.1007/s11269-009-9406-5.

Molina, J.L., Pulido-Velázquez, D., García Aróstegui, J.L., Pulido-Velázquez, M., 2013. Dynamic Bayesian Networks as a decision support tool for assessing climate change impacts on highly stressed groundwater systems. J. Hydrol. 479, 113-129. https://doi.org/10.1016/j.jhydrol.2012.11.038. 
Mugagga, F., Nabaasa, B.B. 2016. The centrality of water resources to the realization of Sustainable Development Goals (SDG). A review of potentials and constraints on the African continent. Int. Soil Water Conserv. Res. 4 (3), 215-223. https://doi.org/10.1016/j.iswcr.2016.05.004.

Mukkala, K., Tervo, H., 2013. Air transportation and regional growth: Which way does the causality run? Environ. Plann. A 45 (6), 1508-1520. https://doi.org/10.1068/a45298.

Nardo, M., Saisana, M., Saltelli, A., Tarantola, S., Hoffman, A., Giovannini, E., 2005. Handbook on constructing composite indicators: Methodology and user guide. OECD Statistics Working Paper. OECD, Paris. https://www.oecd.org/sdd/42495745.pdf (accessed 2019. 12.15).

Ndikumana, L., Pickbourn, L., 2016. The impact of foreign aid allocation on access to social services in subSaharan Africa: The case of water and sanitation. World Dev. 90, 104-114.

http://dx.doi.org/10.1016/j.worlddev.2016.09.001.

Nilsson, M., Chisholm, E., Griggs, D., Howden-Chapman, P., McCollum, D., Messerli, P., Neumann B., Stevance, A.S., Visbeck, M., Stafford-Smith, M., 2018. Mapping interactions between the sustainable development goals: lessons learned and ways forward. . Sustain. Sci. 13 (6), 1489-1503. https://doi.org/10.1007/s11625-018-0604-z.

Nhamo, L., Ndlela, B., Nhemachena, C., Mabhaudhi, T., Mpandeli, S., Matchaya, G., 2018. The water-energyfood nexus: Climate risks and opportunities in Southern Africa. Water 10 (5), 567. https://doi.org/10.3390/w10050567.

Obersteiner, M., Walsh, Br., Frank, St., Havlík, P., Cantele, M., Liu, J., Palazzo, A., Herrero, M., Lu, Y., Mosnier, A., Valin, H., Riahi, K., Kraxner, Fl., Fritz, St., Van Vuuren, D., 2016. Assessing the land resourcefood price nexus of the Sustainable Development Goals. Sci. Adv. 2 (9). https://doi.org/10.1126/sciadv.1501499.

O’Connell, E., 2017. Towards adaptation of water resource systems to climatic and socio-economic change. Water Resour. Manage. 31 (10), 2965-2984. https://doi.org/10.1007/s11269-017-1734-2.

Pahl-Wostl, Cl., 2017. Governance of the water-energy-food security nexus: A multi-level coordination challenge. Environ. Sci. Policy 92, 356-367. https://doi.org/10.1016/j.envsci.2017.07.017.

Panda, S.M., 2007. Mainstreaming gender in water management: A critical view. Gender Technol. Dev. 11 (3), 321-338. https://doi.org/10.1177/097185240701100302.

Pitt, C., Greco, G., Powell-Jackson, T., Mills, A., 2010. Countdown to 2015: Assessment of official development assistance to maternal, newborn, and child health, 2003-08. The Lancet 376 (9751), 1485-1496. https://doi.org/10.1016/S0140-6736(10)61302-5.

Pramova, E., Locatelli, B., Brockhaus, M., Fohlmeister, S., 2012. Ecosystem services in the national adaptation programmes of action. Clim. Policy 12 (4), 393-409. https://doi.org/10.1080/14693062.2011.647848.

Rasul, G., 2016. Managing the food, water, and energy nexus for achieving the Sustainable Development Goals in South Asia. Environ. Dev. 18, 14-25. https://doi.org/10.1016/j.envdev.2015.12.001.

Requejo-Castro, D., Giné-Garriga, R., Pérez-Foguet, A., 2019. Bayesian network modelling of hierarchical composite indicators. Sci. Total Environ. 668, 936-946. https://doi.org/10.1016/j.scitotenv.2019.02.282.

Ringler, C., Bhaduri, A., Lawford, R., 2013. The nexus across water, energy, land and food (WELF): Potential for improved resource use efficiency? Curr. Opin. Environ. Sustain. 5 (6), 617-624.

https://doi.org/10.1016/j.cosust.2013.11.002. 
Rothausen, S.G.S.A., Conway, D., 2011. Greenhouse-gas emissions from energy use in the water sector. Nat. Clim. Chang. 1, 210-219. https://doi.org/10.1038/nclimate1147.

Sachs, J., Schmidt-Traub, G., Kroll, C., Lafortune, G., Fuller, G., 2018. SDG Index and Dashboards Report 2018. New York: Bertelsmann Stiftung and Sustainable Development Solutions Network (SDSN).

https://www.sdgindex.org/assets/files/2018/01\%20SDGS\%20GLOBAL\%20EDITION\%20WEB\%20V9\%2018 0718.pdf (accessed 2019.12.18).

Schmalzbauer B., Visbeck M. (Eds.), 2016. The contribution of science in implementing the Sustainable Development Goals. German Committee Future Earth. Stuttgart/Kiel.

http://futureearth.org/sites/default/files/2016_report_contribution_science_sdgs.pdf (accessed 2019.04.03).

Scutari, M., 2010. Learning Bayesian Networks with the bnlearn R package. J. Stat. Softw. 35 (3), 1-22. https://doi.org/10.18637/jss.v035.i03.

Scutari, M., Auconi, P., Caldarelli, G., Franchi, L., 2017. Bayesian Networks analysis of malocclusion data. Sci. Rep-UK 7, 1-11. http://dx.doi.org/10.1038/s41598-017-15293-w.

Scutari, M., Graafland, C.E., Gutiérrez, J.M., 2018. Who learns better Bayesian Network structures: Constraintbased, score-based or hybrid algorithms? In Proceedings of Machine Learning Research (72, PGM 2018), 416427. Prague. http://proceedings.mlr.press/v72/scutari18a/scutari18a.pdf (accessed 2019.01.07).

SDSN (Sustainable Development Solutions Network), 2015. Indicators and a monitoring framework for Sustainable Development Goals: Launching a data revolution for the SDGs. http://unsdsn.org/wpcontent/uploads/2015/05/FINAL-SDSN-Indicator-Report-WEB.pdf (accessed 2018.11.29).

SDSN (Sustainable Development Solutions Network), 2016. SDG Index and dashboards: A global report. https://www.sdgindex.org/assets/files/sdg_index_and_dashboards_compact.pdf (accessed 2018.11.29).

Sheil, D., Cohen, J., Colfer, C.J.P., Price, D., Puri, R., Ruíz-Pérez, M., Sugandi, Y., Vedeld, P., Wollenberg, E., Yasmi, Y., 2016. The moral basis for conservation-reflections on Dickman et al. Front. Ecol. Environ. 14 (2), 67-69. https://doi.org/10.1002/fee.1224.

Singh, G.G., Cisneros-Montemayor, A.M., Swartz, W., Cheung, W., Guy, J.A., Kenny, T.A., McOwen, C.J., Asch, R., Geffert, J.L., Wabnitz, C.C.C., Sumaila, R., Hanich, Q., Ota, Y., 2018. A rapid assessment of cobenefits and trade-offs among Sustainable Development Goals. Mar. Policy 93, 223-231.

https://doi.org/10.1016/j.marpol.2017.05.030.

Singh, R.K., Murty, H.R., Gupta, S.K., Dikshit, A.K. 2009. An overview of sustainability assessment methodologies. Ecol. Indic. 9 (2), 189-212. https://doi.org/10.1016/j.ecolind.2008.05.011.

Song, G., Semakula, H.M., Fullana-i-Palmer, P., 2018. Chinese household food waste and its' climatic burden driven by urbanization: a Bayesian belief network modelling for reduction possibilities in the context of global efforts. J. Clean. Prod. 202, 916-924. https://doi.org/10.1016/j.jclepro.2018.08.233.

Spaiser, V., Ranganathan, Sh., Swain, R.B., Sumpter, D.J.T., 2017. The Sustainable Development oxymoron: Quantifying and modelling the incompatibility of Sustainable Development Goals. Int. J. Sust. Dev. World 24 (6), 457-470. https://doi.org/10.1080/13504509.2016.1235624.

Stålgren, P., 2006. Corruption in the water sector: Causes, consequences and potential reform. Swedish Water House Policy Brief Nr. 4. SIWI. Stockholm. http://www.swedishwaterhouse.se/wpcontent/uploads/20060906171639CorruptionPB low.pdf (accessed 2019. 04.03). 
Sullivan, C.A., Meigh, J.R., Giacomello, A.M., Fediw, T., Lawrence, P., Samad, M., Mlote, S., Hutton, C., Allan, J.A., Schulze, R.E., Dlamini, D.J., Cosgrove, W., Delli Priscoli, J., Gleick, P., Smout, I., Cobbing, J., Calow, R., Hunt, C., Hussain, A., Acreman, M.C., King, J., Malomo, S., Tate, E.L., O'Regan, D., Milner, S., Steyl, I., 2003. The water poverty index: development and application at the community scale. Nat. Resour. Forum 27 (3), 189-199. https://doi.org/10.1111/1477-8947.00054.

Transparency International, 2008. Global corruption report 2008: Corruption in the water sector. Cambridge. https://www.transparency.org/whatwedo/publication/global_corruption_report 2008 corruption in the water sector (accessed 2019. 04.03).

UNDP (United Nations Development Programme), 2006a. Human Development Report 2006 - Beyond scarcity: Power, poverty and the global water crisis. NewYork.

https://www.undp.org/content/dam/undp/library/corporate/HDR/2006\%20Global\%20HDR/HDR-2006Beyond\%20scarcity-Power-poverty-and-the-global-water-crisis.pdf (accessed 2019.04.01).

UNDP (United Nations Development Programme), 2006b. Resource Guide: Mainstreaming gender in water management. NewYork. https://www.undp.org/content/dam/aplaws/publication/en/publications/environmentenergy/www-ee-library/water-governance/resource-guide-mainstreaming-gender-in-watermanagement/IWRMGenderResourceGuide-English-200610.pdf (accessed 2019.04.01).

UNDP (United Nations Development Programme), 2018. Human Development Data (1990-2015). http://hdr.undp.org/en/data (accessed 2019.01.23).

UNEP (United Nations Environment Programme), 2018. Progress on integrated water resources management. Global baseline for SDG 6 Indicator 6.5.1: degree of IWRM implementation. Washington D.C. http://www.unwater.org/publications/progress-on-integrated-water-resources-management-651 (accessed 2019.03.28).

UNEP-WCMC (United Nations Environment Programme World Conservation Monitoring Centre), IUCN (International Union for Conservation of Nature), 2016. Protected Planet Report 2016: How protected areas contribute to achieving global targets for biodiversity. Cambridge; Gland.

https://wdpa.s3.amazonaws.com/Protected_Planet_Reports $/ 2445 \% 20$ Global\%20Protected\%20Planet $\% 202016$ WEB.pdf (accessed 2019.03.25).

UNEP-WCMC (United Nations Environment Programme World Conservation Monitoring Centre), IUCN (International Union for Conservation of Nature), NGS (National Geographic Society), 2018. Protected Planet Report 2018: Tracking progress towards global targets for protected areas. Cambridge; Gland; Washington D.C. https://www.unepwcmc.org/system/comfy/cms/files/files/000/001/445/original/Global_Protected_Planet 2018.PDF (accessed 2019.03.25).

UN-ESCAP (United Nations Economic and Social Commission for Asia and the Pacific). 2016. Analytical framework for integration of water and sanitation SDGs and targets using a systems thinking approach. Working paper. Bangkok. http://sdghelpdesk.unescap.org/sites/default/files/2018-02/integration\%20sdg6.pdf (accessed 2019.01.21).

UN-IEAG (United Nations Secretary-General's Independent Expert Advisory Group on a Data Revolution for Sustainable Development), 2014. A world that counts: Mobilising the data revolution for sustainable development. New York. http://www.undatarevolution.org/wp-content/uploads/2014/11/A-World-ThatCounts.pdf (accessed 2019.01.09).

United Nations, 2018a. Sustainable Development Goal 6 Synthesis Report 2018 on water and sanitation. New York. http://www.unwater.org/publication categories/sdg-6-synthesis-report-2018-on-water-and-sanitation (accessed 2019.02.05). 
United Nations, 2018b. The Sustainable Development Goals Report 2018. New York.

https://unstats.un.org/sdgs/files/report/2018/TheSustainableDevelopmentGoalsReport2018-EN.pdf (accessed 2019.02.05).

United Nations General Assembly, 2015. Transforming our world: The 2030 Agenda for Sustainable Development. Resolution A/RES/70/1. New York.

https://www.un.org/en/development/desa/population/migration/generalassembly/docs/globalcompact/A_RES 7 0_1_E.pdf (accessed 2019.01.07)

UNSD, 2018. Sustainable Development Goal indicators website. United Nations Statistics Division. https://unstats.un.org/sdgs/indicators/database/ (accessed 2018.12.15).

UN-Habitat (United Nations Human Settlements Programme), 2010. Solid waste management in the world's cities: Water and sanitation in the world cities 2010. Nairobi. https://unhabitat.org/books/solid-wastemanagement-in-the-worlds-cities-water-and-sanitation-in-the-worlds-cities-2010-2 (accessed 2019.01.25).

UN-Habitat (United Nations Human Settlements Programme), 2015. Slum Almanac 2015-2016: Tracking improvement in the lives of slum dwellers. Nairobi. https://unhabitat.org/wp-content/uploads/2016/02old/Slum\%20Almanac\%202015-2016_EN.pdf (accessed 2019.01.25).

UN-Habitat (United Nations Human Settlements Programme), 2018. SDG-11 Synthesis Report 2018: Tracking progress towards inclusive, safe, resilient and sustainable cities and human settlements. Nairobi. https://unhabitat.org/sdg-11-synthesis-report (accessed 2019.01.25).

UN-EMG (United Nations Environment Management Group), 2011. Working towards a balanced and inclusive Green Economy: A United Nations system-wide perspective. Geneve.

http://wedocs.unep.org/bitstream/handle/20.500.11822/8065/-

Working\%20towards\%20a\%20Balanced\%20and\%20Inclusive $\% 20$ Green $\% 20$ Economy $\% 20$ A $\% 20$ United $\% 20$ Nations $\% 20$ System-wide $\% 20$ Perspective $\% 20 \% 20-20111109$.pdf? sequence $=3$ \&isAllowed $=y$ (accessed 2019.03.18).

Unver, O., Bhaduri, A., Hoogeveen, J., 2017. Water-use efficiency and productivity improvements towards a sustainable pathway for meeting future water demand. Water Secur. 1, 21-27.

https://doi.org/10.1016/j.wasec.2017.05.001.

UN-Water, 2016. Water and sanitation interlinkages across the 2030 Agenda for Sustainable Development. Geneva. http://www.unwater.org/publications/water-sanitation-interlinkages-across-2030-agenda-sustainabledevelopment (accessed 2018.10.08). 
UN-Women, 2018. Turning promises into action: Gender equality in the 2030 agenda for sustainable development. New York. http://www.unwomen.org/-

/media/headquarters/attachments/sections/library/publications/2018/sdg-report-gender-equality-in-the-2030agenda-for-sustainable-development-2018-en.pdf?la=en\&vs=4332 (accessed 2019.03.11).

Vörösmarty, C.J., Green, P., Salisbury, J., Lammers, R.B., 2000. Global water resources: Vulnerability from climate change and population growth contemporary population relative to demand per discharge. Science 289 (5477), 284-288. https://doi.org/10.1126/science.289.5477.284.

Watson, J.T., Gayer, M., Connolly, M.A., 2007. Epidemics after natural disasters. Emerg. Infect. Dis. 13 (1), 15. https://dx.doi.org/10.3201/eid1301.060779.

WHO (World Health Organization), 2015a. Water, sanitation and hygiene for accelerating and sustaining progress on Neglected Tropical Diseases: A global strategy 2015-2020. Geneva.

https://apps.who.int/iris/bitstream/handle/10665/182735/WHO_FWC_WSH_15.12_eng.pdf?sequence=1 (accessed 2019.03.15).

WHO (World Health Organization), 2015b. Tracking Universal Health Coverage: First global monitoring report. Geneva. https://apps.who.int/iris/bitstream/handle/10665/174536/9789241564977_eng.pdf? sequence=1 (accessed 2019.03.15).

WHO (World Health Organization), 2018. World health statistics 2018: monitoring health for the Sustainable Development Goals. Geneva. https://apps.who.int/iris/bitstream/handle/10665/272596/9789241565585eng.pdf?ua $=1$ (accessed 2019.03.11).

Wiedmann, T.O., Schandl, H., Lenzen, M., Moran, D., Suh, S., West, J., Kanemoto, K., 2015. The material footprint of nations. P. Natl. Acad. Sci. 112 (20), 6271-6276. https://doi.org/10.1073/pnas.1220362110.

Willetts, J., Halcrow, G., Carrard, N., Rowland, C., Crawford, J., 2010. Addressing two critical MDGs together: Gender in water, sanitation and hygiene initiatives The need for increased attention to water, sanitation and hygiene in the Pacific. Pac. Econ. Bull. 25 (1), 162-176.

Woodhouse, P., Muller, M., 2017. Water governance: An historical perspective on current debates. World Dev. 92, 225-241. http://dx.doi.org/10.1016/j.worlddev.2016.11.014.

World Bank, 2018. Tracking SDG-7: The Energy Progress Report 2018. International Bank for Reconstruction and Development / The World Bank. Washington DC.

http://documents.worldbank.org/curated/en/495461525783464109/pdf/126026-WP-PUBLIC-P167379-trackingsdg7-the-energy-progress-report-full-report.pdf (accessed 2019.03.13).

World Water Council, 2012. Global water security assessment: lessons learnt and long-term implications. World Water Council (eds.). ISBN: 978-981-10-7912-2. https://doi.org/10.1007/s11269-017-1734-2.

WWAP (United Nations World Water Assessment Programme), 2014. The United Nations World Water Development Report 2014: Water and Energy. UNESCO. Paris. http://www.unwater.org/publications/worldwater-development-report-2014-water-energy (accessed 2019.03. 06).

WWAP (United Nations World Water Assessment Programme), 2016. The United Nations World Water Development Report 2016: Water and Jobs. UNESCO. Paris. http://www.unwater.org/publications/world-waterdevelopment-report-2016 (accessed 2019.03.06).

WWAP (United Nations World Water Assessment Programme), 2019. The United NationsWorld Water Development Report 2019: Leaving No One Behind. UNESCO. Paris.

http://www.unwater.org/publications/world-water-development-report-2019 (accessed 2019.04.18). 
Fig S1. SDG indicators distributions (histograms) and associated normality check (Q-Q plot).
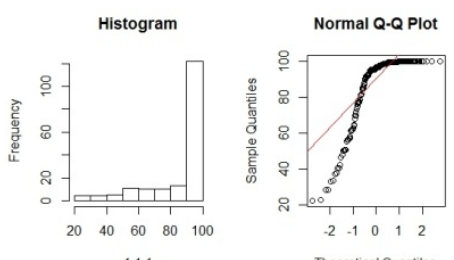

SDG-1.1.1
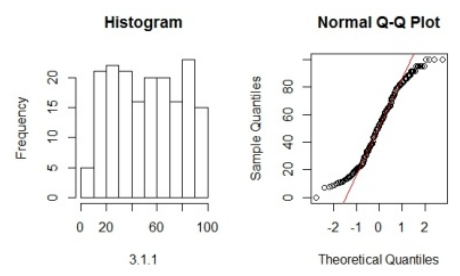

SDG-3.1.1
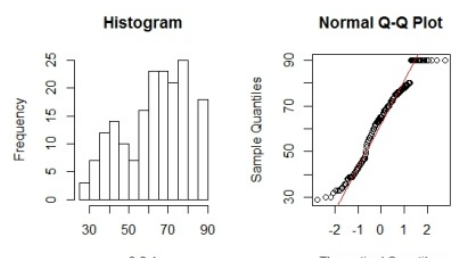

SDG-3.8.1
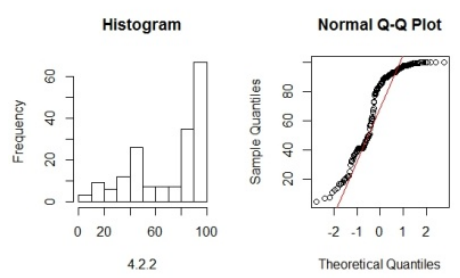

SDG-4.2.2
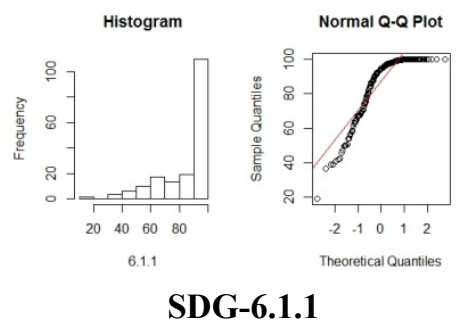

SDG-6.1.1
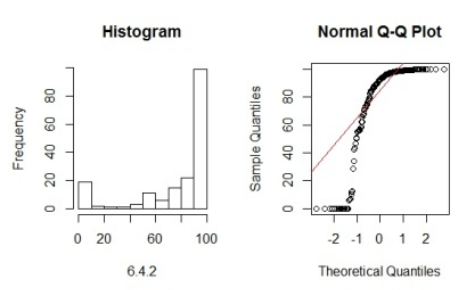

SDG-6.4.2
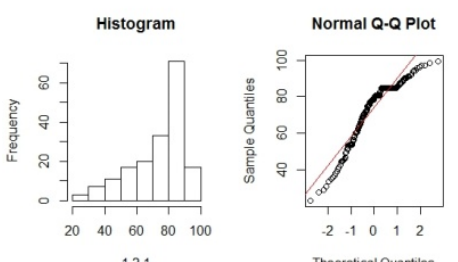

SDG-1.2.1
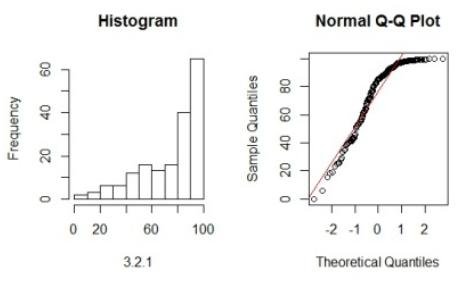

SDG-3.2.1
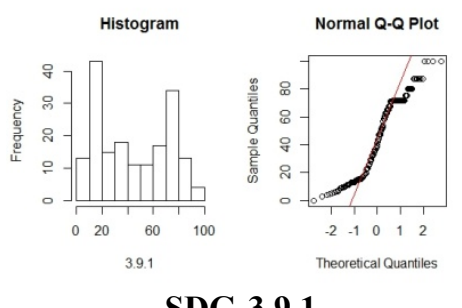

SDG-3.9.1
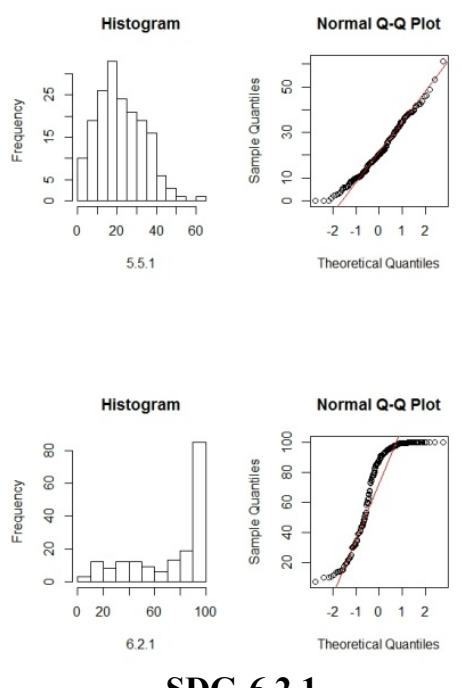

SDG-6.2.1
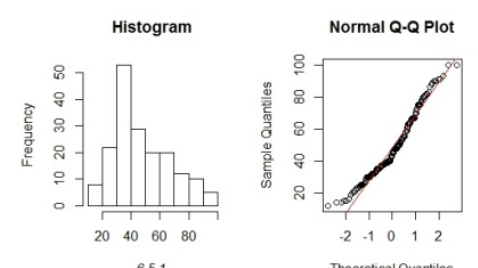

SDG-6.5.1
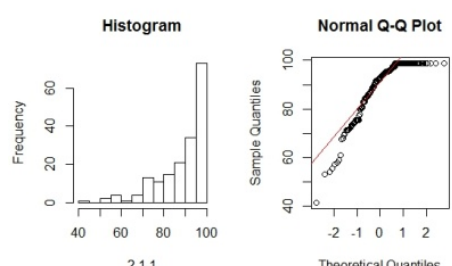

SDG-2.1.1
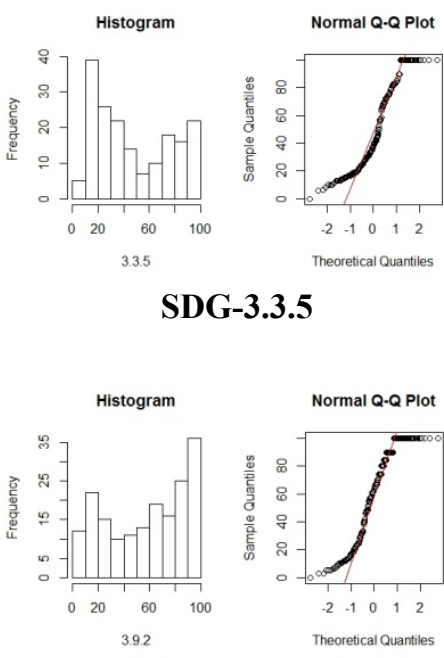

SDG-3.9.2
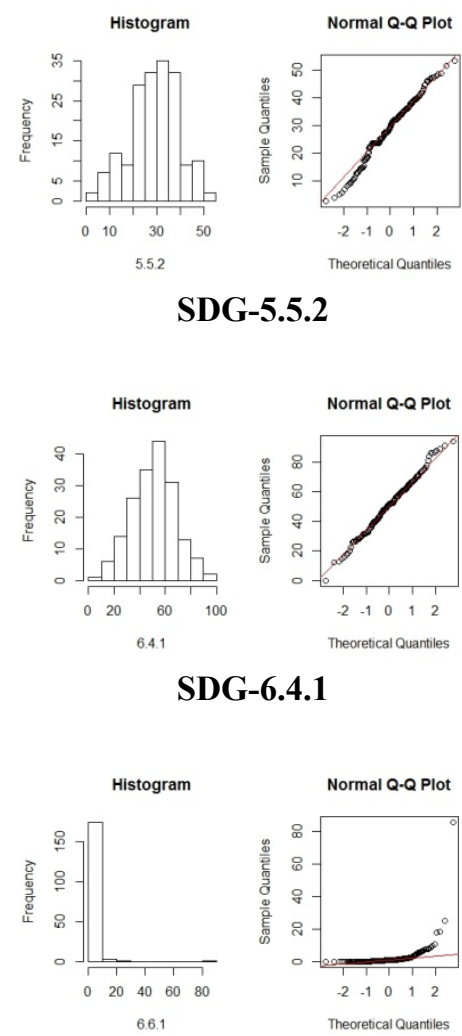

SDG-6.6.1 
Continuation of Fig S1.
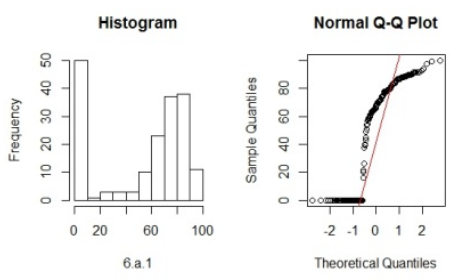

SDG-6.a.1
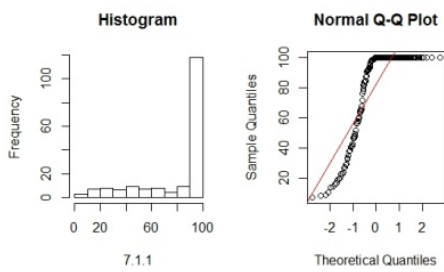

SDG-7.1.1
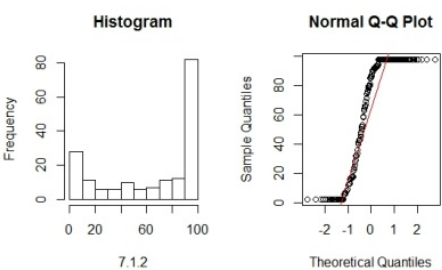

SDG-7.1.2
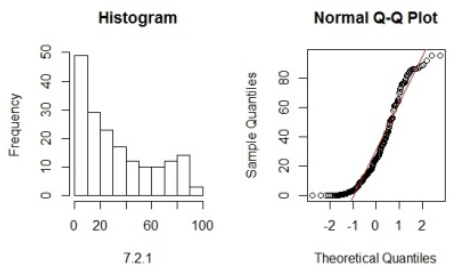

SDG-7.2.1
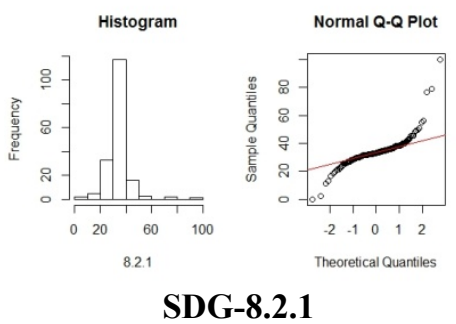

SDG-8.2.1
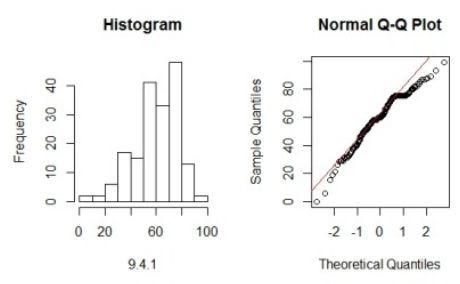

SDG-9.4.1
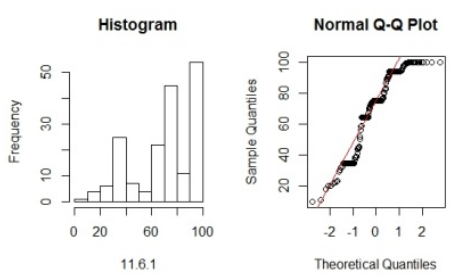

SDG-11.6.1
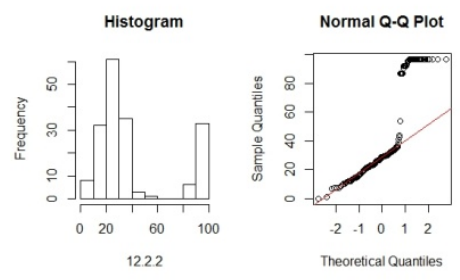

SDG-12.2.2
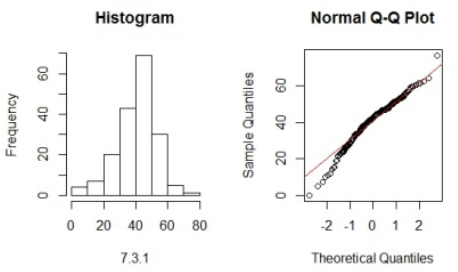

SDG-7.3.1
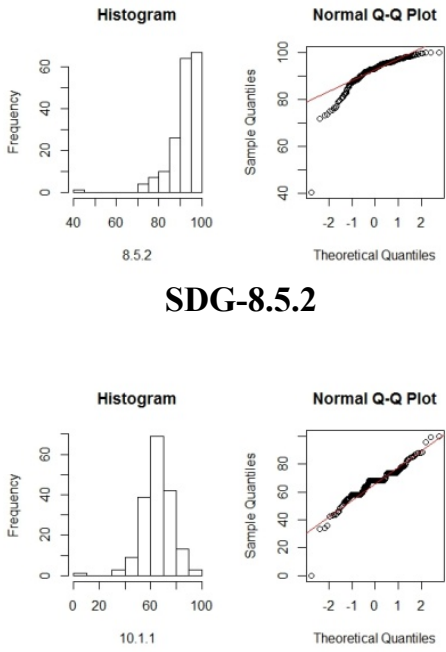

SDG-10.1.1
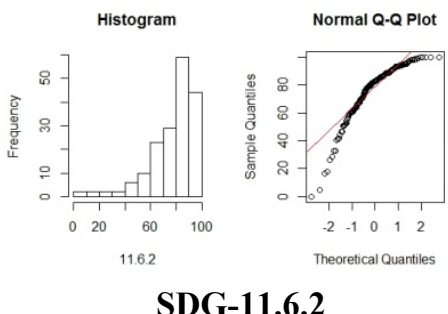

SDG-11.6.2

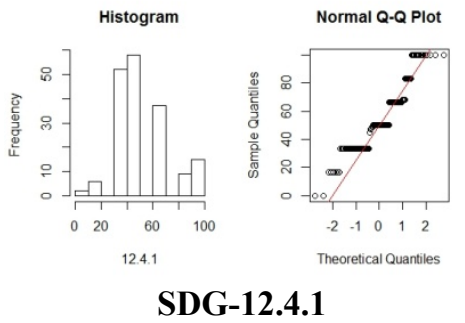

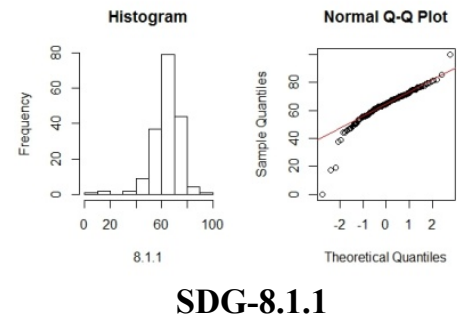
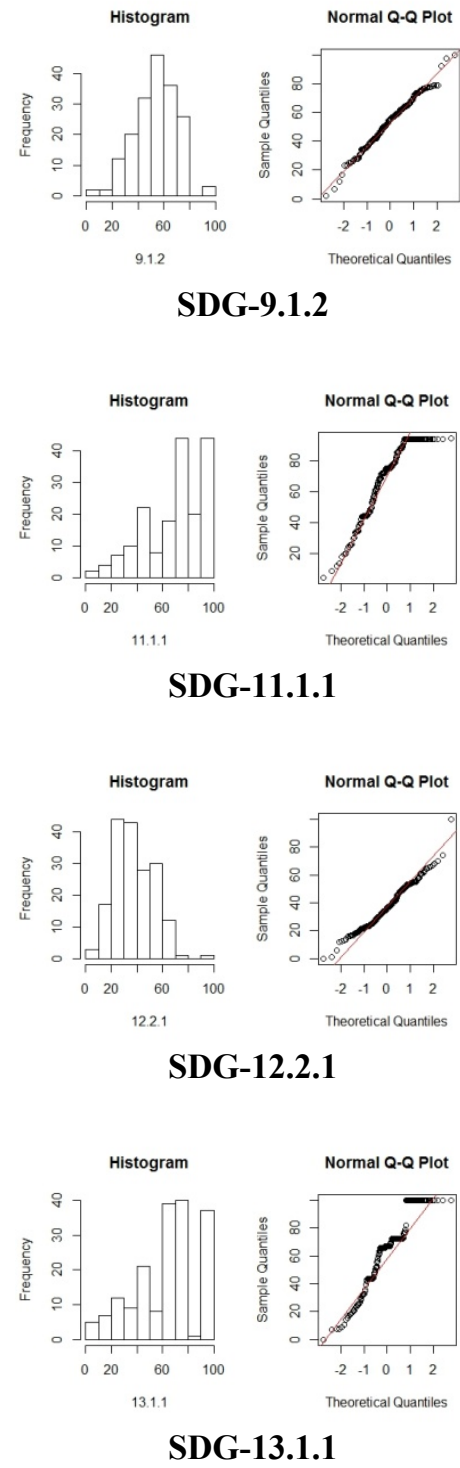
Continuation of Fig S1.
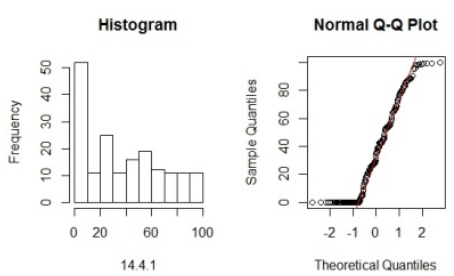

SDG-14.4.1
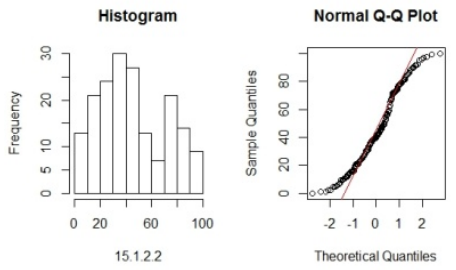

SDG-15.1.2.2
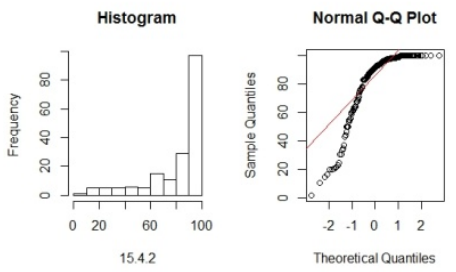

SDG-15.4.2
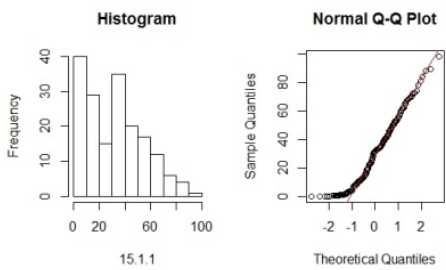

SDG-15.1.1
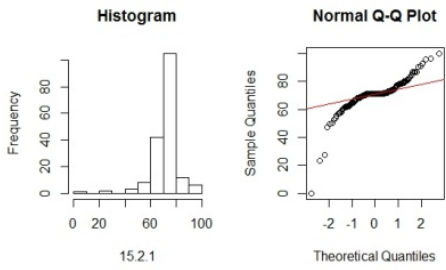

SDG-15.2.1
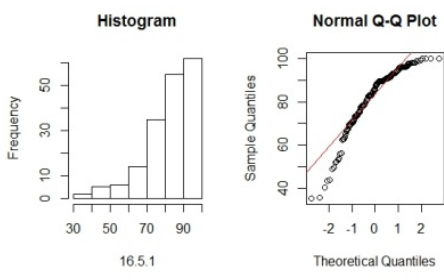

SDG-16.5.1
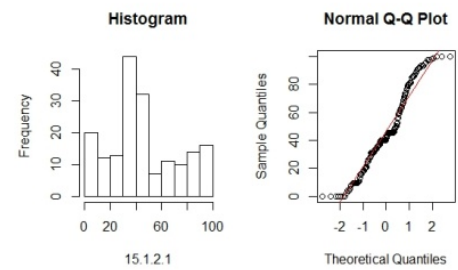

SDG-15.1.2.1

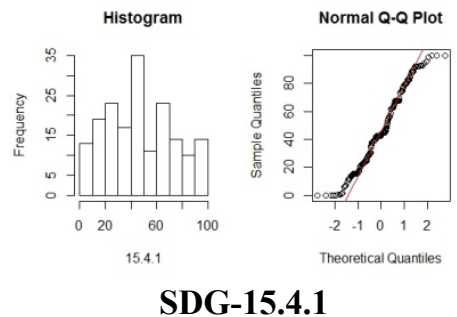

SDG-15.4.1 
Table S1. Evolution in the identification of strong links within the different country samples generated. Corresponding definitions to these indicators can be found in Table 1 of the manuscript.

\begin{tabular}{ccccccccc}
\hline \multirow{2}{*}{ Links } & \multicolumn{7}{c}{ Repetitiveness (\%) } & \\
\cline { 2 - 9 } $\mathbf{3 . 1 . 1}$ & $\mathbf{3 . 9 . 2}$ & 100 & 97 & 80 & 63 & 55 & 53 & 40 \\
\hline $\mathbf{3 . 2 . 1}$ & $\mathbf{3 . 9 . 2}$ & 100 & 100 & 99 & 97 & 83 & 63 & 38 \\
\hline $\mathbf{5 . 5 . 2}$ & $\mathbf{6 . 4 . 2}$ & 99 & 65 & 51 & 38 & 22 & 17 & 8 \\
\hline $\mathbf{6 . 1 . 1}$ & $\mathbf{7 . 1 . 1}$ & 97 & 73 & 57 & 41 & 39 & 29 & 31 \\
\hline $\mathbf{6 . 4 . 2}$ & $\mathbf{1 5 . 1 . 1}$ & 100 & 81 & 58 & 34 & 23 & 23 & 8 \\
\hline $\mathbf{6 . a . 1}$ & $\mathbf{6 . 4 . 1}$ & 100 & 83 & 72 & 58 & 38 & 40 & 22 \\
\hline $\mathbf{6 . a . 1}$ & $\mathbf{1 0 . 1 . 1}$ & 70 & 42 & 44 & 22 & 16 & 11 & 9 \\
\hline 7.1 .1 & 1.1 .1 & 100 & 100 & 98 & 92 & 78 & 70 & 50 \\
\hline 7.1 .2 & 3.9 .1 & 100 & 100 & 100 & 100 & 100 & 100 & 100 \\
\hline 7.1 .2 & 7.2 .1 & 82 & 44 & 40 & 33 & 18 & 10 & 15 \\
\hline 9.4 .1 & 7.2 .1 & 96 & 77 & 55 & 38 & 25 & 18 & 10 \\
\hline 9.4 .1 & 9.1 .2 & 100 & 100 & 100 & 100 & 100 & 100 & 99 \\
\hline 11.6 .2 & 5.5 .2 & 100 & 96 & 85 & 58 & 50 & 39 & 23 \\
\hline 12.2 .2 & 9.1 .2 & 100 & 100 & 100 & 100 & 100 & 100 & 100 \\
\hline 14.4 .1 & 15.1 .2 .2 & 100 & 100 & 93 & 75 & 51 & 54 & 31 \\
\hline 15.1 .1 & 15.4 .2 & 98 & 79 & 57 & 35 & 25 & 16 & 14 \\
\hline 15.1 .2 .2 & 15.1 .2 .1 & 100 & 100 & 100 & 100 & 100 & 100 & 98 \\
\hline 15.1 .2 .2 & 15.4 .1 & 100 & 100 & 100 & 100 & 100 & 100 & 100 \\
\hline
\end{tabular}

In bold, those interlinkages associated with SDG-6 indicators. 
Table S2. Disaggregated identification of all strong links identified for the different country samples. Corresponding definitions to these indicators can be found in Table 1 of the manuscript.

\begin{tabular}{|c|c|c|c|c|c|c|c|c|c|c|c|c|c|c|c|}
\hline from & to & \multicolumn{2}{|c|}{$n=175$} & \multicolumn{2}{|c|}{$n=160$} & \multicolumn{2}{|c|}{$n=145$} & \multicolumn{2}{|c|}{$n=130$} & \multicolumn{2}{|c|}{$n=115$} & \multicolumn{2}{|c|}{$n=100$} & \multicolumn{2}{|c|}{$n=85$} \\
\hline 3.9.2 & 3.1.1 & 58 & \multirow{2}{*}{100} & 46 & \multirow{2}{*}{97} & 45 & \multirow{2}{*}{80} & 44 & \multirow{2}{*}{63} & 40 & \multirow{2}{*}{55} & 32 & \multirow{2}{*}{43} & 38 & \multirow{2}{*}{40} \\
\hline 3.1.1 & 3.9.2 & 42 & & 51 & & 35 & & 19 & & 15 & & 11 & & 2 & \\
\hline 3.2.1 & 3.9.2 & 100 & \multirow{2}{*}{100} & 96 & \multirow{2}{*}{100} & 81 & \multirow{2}{*}{99} & 56 & \multirow{2}{*}{97} & 45 & \multirow{2}{*}{83} & 23 & \multirow{2}{*}{63} & 4 & \multirow{2}{*}{38} \\
\hline 3.9.2 & 3.2.1 & 0 & & 4 & & 18 & & 41 & & 38 & & 40 & & 34 & \\
\hline 5.5 .2 & 6.4 .2 & 90 & \multirow{2}{*}{99} & 56 & \multirow{2}{*}{65} & 35 & & 33 & & 16 & & 13 & & 6 & \\
\hline 6.4 .2 & 5.5 .2 & 9 & & 9 & & 16 & & 5 & & 6 & & 4 & & 2 & \\
\hline 6.1.1 & 7.1.1 & 87 & 07 & 47 & & 29 & & 16 & & 12 & & 9 & & 11 & \\
\hline 7.1.1 & 6.1.1 & 10 & & 26 & & 28 & & 25 & 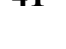 & 27 & & 20 & & 20 & 81 \\
\hline 6.4 .2 & 15.1.1 & 100 & 100 & 81 & & 58 & & 34 & & 22 & & 23 & & 6 & \\
\hline 15.1.1 & 6.4 .2 & 0 & & 0 & & 0 & & 0 & & 1 & & 0 & & 2 & \\
\hline 6.a.1 & 6.4.1 & 100 & 100 & 83 & & 72 & & 57 & & 38 & & 40 & & 21 & \\
\hline 6.4 .1 & 6.a.1 & 0 & & 0 & 05 & 0 & & 1 & & 0 & & 0 & & 1 & \\
\hline 6.a.1 & 10.1.1 & 70 & 70 & 42 & & 43 & & 20 & & 15 & & 10 & & 8 & 0 \\
\hline 10.1.1 & 6.a.1 & 0 & & 0 & & 1 & & 2 & & 1 & & 1 & 1 & 1 & \\
\hline 7.1.1 & 1.1.1 & 100 & 100 & 100 & & 98 & & 92 & & 78 & & 69 & & 48 & \\
\hline 1.1.1 & 7.1.1 & 0 & & 0 & 100 & 0 & & 0 & & 0 & 0 & 1 & & 2 & \\
\hline 7.1.2 & 3.9.1 & 100 & 100 & 100 & & 100 & & 98 & & 100 & & 97 & & 97 & \\
\hline 3.9.1 & 7.1.2 & 0 & & 0 & 100 & 0 & & 2 & 100 & 0 & 100 & 3 & 00 & 3 & 100 \\
\hline 7.2.1 & 7.1 .2 & 32 & 02 & 12 & & 9 & & 9 & & 7 & & 0 & & 2 & \\
\hline 7.1 .2 & 7.2 .1 & 50 & & 32 & 4 & 31 & 40 & 24 & JJ & 11 & 10 & 10 & 10 & 13 & 15 \\
\hline 9.4.1 & 7.2.1 & 94 & 06 & 60 & & 34 & & 18 & & 8 & & 4 & & 2 & \\
\hline 7.2.1 & 9.4.1 & 2 & & 17 & & 21 & & 20 & & 17 & & 14 & & 8 & \\
\hline 9.4.1 & 9.1.2 & 97 & 100 & 95 & & 92 & & 90 & & 89 & & 85 & & 81 & 00 \\
\hline 9.1.2 & 9.4.1 & 3 & & 5 & 100 & 8 & 100 & 10 & 100 & 11 & 100 & 15 & 100 & 18 & \\
\hline 11.6.2 & 5.5 .2 & 100 & 100 & 95 & & 85 & & 56 & & 49 & & 35 & 0 & 20 & \\
\hline 5.5 .2 & 11.6.2 & 0 & & 1 & 0 & 0 & OJ & 2 & 30 & 1 & 30 & 4 & נכ & 3 & $2 J$ \\
\hline 12.2.2 & 9.1.2 & 100 & 100 & 97 & & 95 & & 88 & & 83 & & 77 & & 70 & \\
\hline 9.1.2 & 12.2 .2 & 0 & & 3 & 100 & 5 & 100 & 12 & 100 & 17 & 100 & 23 & 100 & 30 & \\
\hline 14.4.1 & 15.1.2.2 & 72 & 100 & 50 & & 38 & $0 ?$ & 23 & & 19 & & 12 & & 10 & \\
\hline 15.1.2.2 & 14.4.1 & 28 & & 50 & 100 & 55 & נת & 52 & 15 & 32 & 31 & 42 & ד & 21 & Ji \\
\hline 15.1.1 & 15.4 .2 & 66 & 00 & 51 & & 36 & & 25 & & 17 & & 9 & & 9 & \\
\hline 15.4 .2 & 15.1.1 & 32 & & 28 & 13 & 21 & ו & 10 & 3 & 8 & 25 & 7 & 10 & 5 & \\
\hline 15.1.2.2 & 15.1.2.1 & 99 & 100 & 94 & & 91 & & 93 & & 94 & & 88 & & 80 & \\
\hline 15.1.2.1 & 15.1.2.2 & 1 & & 6 & 100 & 9 & 100 & 7 & 100 & 6 & 100 & 12 & 100 & 18 & 70 \\
\hline 15.1.2.2 & 15.4.1 & 100 & & 100 & & 100 & & 100 & & 100 & & 97 & & 94 & \\
\hline 15.4.1 & 15.1.2.2 & 0 & & 0 & & 0 & & 0 & 100 & 0 & 100 & 3 & U & 6 & \\
\hline
\end{tabular}


sizes. The remaining $28 \%$ ( 5 out of 18 ) of the strong links are identified in both directions. Specifically, these links refer to the pairs 3.9.2 - 3.1.1, 3.2.1 - 3.9.2, 6.1.1 - 7.1.1, 9.4.1 - 7.2.1 and 14.4.1 - 15.1.2.2. 
Table S3. Strength of the links (arc strength) and their direction. Results are presented as the mean value of 100 bootstrap networks. Corresponding definitions to these indicators can be found in Table 1 of the manuscript.

\begin{tabular}{|c|c|c|c|c|c|c|c|c|}
\hline \multirow{2}{*}{ from } & \multirow{2}{*}{ ) } & \multicolumn{7}{|c|}{ arc strength (direction) } \\
\hline & & $n=175$ & $n=160$ & $n=145$ & $n=130$ & $n=115$ & $n=100$ & $n=85$ \\
\hline 3.9 .2 & 3.1.1 & $0.93(0.52)$ & $0.91(0.53)$ & $0.90(0.54)$ & $0.91(0.55)$ & $0.91(0.56)$ & $0.89(0.57)$ & $0.90(0.59)$ \\
\hline 3.1 .1 & 3.9 .2 & $0.92(0.51)$ & $0.90(0.52)$ & $0.90(0.52)$ & $0.89(0.53)$ & $0.89(0.54)$ & $0.91(0.53)$ & $0.89(0.54)$ \\
\hline 3.2.1 & 3.9 .2 & $0.99(0.56)$ & $0.97(0.56)$ & $0.94(0.55)$ & $0.92(0.54)$ & $0.90(0.54)$ & $0.88(0.53)$ & $0.88(0.52)$ \\
\hline 3.9 .2 & 3.2 .1 & - & $0.99(0.51)$ & $0.96(0.52)$ & $0.94(0.52)$ & $0.93(0.54)$ & $0.91(0.56)$ & $0.88(0.57)$ \\
\hline 5.5 .2 & 6.4 .2 & $0.86(0.54)$ & $0.87(0.56)$ & $0.86(0.56)$ & $0.87(0.56)$ & $0.89(0.55)$ & $0.88(0.55)$ & $0.91(0.54)$ \\
\hline 6.4 .2 & 5.5 .2 & $0.85(0.51)$ & $0.87(0.52)$ & $0.87(0.53)$ & $0.87(0.54)$ & $0.88(0.53)$ & $0.84(0.53)$ & $0.87(0.52)$ \\
\hline 6.1.1 & 7.1.1 & $0.86(0.53)$ & $0.86(0.53)$ & $0.91(0.53)$ & $0.88(0.53)$ & $0.88(0.53)$ & $0.90(0.53)$ & $0.87(0.54)$ \\
\hline 7.1.1 & 6.1.1 & $0.87(0.52)$ & $0.86(0.53)$ & $0.88(0.54)$ & $0.89(0.55)$ & $0.91(0.55)$ & $0.89(0.55)$ & $0.90(0.55)$ \\
\hline 6.4 .2 & 15.1.1 & $0.88(0.66)$ & $0.87(0.66)$ & $0.87(0.65)$ & $0.86(0.63)$ & $0.87(0.63)$ & $0.87(0.61)$ & $0.84(0.55)$ \\
\hline 15.1.1 & 6.4 .2 & - & - & - & - & $0.83(0.55)$ & - & $0.86(0.52)$ \\
\hline 6.a.1 & 6.4 .1 & $0.90(0.70)$ & $0.89(0.69)$ & $0.89(0.68)$ & $0.89(0.67)$ & $0.87(0.67)$ & $0.88(0.65)$ & $0.87(0.66)$ \\
\hline 6.4 .1 & 6.a.1 & - & - & - & $0.81(0.51)$ & - & - & $0.88(0.51)$ \\
\hline 6.a.1 & 10.1.1 & $0.84(0.69)$ & $0.85(0.66)$ & $0.85(0.66)$ & $0.86(0.64)$ & $0.86(0.64)$ & $0.84(0.61)$ & $0.86(0.57)$ \\
\hline 10.1.1 & 6.a.1 & - & - & $0.80(0.51)$ & $0.91(0.55)$ & $0.97(0.56)$ & $0.82(0.52)$ & $0.85(0.51)$ \\
\hline 7.1.1 & 1.1.1 & $0.98(0.62)$ & $0.97(0.61)$ & $0.95(0.61)$ & $0.94(0.61)$ & $0.93(0.61)$ & $0.91(0.59)$ & $0.91(0.62)$ \\
\hline 1.1.1 & 7.1.1 & - & - & - & - & - & $1.00(0.51)$ & $0.93(0.53)$ \\
\hline 7.1.2 & 3.9.1 & $1.00(0.60)$ & $1.00(0.61)$ & $0.99(0.62)$ & $0.99(0.62)$ & $0.99(0.62)$ & $1.00(0.62)$ & $0.99(0.62)$ \\
\hline 3.9.1 & 7.1.2 & - & - & - & $0.99(0.54)$ & - & $1.00(0.53)$ & $0.99(0.54)$ \\
\hline 7.2.1 & 7.1 .2 & $\begin{array}{c}0.84 \\
(0.52) \\
\end{array}$ & $0.83(0.52)$ & $0.89(0.55)$ & $0.87(0.54)$ & $0.88(0.54)$ & - & $0.96(0.56)$ \\
\hline 7.1 .2 & 7.2.1 & $0.84(0.59)$ & $0.86(0.54)$ & $0.87(0.55)$ & $0.86(0.57)$ & $0.87(0.57)$ & $0.87(0.60)$ & $0.89(0.59)$ \\
\hline 9.4.1 & 7.2.1 & $0.88(0.58)$ & $0.86(0.60)$ & $0.85(0.60)$ & $0.85(0.61)$ & $0.86(0.57)$ & $0.91(0.59)$ & $0.84(0.59)$ \\
\hline 7.2.1 & 9.4.1 & $0.88(0.52)$ & $0.88(0.53)$ & $0.86(0.60)$ & $0.86(0.57)$ & $0.86(0.57)$ & $0.85(0.60)$ & $0.87(0.58)$ \\
\hline 9.4.1 & 9.1.2 & $1.00(0.55)$ & $1.00(0.56)$ & $0.99(0.57)$ & $0.99(0.58)$ & $0.99(0.59)$ & $0.99(0.59)$ & $0.98(0.59)$ \\
\hline 9.1 .2 & 9.4.1 & $1.00(0.51)$ & $1.00(0.51)$ & $0.99(0.52)$ & $0.99(0.52)$ & $0.99(0.52)$ & $0.99(0.52)$ & $0.97(0.53)$ \\
\hline 11.6.2 & 5.5 .2 & $0.94(0.61)$ & $0.91(0.60)$ & $0.90(0.59)$ & $0.91(0.58)$ & $0.88(0.60)$ & $0.88(0.58)$ & $0.89(0.56)$ \\
\hline 5.5 .2 & 11.6.2 & - & $0.89(0.51)$ & - & $0.85(0.53)$ & $0.91(0.51)$ & $0.91(0.52)$ & $0.87(0.52)$ \\
\hline 12.2.2 & 9.1.2 & $0.99(0.58)$ & $1.00(0.58)$ & $0.99(0.58)$ & $0.99(0.57)$ & $0.99(0.57)$ & $0.99(0.58)$ & $0.98(0.57)$ \\
\hline 9.1 .2 & 12.2.2 & - & $1.00(0.51)$ & $0.99(0.52)$ & $0.99(0.52)$ & $0.99(0.53)$ & $0.99(0.54)$ & $0.97(0.54)$ \\
\hline 14.4.1 & 15.1.2.2 & $0.95(0.53)$ & $0.92(0.52)$ & $0.91(0.53)$ & $0.89(0.54)$ & $0.88(0.53)$ & $0.89(0.55)$ & $0.87(0.53)$ \\
\hline 15.1.2.2 & 14.4.1 & $0.95(0.51)$ & $0.94(0.53)$ & $0.93(0.54)$ & $0.92(0.55)$ & $0.92(0.55)$ & $0.91(0.57)$ & $0.90(0.57)$ \\
\hline 15.1.1 & 15.4 .2 & $0.88(0.53)$ & $0.87(0.54)$ & $0.88(0.55)$ & $0.87(0.56)$ & $0.87(0.57)$ & $0.85(0.54)$ & $0.88(0.56)$ \\
\hline 15.4 .2 & 15.1.1 & $0.89(0.52)$ & $0.88(0.51)$ & $0.87(0.53)$ & $0.90(0.54)$ & $0.88(0.53)$ & $0.91(0.53)$ & $0.90(0.53)$ \\
\hline 15.1.2.2 & 15.1.2.1 & $1.00(0.57)$ & $1.00(0.57)$ & $1.00(0.59)$ & $1.00(0.58)$ & $0.99(0.58)$ & $0.99(0.58)$ & $0.97(0.58)$ \\
\hline 15.1.2.1 & 15.1.2.2 & $1.00(0.52)$ & $1.00(0.53)$ & $1.00(0.53)$ & $1.00(0.54)$ & $0.99(0.52)$ & $0.97(0.52)$ & $0.98(0.53)$ \\
\hline 15.1.2.2 & 15.4.1 & $1.00(0.73)$ & $1.00(0.71)$ & $1.00(0.69)$ & $1.00(0.67)$ & $0.99(0.66)$ & $1.00(0.65)$ & $0.99(0.62)$ \\
\hline 15.4.1 & 15.1.2.2 & - & - & - & - & - & $1.00(0.55)$ & $0.99(0.52)$ \\
\hline
\end{tabular}


The direction of the links (i.e. cause-effect direction) is associated to a value, where 0.5 is related to an undirected link and 1.0 to the maximum value, which assures the direction of the link. To this respect, only $31 \%$ ( 4 out of 13) linkages present values higher than 0.6. Considering the results presented in Table S2, 28\% ( 5 out of 18) of the strong links are identified in both directions. This is coherent with the values obtained for their directions, which are close to 0.5 and, thus, fluctuate in the identification of one of the two possible directions. 
Table S4. Overall interlinkages identified in relation to SDG-6 indicators for the different country samples generated.

\begin{tabular}{|c|c|c|c|c|c|c|c|c|c|}
\hline \multirow{2}{*}{\multicolumn{3}{|c|}{ SDG6-related links identified }} & \multicolumn{7}{|c|}{ Repetitiveness (\%) } \\
\hline & & & \multirow{2}{*}{$\begin{array}{c}\mathbf{n}=\mathbf{1 7 5} \\
100\end{array}$} & \multirow{2}{*}{$\begin{array}{c}\mathbf{n}=\mathbf{1 6 0} \\
100 \\
\end{array}$} & \multirow{2}{*}{$\begin{array}{c}\mathbf{n}=\mathbf{1 4 5} \\
100\end{array}$} & \multirow{2}{*}{$\begin{array}{c}\mathbf{n}=\mathbf{1 3 0} \\
86\end{array}$} & \multirow{2}{*}{$\begin{array}{c}\mathbf{n}=\mathbf{1 1 5} \\
91\end{array}$} & \multirow{2}{*}{$\begin{array}{c}\mathbf{n}=\mathbf{1 0 0} \\
90\end{array}$} & \multirow{2}{*}{$\begin{array}{c}\mathbf{n}=\mathbf{8 5} \\
83 \\
\end{array}$} \\
\hline \multirow{5}{*}{$\begin{array}{c}3.9 .2 \\
\text { (mortality rate due to } \\
\text { unsafe WaSH) }\end{array}$} & 3.1 .1 & Maternal mortality ratio & & & & & & & \\
\hline & 3.2 .1 & Infant mortality rate & 100 & 100 & 100 & 100 & 100 & 98 & 88 \\
\hline & 3.3 .5 & People requiring interventions against NTD & 100 & 99 & 94 & 89 & 76 & 70 & 65 \\
\hline & 6.2 .1 & Population using AT LEAST BASIC sanitation services & 100 & 98 & 84 & 86 & 65 & 69 & 55 \\
\hline & 7.2 .1 & Renewable energy share in total final energy consumption & 85 & 51 & 42 & 28 & 32 & 28 & 29 \\
\hline \multirow{2}{*}{$\begin{array}{c}6.1 .1 \\
\text { (basic drinking water) } \\
\end{array}$} & 6.2 .1 & Population using AT LEAST BASIC sanitation services & 99 & 87 & 70 & 68 & 63 & 60 & 50 \\
\hline & 7.1 .1 & Population with access to electricity & 100 & 100 & 100 & 96 & 95 & 82 & 80 \\
\hline \multirow{4}{*}{$\begin{array}{c}6.2 .1 \\
\text { (basic sanitation) }\end{array}$} & 3.8 .1 & Universal health coverage (UHC) & 84 & 80 & 74 & 63 & 60 & 57 & 53 \\
\hline & 3.9 .2 & Mortality rate attributed to unsafe $\mathrm{WaSH}$ & 100 & 98 & 84 & 86 & 65 & 69 & 55 \\
\hline & 6.1 .1 & Population using AT LEAST BASIC drinking water services & 99 & 87 & 70 & 68 & 63 & 60 & 50 \\
\hline & 7.1 .2 & Population with primary reliance on clean fuels and tech. & 94 & 64 & 60 & 59 & 51 & 50 & 47 \\
\hline \multirow{4}{*}{$\begin{array}{c}6.4 .1 \\
\text { (water-use efficiency) }\end{array}$} & 3.8 .1 & Universal health coverage (UHC) & 63 & 49 & 27 & 30 & 24 & 29 & 21 \\
\hline & 6.5 .1 & Degree of IWRM implementation & 89 & 62 & 52 & 38 & 38 & 32 & 30 \\
\hline & 6.a.1 & Total official development assistance (ODA) & 100 & 100 & 100 & 99 & 95 & 96 & 87 \\
\hline & 8.1 .1 & Annual growth rate of real GDP per capita & 97 & 78 & 62 & 59 & 44 & 33 & 25 \\
\hline \multirow{3}{*}{$\begin{array}{c}6.4 .2 \\
\text { (freshwater } \\
\text { withdrawal) }\end{array}$} & 5.5 .2 & Proportion of women in managerial positions & 100 & 100 & 99 & 97 & 94 & 84 & 68 \\
\hline & 7.2 .1 & Renewable energy share in the total final energy consumption & 62 & 49 & 56 & 51 & 46 & 47 & 48 \\
\hline & 15.1.1 & Forest area as a proportion of total land area & 100 & 100 & 97 & 94 & 91 & 91 & 74 \\
\hline \multirow{3}{*}{$\begin{array}{c}\text { 6.5.1 } \\
\text { (IWRM) }\end{array}$} & 6.4 .1 & Water-Use Efficiency & 62 & 52 & 38 & 38 & 32 & 30 & 62 \\
\hline & 10.1 .1 & Growth rates of household expenditure (bottom $40 \%$ pop.) & 63 & 46 & 30 & 27 & 27 & 21 & 63 \\
\hline & 15.1 .2 .2 & Average proportion of KBAs covered by protected areas & 83 & 69 & 62 & 53 & 46 & 37 & 83 \\
\hline \multirow{6}{*}{$\begin{array}{c}\text { 6.a.1 } \\
\text { (cooperation and } \\
\text { capacity building) }\end{array}$} & 3.1 .1 & Maternal mortality ratio & 83 & 67 & 63 & 52 & 51 & 38 & 83 \\
\hline & 3.3 .5 & People requiring interventions against NTD & 66 & 71 & 60 & 58 & 49 & 51 & 66 \\
\hline & 6.4 .1 & Water-Use Efficiency & 100 & 100 & 99 & 95 & 96 & 87 & 100 \\
\hline & 10.1.1 & Growth rates of household expenditure (bottom $40 \%$ pop.) & 98 & 93 & 88 & 78 & 65 & 57 & 98 \\
\hline & 11.6 .1 & Municipal Solid Waste collection coverage & 47 & 35 & 36 & 32 & 30 & 23 & 47 \\
\hline & 12.2 .1 & Material footprint per capita - raw material - & 98 & 94 & 82 & 82 & 61 & 55 & 98 \\
\hline
\end{tabular}

In bold, those interlinkages identified as strong ones. 
Table S5. Contingency tables associated with SDG-6 interlinkages identified (3.9.2 indicator is included as well). Results are obtained from the 179 countries considered within this study. Corresponding definitions to these indicators can be found in Table 1 of the manuscript.

SDG 3.9.2: Mortality rate attributed to unsafe water, unsafe sanitation and lack of hygiene

\begin{tabular}{|c|c|c|c|c|c|c|c|c|c|c|c|}
\hline \multirow[b]{2}{*}{ 3.9.2 } & \multicolumn{5}{|c|}{3.1 .1} & \multicolumn{6}{|c|}{3.2 .1} \\
\hline & 0-20 & $21-40$ & 41-60 & $61-80$ & 81-100 & 3.9 .2 & $0-20$ & $21-40$ & 41-60 & $61-80$ & $81-100$ \\
\hline 0-20 & 24 & 10 & 0 & 0 & 0 & 0-20 & 5 & 10 & 16 & 3 & 0 \\
\hline $21-40$ & 1 & 23 & 1 & 0 & 0 & $21-40$ & 0 & 2 & 10 & 13 & 0 \\
\hline $41-60$ & 0 & 8 & 11 & 5 & 0 & $41-60$ & 0 & 0 & 2 & 11 & 11 \\
\hline $61-80$ & 0 & 2 & 19 & 11 & 3 & $61-80$ & 0 & 0 & 0 & 2 & 33 \\
\hline $81-100$ & 1 & 0 & 5 & 20 & 35 & $81-100$ & 0 & 0 & 0 & 0 & 61 \\
\hline \multirow[t]{2}{*}{$\Sigma$} & 26 & 43 & 36 & 36 & 38 & $\Sigma$ & 5 & 12 & 28 & 29 & 105 \\
\hline & \multicolumn{5}{|c|}{3.3 .5} & & \multicolumn{5}{|c|}{6.2 .1} \\
\hline 3.9 .2 & $0-20$ & 21-40 & 41-60 & 61-80 & 81-100 & 3.9 .2 & $0-20$ & $21-40$ & 41-60 & 61-80 & $81-100$ \\
\hline $0-20$ & 24 & 10 & 0 & 0 & 0 & $0-20$ & 13 & 14 & 7 & 0 & 0 \\
\hline 21-40 & 15 & 10 & 0 & 0 & 0 & $21-40$ & 2 & 5 & 12 & 6 & 0 \\
\hline $41-60$ & 2 & 16 & 2 & 3 & 1 & $41-60$ & 0 & 1 & 1 & 9 & 13 \\
\hline $61-80$ & 3 & 11 & 9 & 5 & 7 & $61-80$ & 0 & 0 & 1 & 2 & 32 \\
\hline $81-100$ & 0 & 1 & 10 & 20 & 30 & $81-100$ & 0 & 0 & 0 & 2 & 59 \\
\hline$\Sigma$ & 44 & 48 & 21 & 28 & 38 & $\Sigma$ & 15 & 20 & 21 & 19 & 104 \\
\hline
\end{tabular}

\subsection{2}

\begin{tabular}{cccccc}
\hline $\mathbf{3 . 9 . 2}$ & $\mathbf{0 - 2 0}$ & $\mathbf{2 1 - 4 0}$ & $\mathbf{4 1 - 6 0}$ & $\mathbf{6 1 - 8 0}$ & $\mathbf{8 1 - 1 0 0}$ \\
\hline $\mathbf{0 - 2 0}$ & 28 & 3 & 3 & 0 & 0 \\
\hline $\mathbf{2 1 - 4 0}$ & 10 & 6 & 5 & 3 & 1 \\
\hline $\mathbf{4 1 - 6 0}$ & 1 & 1 & 5 & 6 & 11 \\
\hline $\mathbf{6 1 - 8 0}$ & 0 & 2 & 3 & 4 & 26 \\
\hline $\mathbf{8 1 - 1 0 0}$ & 0 & 0 & 0 & 5 & 56 \\
\hline $\boldsymbol{\Sigma}$ & 39 & 12 & 16 & 18 & 94 \\
\hline
\end{tabular}

SDG 6.1.1: Proportion of population using AT LEAST BASIC drinking water services

\begin{tabular}{|c|c|c|c|c|c|c|c|c|c|c|c|}
\hline \multirow[b]{2}{*}{ 6.1.1 } & \multicolumn{5}{|c|}{6.2 .1} & \multicolumn{6}{|c|}{7.1 .1} \\
\hline & 0-20 & $21-40$ & $41-60$ & $61-80$ & 81-100 & 6.1.1 & 0-20 & $21-40$ & $41-60$ & $61-80$ & $81-100$ \\
\hline 0-20 & 1 & 0 & 0 & 0 & 0 & 0-20 & 0 & 0 & 1 & 0 & 0 \\
\hline $21-40$ & 3 & 0 & 0 & 0 & 0 & $21-40$ & 0 & 2 & 1 & 0 & 0 \\
\hline 41-60 & 6 & 7 & 1 & 2 & 0 & 41-60 & 7 & 6 & 2 & 1 & 0 \\
\hline 61-80 & 5 & 12 & 11 & 1 & 1 & $61-80$ & 3 & 6 & 10 & 9 & 2 \\
\hline 81-100 & 0 & 1 & 9 & 16 & 103 & $81-100$ & 0 & 0 & 2 & 2 & 125 \\
\hline$\Sigma$ & 15 & 20 & 21 & 19 & 104 & $\Sigma$ & 10 & 14 & 16 & 12 & 127 \\
\hline
\end{tabular}


Continuation of Table S5.

SDG 6.2.1: Proportion of population using AT LEAST BASIC sanitation services

\begin{tabular}{cccccc}
\hline \multicolumn{7}{c}{ 3.8.1 } \\
\hline $\mathbf{6 . 2 . 1}$ & $\mathbf{0 - 2 0}$ & $\mathbf{2 1 - 4 0}$ & $\mathbf{4 1 - 6 0}$ & $\mathbf{6 1 - 8 0}$ & $\mathbf{8 1 - 1 0 0}$ \\
\hline $\mathbf{0 - 2 0}$ & 0 & 10 & 5 & 0 & 0 \\
\hline $\mathbf{2 1 - 4 0}$ & 0 & 9 & 11 & 0 & 0 \\
\hline $\mathbf{4 1 - 6 0}$ & 0 & 3 & 17 & 1 & 0 \\
\hline $\mathbf{6 1 - 8 0}$ & 0 & 0 & 8 & 11 & 0 \\
\hline $\mathbf{8 1 - 1 0 0}$ & 0 & 0 & 6 & 80 & 18 \\
\hline $\boldsymbol{\Sigma}$ & 0 & 22 & 47 & 92 & 18 \\
\hline
\end{tabular}

\begin{tabular}{cccccc}
\hline \multicolumn{7}{c}{$\mathbf{3 . 9 . 2}$} \\
\hline $\mathbf{6 . 2 . 1}$ & $\mathbf{0 - 2 0}$ & $\mathbf{2 1 - 4 0}$ & $\mathbf{4 1 - 6 0}$ & $\mathbf{6 1 - 8 0}$ & $\mathbf{8 1 - 1 0 0}$ \\
\hline $\mathbf{0 - 2 0}$ & 13 & 2 & 0 & 0 & 0 \\
\hline $\mathbf{2 1 - 4 0}$ & 14 & 5 & 1 & 0 & 0 \\
\hline $\mathbf{4 1 - 6 0}$ & 7 & 12 & 1 & 1 & 0 \\
\hline $\mathbf{6 1 - 8 0}$ & 0 & 6 & 9 & 2 & 2 \\
\hline $\mathbf{8 1 - 1 0 0}$ & 0 & 0 & 13 & 32 & 59 \\
\hline $\boldsymbol{\Sigma}$ & 34 & 25 & 24 & 35 & 61 \\
\hline
\end{tabular}

\subsection{1}

\subsection{2}

\begin{tabular}{cccccc}
\hline $\mathbf{6 . 2 . 1}$ & $\mathbf{0 - 2 0}$ & $\mathbf{2 1 - 4 0}$ & $\mathbf{4 1 - 6 0}$ & $\mathbf{6 1 - 8 0}$ & $\mathbf{8 1 - 1 0 0}$ \\
\hline $\mathbf{0 - 2 0}$ & 1 & 3 & 6 & 5 & 0 \\
\hline $\mathbf{2 1 - 4 0}$ & 0 & 0 & 7 & 12 & 1 \\
\hline $\mathbf{4 1 - 6 0}$ & 0 & 0 & 1 & 11 & 9 \\
\hline $\mathbf{6 1 - 8 0}$ & 0 & 0 & 2 & 1 & 16 \\
\hline $\mathbf{8 1 - 1 0 0}$ & 0 & 0 & 0 & 1 & 103 \\
\hline $\boldsymbol{\Sigma}$ & 1 & 3 & 16 & 30 & 129 \\
\hline
\end{tabular}

\begin{tabular}{cccccc}
\hline $\mathbf{6 . 2 . 1}$ & $\mathbf{0 - 2 0}$ & $\mathbf{2 1 - 4 0}$ & $\mathbf{4 1 - 6 0}$ & $\mathbf{6 1 - 8 0}$ & $\mathbf{8 1 - 1 0 0}$ \\
\hline $\mathbf{0 - 2 0}$ & 13 & 2 & 0 & 0 & 0 \\
\hline $\mathbf{2 1 - 4 0}$ & 14 & 3 & 3 & 0 & 0 \\
\hline $\mathbf{4 1 - 6 0}$ & 9 & 3 & 5 & 4 & 0 \\
\hline $\mathbf{6 1 - 8 0}$ & 3 & 1 & 7 & 3 & 5 \\
\hline $\mathbf{8 1 - 1 0 0}$ & 0 & 3 & 1 & 11 & 89 \\
\hline $\boldsymbol{\Sigma}$ & 39 & 12 & 16 & 18 & 94 \\
\hline
\end{tabular}

\section{SDG 6.4.1: Water-Use Efficiency}

\begin{tabular}{|c|c|c|c|c|c|c|c|c|c|c|c|}
\hline & \multicolumn{5}{|c|}{3.8 .1} & \multicolumn{6}{|c|}{6.5 .1} \\
\hline 6.4 .1 & $0-20$ & $21-40$ & $41-60$ & $61-80$ & 81-100 & 6.4 .1 & $0-20$ & $21-40$ & $41-60$ & $61-80$ & $81-100$ \\
\hline $0-20$ & 0 & 0 & 1 & 2 & 4 & $0-20$ & 0 & 1 & 0 & 2 & 4 \\
\hline $21-40$ & 0 & 2 & 2 & 26 & 10 & $21-40$ & 1 & 10 & 10 & 9 & 10 \\
\hline $41-60$ & 0 & 7 & 20 & 48 & 4 & 41-60 & 3 & 35 & 23 & 17 & 1 \\
\hline $61-80$ & 0 & 10 & 22 & 12 & 0 & $61-80$ & 2 & 24 & 14 & 4 & 0 \\
\hline 81-100 & 0 & 3 & 2 & 4 & 0 & $81-100$ & 2 & 5 & 2 & 0 & 0 \\
\hline \multirow[t]{2}{*}{$\Sigma$} & 0 & 22 & 47 & 92 & 18 & $\Sigma$ & 8 & 75 & 49 & 32 & 15 \\
\hline & \multicolumn{5}{|c|}{ 6.a.1 } & & \multicolumn{5}{|c|}{ 8.1.1 } \\
\hline 6.4.1 & $0-20$ & $21-40$ & 41-60 & 61-80 & 81-100 & 6.4 .1 & $0-20$ & 21-40 & 41-60 & 61-80 & 81-100 \\
\hline $0-20$ & 6 & 0 & 0 & 0 & 1 & $0-20$ & 1 & 0 & 1 & 5 & 0 \\
\hline $21-40$ & 30 & 1 & 3 & 6 & 0 & $21-40$ & 0 & 0 & 11 & 28 & 1 \\
\hline $41-60$ & 14 & 5 & 5 & 33 & 22 & $41-60$ & 2 & 1 & 20 & 55 & 1 \\
\hline $61-80$ & 1 & 0 & 5 & 17 & 21 & $61-80$ & 0 & 1 & 14 & 26 & 3 \\
\hline 81-100 & 0 & 0 & 0 & 4 & 5 & 81-100 & 0 & 0 & 0 & 9 & 0 \\
\hline$\Sigma$ & 51 & 6 & 13 & 60 & 49 & $\Sigma$ & 3 & 2 & 46 & 123 & 5 \\
\hline
\end{tabular}


Continuation of Table S5.

SDG 6.4.2: Level of water stress

\begin{tabular}{|c|c|c|c|c|c|c|c|c|c|c|c|}
\hline \multirow[b]{2}{*}{6.4 .2} & \multicolumn{5}{|c|}{5.5 .2} & \multicolumn{6}{|c|}{7.2 .1} \\
\hline & $0-20$ & $21-40$ & 41-60 & $61-80$ & $81-100$ & 6.4 .2 & $0-20$ & $21-40$ & 41-60 & 61-80 & $81-100$ \\
\hline $0-20$ & 14 & 6 & 1 & 0 & 0 & $0-20$ & 19 & 0 & 1 & 1 & 0 \\
\hline $21-40$ & 1 & 1 & 0 & 0 & 0 & $21-40$ & 1 & 0 & 1 & 0 & 0 \\
\hline $41-60$ & 3 & 11 & 0 & 0 & 0 & $41-60$ & 12 & 2 & 0 & 0 & 0 \\
\hline 61-80 & 3 & 15 & 3 & 0 & 0 & 61-80 & 15 & 3 & 1 & 1 & 1 \\
\hline 81-100 & 9 & 95 & 17 & 0 & 0 & 81-100 & 31 & 35 & 19 & 20 & 16 \\
\hline$\Sigma$ & 30 & 128 & 21 & 0 & 0 & $\Sigma$ & 78 & 40 & 22 & 22 & 17 \\
\hline
\end{tabular}

\subsection{1}

\begin{tabular}{cccccc}
\hline $\mathbf{6 . 4 - 2}$ & $\mathbf{0 - 2 0}$ & $\mathbf{2 1 - 4 0}$ & $\mathbf{4 1 - 6 0}$ & $\mathbf{6 1 - 8 0}$ & $\mathbf{8 1 - 1 0 0}$ \\
\hline $\mathbf{0 - 2 0}$ & 21 & 0 & 0 & 0 & 0 \\
\hline $\mathbf{2 1 - 4 0}$ & 2 & 0 & 0 & 0 & 0 \\
\hline $\mathbf{4 1 - 6 0}$ & 6 & 6 & 1 & 1 & 0 \\
\hline $\mathbf{6 1 - 8 0}$ & 7 & 12 & 1 & 1 & 0 \\
\hline $\mathbf{8 1 - 1 0 0}$ & 33 & 32 & 35 & 16 & 5 \\
\hline $\boldsymbol{\Sigma}$ & 69 & 50 & 37 & 18 & 5 \\
\hline
\end{tabular}

SDG 6.5.1: Degree of integrated water resources management implementation

\begin{tabular}{|c|c|c|c|c|c|c|c|c|c|c|c|}
\hline \multirow[b]{2}{*}{6.5 .1} & \multicolumn{5}{|c|}{6.4 .1} & \multicolumn{6}{|c|}{ 10.1.1 } \\
\hline & $0-20$ & $21-40$ & 41-60 & 61-80 & 81-100 & 6.5 .1 & $0-20$ & $21-40$ & $41-60$ & $61-80$ & $81-100$ \\
\hline 0-20 & 0 & 1 & 3 & 2 & 2 & $0-20$ & 0 & 0 & 0 & 8 & 0 \\
\hline $21-40$ & 1 & 10 & 35 & 24 & 5 & $21-40$ & 0 & 0 & 11 & 53 & 11 \\
\hline $41-60$ & 0 & 10 & 23 & 14 & 2 & 41-60 & 0 & 0 & 15 & 31 & 3 \\
\hline 61-80 & 2 & 9 & 17 & 4 & 0 & $61-80$ & 0 & 2 & 12 & 16 & 2 \\
\hline 81-100 & 4 & 10 & 1 & 0 & 0 & 81-100 & 1 & 1 & 10 & 3 & 0 \\
\hline$\Sigma$ & 7 & 40 & 79 & 44 & 9 & $\Sigma$ & 1 & 3 & 48 & 111 & 16 \\
\hline
\end{tabular}

\subsubsection{2}

\begin{tabular}{cccccc}
\hline $\mathbf{6 . 5 . 1}$ & $\mathbf{0 - 2 0}$ & $\mathbf{2 1 - 4 0}$ & $\mathbf{4 1 - 6 0}$ & $\mathbf{6 1 - 8 0}$ & $\mathbf{8 1 - 1 0 0}$ \\
\hline $\mathbf{0 - 2 0}$ & 2 & 2 & 2 & 1 & 1 \\
\hline $\mathbf{2 1 - 4 0}$ & 19 & 28 & 14 & 10 & 4 \\
\hline $\mathbf{4 1 - 6 0}$ & 9 & 15 & 15 & 6 & 4 \\
\hline $\mathbf{6 1 - 8 0}$ & 4 & 7 & 4 & 6 & 11 \\
\hline $\mathbf{8 1 - 1 0 0}$ & 0 & 2 & 5 & 5 & 3 \\
\hline $\boldsymbol{\Sigma}$ & 34 & 54 & 40 & 28 & 23 \\
\hline
\end{tabular}


Continuation of Table S5.

SDG 6.a.1: Total official development assistance for water supply and sanitation

\begin{tabular}{cccccc}
\hline \multicolumn{6}{c}{3.1 .1} \\
\hline $\mathbf{6 . a . 1}$ & $\mathbf{0 - 2 0}$ & $\mathbf{2 1 - 4 0}$ & $\mathbf{4 1 - 6 0}$ & $\mathbf{6 1 - 8 0}$ & $\mathbf{8 1 - 1 0 0}$ \\
\hline $\mathbf{0 - 2 0}$ & 0 & 1 & 1 & 14 & 35 \\
\hline $\mathbf{2 1 - 4 0}$ & 0 & 0 & 4 & 2 & 0 \\
\hline $\mathbf{4 1 - 6 0}$ & 3 & 2 & 4 & 4 & 0 \\
\hline $\mathbf{6 1 - 8 0}$ & 13 & 20 & 18 & 6 & 3 \\
\hline $\mathbf{8 1 - 1 0 0}$ & 10 & 20 & 9 & 10 & 0 \\
\hline $\boldsymbol{\Sigma}$ & 26 & 43 & 36 & 36 & 38 \\
\hline
\end{tabular}

\begin{tabular}{cccccc}
\hline \multicolumn{7}{c}{$\mathbf{3 . 3 . 5}$} \\
\hline $\mathbf{6 . a . 1}$ & $\mathbf{0 - 2 0}$ & $\mathbf{2 1 - 4 0}$ & $\mathbf{4 1 - 6 0}$ & $\mathbf{6 1 - 8 0}$ & $\mathbf{8 1 - 1 0 0}$ \\
\hline $\mathbf{0 - 2 0}$ & 0 & 1 & 6 & 19 & 25 \\
\hline $\mathbf{2 1 - 4 0}$ & 0 & 2 & 0 & 4 & 0 \\
\hline $\mathbf{4 1 - 6 0}$ & 0 & 6 & 6 & 0 & 1 \\
\hline $\mathbf{6 1 - 8 0}$ & 15 & 28 & 6 & 2 & 9 \\
\hline $\mathbf{8 1 - 1 0 0}$ & 29 & 11 & 3 & 3 & 3 \\
\hline $\boldsymbol{\Sigma}$ & 44 & 48 & 21 & 28 & 38 \\
\hline
\end{tabular}

\subsection{1}

\subsection{1}

\begin{tabular}{cccccc}
\hline $\mathbf{6 . a . 1}$ & $\mathbf{0 - 2 0}$ & $\mathbf{2 1 - 4 0}$ & $\mathbf{4 1 - 6 0}$ & $\mathbf{6 1 - 8 0}$ & $\mathbf{8 1 - 1 0 0}$ \\
\hline $\mathbf{0 - 2 0}$ & 6 & 30 & 14 & 1 & 0 \\
\hline $\mathbf{2 1 - 4 0}$ & 0 & 1 & 5 & 0 & 0 \\
\hline $\mathbf{4 1 - 6 0}$ & 0 & 3 & 5 & 5 & 0 \\
\hline $\mathbf{6 1 - 8 0}$ & 0 & 6 & 33 & 17 & 4 \\
\hline $\mathbf{8 1 - 1 0 0}$ & 1 & 0 & 22 & 21 & 5 \\
\hline $\boldsymbol{\Sigma}$ & 7 & 40 & 79 & 44 & 9 \\
\hline
\end{tabular}

\begin{tabular}{cccccc}
\hline $\mathbf{6 . a . 1}$ & $\mathbf{0 - 2 0}$ & $\mathbf{2 1 - 4 0}$ & $\mathbf{4 1 - 6 0}$ & $\mathbf{6 1 - 8 0}$ & $\mathbf{8 1 - 1 0 0}$ \\
\hline $\mathbf{0 - 2 0}$ & 1 & 2 & 35 & 13 & 0 \\
\hline $\mathbf{2 1 - 4 0}$ & 0 & 0 & 0 & 6 & 0 \\
\hline $\mathbf{4 1 - 6 0}$ & 0 & 0 & 0 & 11 & 2 \\
\hline $\mathbf{6 1 - 8 0}$ & 0 & 1 & 7 & 43 & 9 \\
\hline $\mathbf{8 1 - 1 0 0}$ & 0 & 0 & 6 & 38 & 5 \\
\hline $\boldsymbol{\Sigma}$ & 1 & 3 & 48 & 111 & 16 \\
\hline & & & & &
\end{tabular}

\begin{tabular}{cccccc}
\hline \multicolumn{6}{c}{$\mathbf{1 1 . 6 . 1}$} \\
\hline $\mathbf{6 . a . 1}$ & $\mathbf{0 - 2 0}$ & $\mathbf{2 1 - 4 0}$ & $\mathbf{4 1 - 6 0}$ & $\mathbf{6 1 - 8 0}$ & $\mathbf{8 1 - 1 0 0}$ \\
\hline $\mathbf{0 - 2 0}$ & 0 & 0 & 1 & 2 & 48 \\
\hline $\mathbf{2 1 - 4 0}$ & 0 & 0 & 0 & 4 & 2 \\
\hline $\mathbf{4 1 - 6 0}$ & 0 & 2 & 1 & 9 & 1 \\
\hline $\mathbf{6 1 - 8 0}$ & 3 & 16 & 4 & 28 & 9 \\
\hline $\mathbf{8 1 - 1 0 0}$ & 2 & 13 & 5 & 24 & 5 \\
\hline $\boldsymbol{\Sigma}$ & 5 & 31 & 11 & 67 & 65 \\
\hline
\end{tabular}

\begin{tabular}{cccccc}
\hline \multicolumn{7}{c}{ 12.2.1 } \\
\hline 6.a.1 & $\mathbf{0 - 2 0}$ & $\mathbf{2 1 - 4 0}$ & $\mathbf{4 1 - 6 0}$ & $\mathbf{6 1 - 8 0}$ & $\mathbf{8 1 - 1 0 0}$ \\
\hline $\mathbf{0 - 2 0}$ & 16 & 34 & 1 & 0 & 0 \\
\hline $\mathbf{2 1 - 4 0}$ & 0 & 6 & 0 & 0 & 0 \\
\hline $\mathbf{4 1 - 6 0}$ & 2 & 7 & 4 & 0 & 0 \\
\hline $\mathbf{6 1 - 8 0}$ & 2 & 30 & 20 & 7 & 1 \\
\hline $\mathbf{8 1 - 1 0 0}$ & 0 & 10 & 33 & 6 & 0 \\
\hline $\boldsymbol{\Sigma}$ & 20 & 87 & 58 & 13 & 1 \\
\hline
\end{tabular}


Table S6. Further contingency tables associated with SDG-6 indirect interlinkages identified. Results are obtained from the 179 countries considered within this study.

\subsection{1}

\begin{tabular}{cccccc}
\hline $\mathbf{6 . 4 . 2}$ & $\mathbf{0 - 2 0}$ & $\mathbf{2 1 - 4 0}$ & $\mathbf{4 1 - 6 0}$ & $\mathbf{6 1 - 8 0}$ & $\mathbf{8 1 - 1 0 0}$ \\
\hline $\mathbf{0 - 2 0}$ & 0 & 3 & 13 & 5 & 0 \\
\hline $\mathbf{2 1 - 4 0}$ & 0 & 0 & 0 & 2 & 0 \\
\hline $\mathbf{4 1 - 6 0}$ & 1 & 5 & 4 & 3 & 1 \\
\hline $\mathbf{6 1 - 8 0}$ & 2 & 6 & 6 & 7 & 0 \\
\hline $\mathbf{8 1 - 1 0 0}$ & 1 & 9 & 33 & 64 & 14 \\
\hline $\boldsymbol{\Sigma}$ & 4 & 23 & 56 & 81 & 15 \\
\hline
\end{tabular}

\subsection{1}

\begin{tabular}{cccccc}
\hline $\mathbf{6 . 4 - 2}$ & $\mathbf{0 - 2 0}$ & $\mathbf{2 1 - 4 0}$ & $\mathbf{4 1 - 6 0}$ & $\mathbf{6 1 - 8 0}$ & $\mathbf{8 1 - 1 0 0}$ \\
\hline $\mathbf{0 - 2 0}$ & 8 & 8 & 2 & 2 & 1 \\
\hline $\mathbf{2 1 - 4 0}$ & 2 & 0 & 0 & 0 & 0 \\
\hline $\mathbf{4 1 - 6 0}$ & 2 & 4 & 1 & 2 & 5 \\
\hline $\mathbf{6 1 - 8 0}$ & 7 & 2 & 4 & 4 & 4 \\
\hline $\mathbf{8 1 - 1 0 0}$ & 44 & 22 & 28 & 15 & 12 \\
\hline $\boldsymbol{\Sigma}$ & 63 & 36 & 35 & 23 & 22 \\
\hline
\end{tabular}

\subsection{2}

\begin{tabular}{cccccc}
\hline $\mathbf{6 . 4 . 2}$ & $\mathbf{0 - 2 0}$ & $\mathbf{2 1 - 4 0}$ & $\mathbf{4 1 - 6 0}$ & $\mathbf{6 1 - 8 0}$ & $\mathbf{8 1 - 1 0 0}$ \\
\hline $\mathbf{0 - 2 0}$ & 0 & 1 & 0 & 6 & 14 \\
\hline $\mathbf{2 1 - 4 0}$ & 0 & 0 & 0 & 1 & 1 \\
\hline $\mathbf{4 1 - 6 0}$ & 0 & 0 & 2 & 3 & 9 \\
\hline $\mathbf{6 1 - 8 0}$ & 0 & 0 & 0 & 3 & 18 \\
\hline $\mathbf{8 1 - 1 0 0}$ & 0 & 1 & 9 & 36 & 75 \\
\hline $\boldsymbol{\Sigma}$ & 0 & 2 & 11 & 49 & 117
\end{tabular}

\subsection{2}

\begin{tabular}{cccccc}
\hline $\mathbf{6 . 4 - 2}$ & $\mathbf{0 - 2 0}$ & $\mathbf{2 1 - 4 0}$ & $\mathbf{4 1 - 6 0}$ & $\mathbf{6 1 - 8 0}$ & $\mathbf{8 1 - 1 0 0}$ \\
\hline $\mathbf{0 - 2 0}$ & 3 & 5 & 3 & 7 & 3 \\
\hline $\mathbf{2 1 - 4 0}$ & 0 & 1 & 0 & 0 & 1 \\
\hline $\mathbf{4 1 - 6 0}$ & 0 & 1 & 1 & 1 & 11 \\
\hline $\mathbf{6 1 - 8 0}$ & 0 & 0 & 3 & 2 & 16 \\
\hline $\mathbf{8 1 - 1 0 0}$ & 3 & 3 & 4 & 16 & 95 \\
\hline $\boldsymbol{\Sigma}$ & 6 & 10 & 11 & 26 & 126 \\
\hline
\end{tabular}

